Review

\title{
Progress in Metal-Organic Frameworks Facilitated Mercury Detection and Removal
}

\author{
Muthaiah Shellaiah (D) and Kien-Wen Sun *(D) \\ Department of Applied Chemistry, National Yang Ming Chiao Tung University, Hsinchu 30010, Taiwan; \\ muthaiah1981@nctu.edu.tw \\ * Correspondence: kwsun@mail.nctu.edu.tw
}

Citation: Shellaiah, M.; Sun, K.-W.

Progress in Metal-Organic

Frameworks Facilitated Mercury

Detection and Removal. Chemosensors

2021, 9, 101. https://doi.org/

$10.3390 /$ chemosensors 9050101

Academic Editor: Vardan Galstyan

Received: 1 April 2021

Accepted: 2 May 2021

Published: 4 May 2021

Publisher's Note: MDPI stays neutral with regard to jurisdictional claims in published maps and institutional affiliations.

Copyright: (c) 2021 by the authors. Licensee MDPI, Basel, Switzerland. This article is an open access article distributed under the terms and conditions of the Creative Commons Attribution (CC BY) license (https:// creativecommons.org/licenses/by/ $4.0 /)$.

\begin{abstract}
Metal Organic Frameworks (MOFs) are noted as exceptional candidates towards the detection and removal of specific analytes. MOFs were reported in particular for the detection/removal of environmental contaminants, such as heavy metal ions, toxic anions, hazardous gases, explosives, etc. Among heavy metal ions, mercury has been noted as a global hazard because of its high toxicity in the elemental $\left(\mathrm{Hg}^{0}\right)$, divalent cationic $\left(\mathrm{Hg}^{2+}\right)$, and methyl mercury $\left(\mathrm{CH}_{3} \mathrm{Hg}^{+}\right)$forms. To secure the environment and living organisms, many countries have imposed stringent regulations to monitor mercury at all costs. Regarding the detection/removal requirements of mercury, researchers have proposed and reported all kinds of MOFs-based luminescent/non-luminescent probes towards mercury. This review provides valuable information about the MOFs which have been engaged in detection and removal of elemental mercury and $\mathrm{Hg}^{2+}$ ions. Moreover, the involved mechanisms or adsorption isotherms related to sensors or removal studies are clarified for the readers. Finally, advantages and limitations of MOFs in mercury detection/removal are described together with future scopes.
\end{abstract}

Keywords: $\mathrm{Hg}^{2+} ; \mathrm{CH}_{3} \mathrm{Hg}^{+}$; elemental mercury; luminescent detection; adsorption isotherms; MOFs; real analysis; non-luminescent probes; organic linkers; metal nodes

\section{Introduction}

Due to the harmful and hazardous effects on ecosystem, detection/removal of mercury in different states, such as elemental, ionic, and organometallic (like methyl mercury), is in high demand and has attracted intense research interest [1-5]. Accumulated mercury in environmental water often sedimented and converted as toxic methylmercury, which entered the food cycle and caused serious diseases in living beings as stated next [6]. Accumulation of mercury in human body may lead to various health issues, such as brain damage, central nervous syndromes, Minamata disease, cognitive and motion disorders, etc. [7-9] Therefore, U.S. Environmental Protection Agency (EPA) regulated an allowable maximum level of mercury of $2 \mathrm{ppb}(10 \mathrm{nM})$ in the drinking water and $3 \mathrm{ppm}(1.5 \mu \mathrm{M})$ in fish tissue [10,11]. Moreover, Agency for Toxic Substances and Disease Registry (ATSDR) of the U. S. Department of Health and Human Service has set a highest allowable mercury concentration of $625 \mathrm{ppb}$ in normal soil [1-13]. Till now the development of innovative tactics towards detection and removal of mercury are still the main focus of many research groups [12,13]. In this light, luminescent approaches comprising of nanoprobes, small molecules, supramolecular assemblies, aggregation induced emission, and covalent or metal organic frameworks (COFs/MOFs) are seemingly impressive with respect to their applicability, such as in vitro/vivo imaging studies [14-19]. However, design and development of metal organic frameworks (MOFs)-based probes towards specific analytes discrimination are highly anticipated with real time applications [20-24] due to the following advantages: existence of porosity to adsorb specific analyte, improved aqueous solubility, exceptional photophysical and chemical properties. 
In fact, the majority of the MOFs are composed of organic ligand and metal nodes with certain porosity and tend to form different micro/nano-structures, such as particles, cubes, rods, spheres, etc. [25-29] Moreover, they also find their applications in multiple opto-electronics, photovoltaics, electronics, solar cells, light emitting devices (LEDs), field effect transistors (FETs), DNA detection, bio-analysis, real time detection/removal of specific analytes, etc. [30-33] In sensory studies, they can behave as single, dual, and non-emissive materials, which tend to provide diverse responses upon interaction with guest analytes [34]. Moreover, the MOFs may display luminescent responses when interact with guest analytes via one-dimension (1D) (wavelength change and intensity alteration) or two-dimension (2D) (ratiometric variation combined with 1D responses) signals [21,35]. However, by tuning the functional organic units mediated responses, MOFs can be utilized in numerous sensory applications, such as $\mathrm{pH}$ sensors, virus and antibiotic detection, metal ions recognition, anions detection, volatile explosives quantification, etc. [36-41] Similarly, by modulating the functional units in MOFs, capture and removal of specific analytes can be achieved and become an effective approach for toxic analyte removal [42-46]. In this track, studies on detection and removal of highly toxic mercury and its analogous can find inspiring and exceptional applicability towards the environmental and health safety [47].

So far, diverse MOFs have been demonstrated for exceptional detection and removal elemental mercury and $\mathrm{Hg}^{2+}$ [48-51]. In fact, detection of $\mathrm{Hg}^{2+}$ can be attained by assorted mechanisms, such as bands overlapping, ligand interaction, cation exchange, and framework collapse, etc. $[20,33]$ On the contrary, removal of elemental mercury and $\mathrm{Hg}^{2+}$ ions are mostly achieved by tuning structural functionalities with organic ligands [52]. In addition, metal-organic coordination polymers and MOFs composited materials were demonstrated for mercury determination and removal $[53,54]$. So far, reviews on MOFs-based mercury detection and removal are deficient in valuable information, which encourages us to deliver a compact review to summarize the recent studies on this subject.

In this review, we described the sensory detection and removal utilities of simple and polymeric MOFs and composited MOFs towards elemental mercury and $\mathrm{Hg}^{2+}$ as noted in Figure 1. Moreover, mechanism, electron transport, and structural benefits for mercury quantification were outlined for reader's clarifications. Finally, a brief note on the synthesis of MOFs involved in discrimination and removal of mercury and its analogous was provided in this paper.

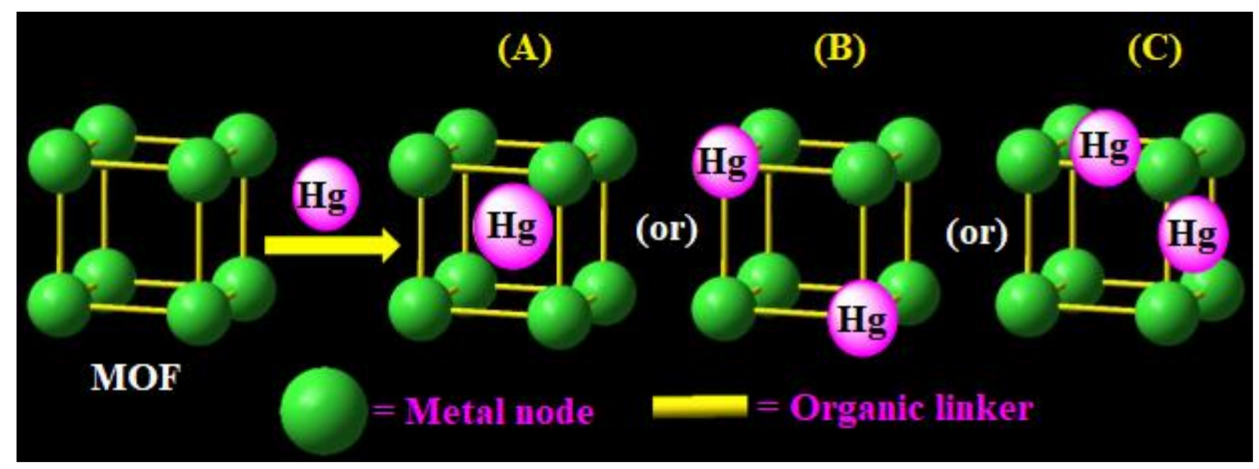

Figure 1. Schematic illustration of three possible MOFs-based mercury detection and removal mechanisms by (A) cavity trapping, (B) metal node displacement, and (C) interactive organic linkers.

\section{Optimization Requirements for MOFs-Based Mercury Detection/Removal}

To detect/remove mercury and it's analogous by using MOFs, following optimization requirements must be taken into account.

A. Selection of suitable organic linkers that can form MOFs with designated metal nodes with greater surface area to interact with mercury analogous in the environment. Similarly, organic linkers with side chains, such as thiol (-SH; which shows the greater affinity to $\mathrm{Hg}^{2+}, \mathrm{Hg}^{0}$ and $\mathrm{CH}_{3} \mathrm{Hg}^{+}$), can be chosen for effective removal and detection mercury [55]. 
B. Selection of suitable metal nodes that can form MOFs with good stability in aqua/nonaqua solvents and afford large surface area for analyte $\left(\mathrm{Hg}^{2+}\right)$ adsorption or collision for improving signal detection or quantification [56].

C. Selection of appropriate synthetic tactics/conditions to afford high yield over impurities. Similarly, the selection of suitable solvent for sensory studies also needs attention [18].

D. Many MOFs are well known coordinating polymers with porous nano/micro-structures [27], the design for capturing mercury requires more attention with respect to linkers, nodes, adsorbing ability, and opto-electronic properties.

E. In the case of removal of mercury from environmental samples, design and development of MOFs with high adsorption efficiency and stability in aqua medium need more attention and optimization for improvement [57].

F. To avoid the interfering effect from competing species, a unique MOF design with selectivity only to the mercury analogous must require optimization either by modulation of organic linkers or metal nodes or by tuning the opto-electronic properties [58].

G. Post-modification of MOFs with certain materials to form composited structures towards mercury detection/removal also requires optimization for authorized applicability [59].

\section{Synthetic Tactics Involved in MOFs Construction}

By bridging the organic linkers with metal nodes, MOFs can be synthesized by many tactics as presented below [60].

(1) Diffusion method: This is a tactic that involves gradual conveyance of various species into interaction and can be sub-divided into (i) solvent liquid diffusion method, which takes place between precipitant solvent and product in the solvent and leads to crystallization at interface via gradual diffusion; (ii) gradual diffusion of reactants by adjusting the physical barriers, such as placing two reactant vials with different sizes to form MOFs [60,61].

(2) Hydro/solvothermal method: This technique involves self-assembly of products from soluble precursors. Wherein, precursors are introduced into the sealed tube under certain pressure and kept at $80-260^{\circ} \mathrm{C}$ for days or weeks to produce the designated MOFs [60,62].

(3) Microwave method: In this tactic, solution containing small metal oxide particles is treated with microwave to raise temperature so that nano-sized metal crystals can be generated and leads to MOFs formation with controlled shape and size [63]. Contrary to other synthetic methods, microwave technology is a promising tactic with reduced reaction time and less processing energy consumption to have control over MOF properties. It is able to easily produce MOFs and MOF-hybrids in an isolated manner [64]. For example, Le et al. developed the mesoporous MOF-MIL-100 (Fe) via microwave-assisted continuous flow synthesis [by reacting iron(III) chloride hexahydrate $\left(\mathrm{FeCl}_{3} \cdot 6 \mathrm{H}_{2} \mathrm{O}\right)$, 1,3,5-benzenetricarboxylic acid $\left.\left(\mathrm{H}_{3} \mathrm{BTC}\right)\right]$ to support the construction of $\mathrm{Cu}(\mathrm{I})$ modified adsorbents towards $\mathrm{CO} / \mathrm{CO}_{2}$ separation [65].

(4) Electrochemical method: This tactic is generally used in the industry to produce MOFs in bulk. Contrary to solvothermal synthesis, this method has the advantage of quick synthesis at low temperature and also avoids usage of anionic metal salts, such as metallic nitrates [66]. However, fine tuning in applied voltage is required to attain better results towards designed MOFs.

(5) Mechanochemical method: Contrast to traditional way of synthesis (dissolving, heating, and stirring chemicals in a solution), this method is environmentally friendly for synthesizing MOFs via mechanical forces, such as grinding and ball milling at ambient temperature without any solvent consumption. Moreover, certain number of MOFs can be obtained in a short time (10-20 min). This method is also noted as a technique at the interface of mechanical engineering and chemistry [67].

(6) Sonochemistry method: This is a quick synthesis tactic reported for producing MOFs in an environmentally friendly manner via treating the reaction mixture with high energy ultrasound force (10-20 MHz with upper limit of human hearing). During this 
process, dissolution of the starting materials can be enhanced, thereby becoming a special research topic for scientists for producing MOFs in bulk [68].

(7) Post-synthetic modifications: Apart from the aforementioned tactics, the designated MOFs can be synthesized via post-synthetic modifications, such as ligand exchange, metal exchange, opening of the coordinating sites, etc [69].

\section{MOFs in Optical Detection of $\mathbf{H g}^{2+}$}

Similar to nanomaterials-based sensors [70], MOFs in the form of micro/nano-structures can be used in effective detection of $\mathrm{Hg}^{2+}$. In this light, the zirconium $(\mathrm{Zr})$ metal-incorporated MOFs were reported for luminescent and colorimetric quantification of $\mathrm{Hg}^{2+}$ ions [71-77]. Yang and co-workers developed a porous phorpyrinic luminescent metal-organic framework (LMOF; PCN-224) with meso-tetra(4-carboxyphenyl) porphyrin (TCPP) ligands and Zr metal nodes via modified solvothermal method and applied in $\mathrm{Hg}^{2+}$ sensors [71]. During detection of $\mathrm{Hg}^{2+}$, the probe displayed a bright red to dark red fluorescent quenching and a purple to light green colorimetric response within $2 \mathrm{~min}$. The sensor response of PCN-224 was not affected by the presence of any competing ions and was reversible in the presence of KI solution (up to seven cycles) as depicted in Figure 2. The PCN-224 revealed a linear response to $\mathrm{Hg}^{2+}$ from 0.1 to 10 micromole $(\mu \mathrm{M})$ with a detection limit (LOD) of 6 nanomole $(\mathrm{nM})$. Moreover, probe PCN-224 was also more effective towards the detection of $\mathrm{Hg}^{2+}$ in real samples, such as tab and river water.

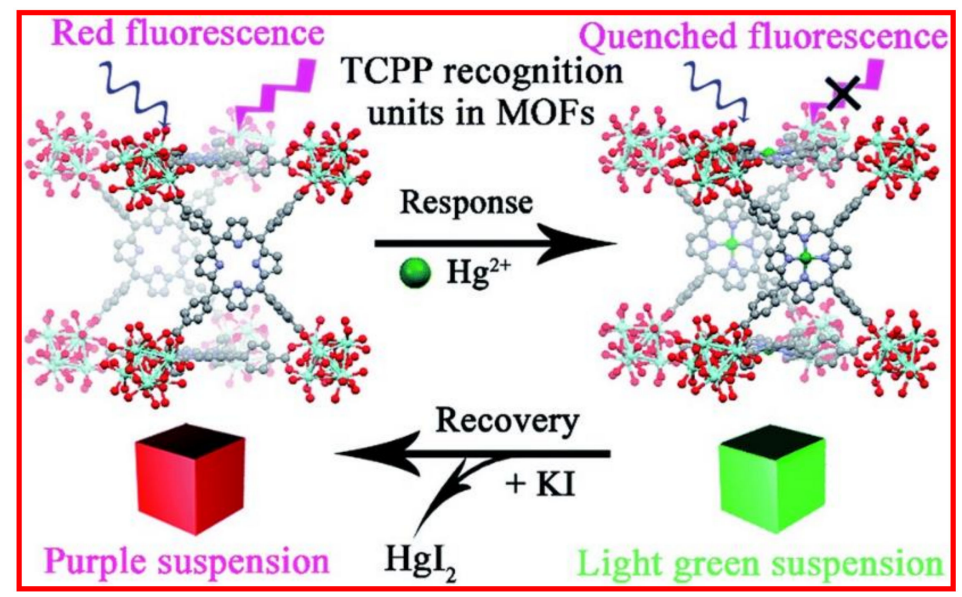

Figure 2. Illustration of the sensor construction protocol. The inherent TCPP linker was designed as the recognition site as well as the signal reporter for $\mathrm{Hg}^{2+}$ sensing at the same time. Upon the addition of solution into the $\mathbf{P C N}-224-\mathrm{Hg}^{2+}$ system, analytes were disassociated and fluorescence of PCN-224 was recovered while the visual colour also turned from light green to purple (Reproduced with the permission from Ref [71]).

The UIO-66 (archetypal metal-organic framework (MOF) was reported for effective detection of $\mathrm{Hg}^{2+}$. It contains the metal nodes that comprise a zirconium oxide complex bridged by terepthalic acid (1,4-benzenedicarboxylic acid) ligands). $\mathrm{Hg}^{2+}$ detection in aqueous media can be further improved by tuning the structural features of UIO-66 via modifying the terephthalic acid bridging unit or by post-doping process (PSM) [72-74]. Zhang et al. developed the fluorescent MOF (UIO-66-PSM) via coupling UIO-66- $\mathbf{N}_{3}$ with phenylacetylene to use in sensing of $\mathrm{Hg}^{2+}$ in aqueous media [72]. Terephthalic acid with azide group was used to synthesize the UIO-66- $\mathbf{N}_{3}$, which showed reactivity to phenylacetylene. The Brunauer-Emmett-Teller (BET) surface area of UIO-66-PSM was estimated as $606 \mathrm{~m}^{2} \mathrm{~g}^{-1}$ to $\mathrm{N}_{2}$ gas at 77K. In this work, UIO-66-PSM displayed great selectivity to $\mathrm{Hg}^{2+}$ via fluorescence quenching with a linear behavior from 0 to $78.1 \mu \mathrm{M}$ and an estimated LOD of $5.88 \mu \mathrm{M}$. Moreover, $\mathrm{Hg}^{2+}$ detection by the UIO-66-PSM was demonstrated in tap and lake water interrogations. However, the adsorption capability of UIO-66-PSM to $\mathrm{Hg}^{2+}$ in the presence of other ions still needs to be clarified. In a similar 
fashion, Samanta and co-workers described synthesis of the UIO-66@Butyne by reacting $\mathrm{ZrCl}_{4}$ with 2,5-bis(but-3-yn-1-yloxy) terephthalic acid and applied it in quantifying $\mathrm{Hg}^{2+}$ in aqueous medium [73]. The UIO-66@Butyne displayed a fluorescence quenching response to $\mathrm{Hg}^{2+}$ via the reaction-based chemodosimeter mechanism. In which, the triple bonded acetylene unit present over the surface reacted with $\mathrm{Hg}^{2+}$ and led to green fluorescence quenching with a LOD of $10.9 \mathrm{nM}$. It also showed higher selectivity to $\mathrm{Hg}^{2+}$ than that of other ions. The BET surface area of UIO-66@Butyne was found to be $74 \mathrm{~m}^{2} \mathrm{~g}^{-1}$ for $\mathrm{Hg}^{2+}$ at 77K. Regarding to structural modification, Xiaoxiong et al. proposed post doping of $\mathrm{Eu}^{3+}$ over the surface of UIO-66 type MOF (Eu ${ }^{3+} @$ UIO-66 (DPA) (synthesized by reacting $\mathrm{ZrCl}_{4}$ and isophthalic acid with 2,6-pyridinedicarboxylic acid (DPA)) to apply in sensor studies [74]. Due to the doping of $\mathrm{Eu}^{3+}$, the MOF displayed strong red fluorescence via coordination of $\mathrm{Eu}^{3+}$ with pyridine "nitrogen" and acid group. Upon the addition of metal ions to the above MOF system, only $\mathrm{Fe}^{3+}$ and $\mathrm{Hg}^{2+}$ ions showed fluorescence quenching at $615 \mathrm{~nm}$ (in water) via $\mathrm{Eu}^{3+}$ atom displacement. However, adding hydrogen peroxide $\left(\mathrm{H}_{2} \mathrm{O}_{2}\right.$; acted as a masking agent for $\left.\mathrm{Fe}^{3+}\right)$ eliminated the interfering effect of $\mathrm{Fe}^{3+}$ over $\mathrm{Hg}^{2+}$ selectivity and delivered a linear response between $10 \mathrm{nM}$ to $2.5 \mu \mathrm{M}$ with a LOD of $8.26 \mathrm{nM}$ (lower than the allowed limit). In terms of the strategy and LOD, this work is an impressive one, but demonstrations in real time applications are missing in this report.

Wang and co-workers constructed a novel Zr-based MOF (RuUIO-67) integrated with ruthenium $(\mathrm{Ru})$ complex for colorimetric sensing of $\mathrm{Hg}^{2+}$, which was reversible with KI solution [75]. The UIO-67 is comprised of $\mathrm{Zr}_{6} \mathrm{O}_{4}(\mathrm{OH})_{4}$ nodes strutted by linear $4,4^{\prime}$-biphenyldicarboxylic acid $\left(\mathrm{H}_{2}\right.$ bpdc) bridging ligands. It is further doped with ruthe-

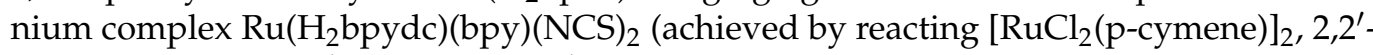
bipyridine (bpy), 2,2'-bipyridine-5,5'-dicarboxy $\left(\mathrm{H}_{2}\right.$ bpydc) with ammonium thiocyanate $\left(\mathrm{NH}_{4} \mathrm{NCS}\right)$ ) to yield the RuUIO-67 MOF. Upon the addition of $\mathrm{Hg}^{2+}$ (in HEPES buffer, $\mathrm{pH}$ 7.4) to RuUIO-67 in methanol-water (8:2), the initial absorption band at $540 \mathrm{~nm}$ gradually disappeared and a new band at $435 \mathrm{~nm}$ was visualized due to the strong binding of sulphur " $\mathrm{S}$ " atom present in the NCS group. The MOF showed a linear response between 0-13 $\mu \mathrm{M}$ with a LOD of $0.5 \mu \mathrm{M}(0.1 \mathrm{ppm})$ and a naked eye LOD of $7.2 \mu \mathrm{M}$. Moreover, reversibility up to six cycles was achieved when $\mathrm{I}^{-}$(KI solution) was added to the sensory system. However, it still needs to focus on competing interrogations. Li et al. described the modified UIO-68 $\left(\mathrm{Zr}_{6} \mathrm{O}_{4}(\mathrm{OH})_{4}\right.$ clusters linked with 4,4'-terphenyldicarboxylate (TPDC)) MOFs UIO-68-NCS, UIO-68-R6G, and UIO-68-R6G' via post-synthetic modification strategy towards colorimetric and fluorescent detection of $\mathrm{Hg}^{2+}$ [76]. Reaction of the UIO-68-NH with thio-phosgene and triethylamine led to formation of the UIO-68-NCS, which was further reacted with $\mathrm{N}$-(rhodamine-6G) lactam-ethylenediamine (R6G-EDA) and $\mathrm{Hg}\left(\mathrm{NO}_{3}\right)_{2}$ hydrate to yield the UIO-68-R6G and UIO-68-R6G', respectively. In the presence of $\mathrm{Hg}^{2+}$, UIO-68-R6G displayed in red and enhanced "turn-on" red emission with corresponding changes in particle sizes as seen in Figure 3.

Based on the $\mathrm{N}_{2}$ uptake at 77K, the BET surface area of UIO-68- $\mathbf{N H}_{2}$, UIO-68-NCS, UIO-68-R6G, and UIO-68-R6G' were established as $674 \mathrm{~cm}^{3} \mathrm{~g}^{-1}, 620 \mathrm{~cm}_{3} \mathrm{~g}^{-1}, 405 \mathrm{~cm}^{3} \mathrm{~g}^{-1}$, and $326.83 \mathrm{~cm}^{3} \mathrm{~g}^{-1}$, correspondingly. The decrease in BET surface area was attributed to the incorporation of larger rhodamine-thiocarbamide unit, which reduced the porosity. The UIO-68-R6G in Tris-HCl buffer solution displayed a linear response to $\mathrm{Hg}^{2+}$ from $10^{-8}$ to $10^{-1} \mathrm{M}$ with a LOD of $0.1 \mathrm{nM}$ and was demonstrated with applicability in in-vitro/in- vivo bio-imaging studies. Thereafter, Kim and co-workers presented the MOF-SALI-MAA-3eq via incorporation of three equivalents of mercaptoacetic acid into NU-1000 (comprised of $\mathrm{Zr}_{6}\left(\mu_{3}-\mathrm{O}\right)_{4}\left(\mu_{3}-\mathrm{OH}\right)_{4}\left(\mathrm{H}_{2} \mathrm{O}\right)_{4}(\mathrm{OH})_{4}$ nodes and tetratopic 1,3,6,8-( $p$-benzoate)pyrene linkers) towards the determination of $\mathrm{Hg}^{2+}$ [77]. Based on the $\mathrm{N}_{2}$ adsorption-desorption isotherms at 77K, the BET surface area of NU-1000 and SALI-MAA-3eq were found as $2253 \mathrm{~m}^{2} \mathrm{~g}^{-1}$ and $1906 \mathrm{~m}^{2} \mathrm{~g}^{-1}$, correspondingly. The decrease in surface area was related to the incorporation of mercaptoacetic acid. The SALI-MAA-3eq in water showed a linear response from 0.1 to $10 \mathrm{mM}$, however, the LOD was not provided. This work requires further investigations in competing and applicability studies. 


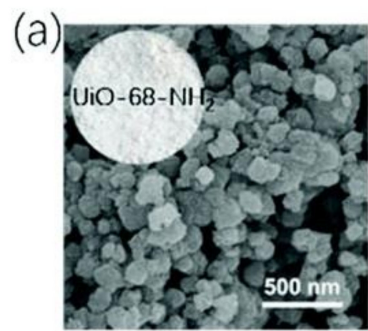

(b)
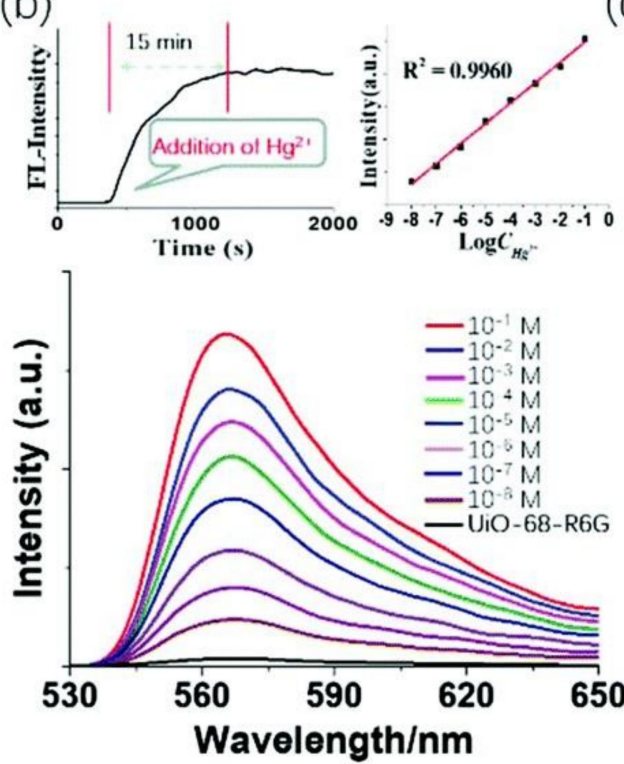
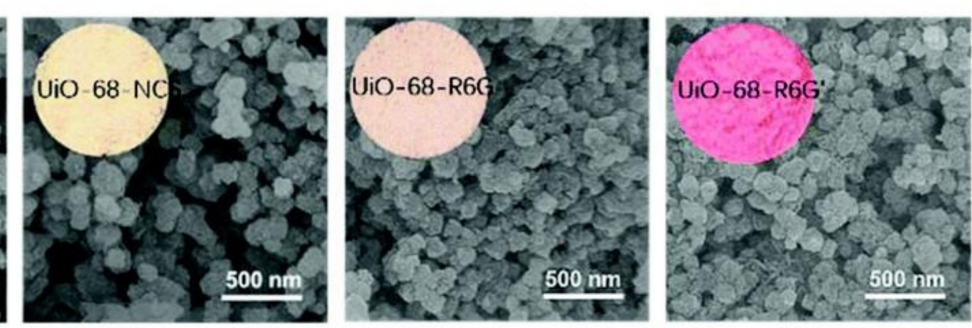

(c)
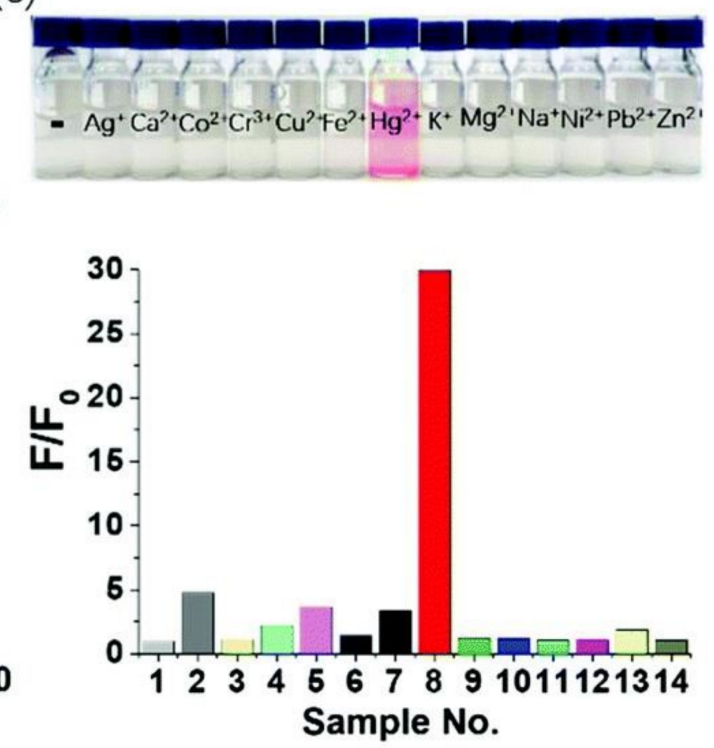

Figure 3. (a) SEM images of UIO-68-NH2, UIO-68-NCS, UIO-68-R6G, and UIO-68-R6G' and their as-synthesized samples. (b) Emission spectra of UIO-68-R6G $\left(0.1 \mathrm{mg} \mathrm{mL}^{-1}\right)$ upon the addition of $\mathrm{Hg}^{2+}$ at different concentrations in the Tris- $\mathrm{HCl}$ buffer solution. $K_{\mathrm{sv}}=4.1 \times 10^{9} \mathrm{~L} \mathrm{~mol}^{-1}$. The emission maximum was observed at $566 \mathrm{~nm}\left(\lambda_{\mathrm{ex}}=488 \mathrm{~nm}\right)$. Linearity relationship between $\mathrm{Hg}^{2+}$ with different concentrations and relative emission intensities, and the time-dependent emission of UIO-68-R6G with the sequential addition of $\mathrm{Hg}^{2+}$ are shown in the insets. (c) Emission response of UIO-68-R6G toward various metal ions $\left(10^{-4} \mathrm{M}\right)$ in an aqueous solution $(0.9 \mathrm{~mL})$ of UIO-68-R6G $\left(0.1 \mathrm{mg} \mathrm{mL}^{-1}\right)$ : (1) blank, (2) Ag ${ }^{+}$, (3) $\mathrm{Ca}^{2+}$, (4) $\mathrm{Co}^{2+}$, (5) $\mathrm{Cr}^{3+}$, (6) $\mathrm{Cu}^{2+}$, (7) $\mathrm{Fe}^{2+}$, (8) $\mathrm{Hg}^{2+}$, (9) $\mathrm{K}^{+}$, (10) $\mathrm{Mg}^{2+}$, (11) $\mathrm{Na}^{+}$, (12) $\mathrm{Ni}^{2+}$, (13) $\mathrm{Pb}^{2+}$, and (14) $\mathrm{Zn}^{2+}$. $\mathrm{The}^{2}$ corresponding sample photographs are inserted (Reproduced with the permission from Ref [76]).

Subsequently, by coordinating the 5-boronobezene-1, 3-dicarboxylic acid with $\mathrm{Eu}^{3+}$ ions, the boric acid (BA)-functionalized lanthanide metal-organic framework (BA-Eu-MOF) was reported in detection of $\mathrm{Hg}^{2+}$ and $\mathrm{CH}_{3} \mathrm{Hg}^{+}$species in aqueous medium [78]. The BAEu-MOF was in the form of meso-porous nanoparticles with a uniform size distribution of $\sim 400 \mathrm{~nm}$. It also showed characteristics of red emission, good dispersive ability, and water solubility. Initially, the "antenna" effect was passivated by boric acid (BA) and the BAEu-MOF showed weak red emission. During detection of $\mathrm{Hg}^{2+}$ and $\mathrm{CH}_{3} \mathrm{Hg}^{+}$species via chemodosimeter reaction between BA and the analytes, the "antenna" effect was recovered and led to strong red fluorescence under UV-lamp $\left(\lambda_{\mathrm{ex}}=365 \mathrm{~nm}\right)$. The BET surface area of BA-Eu-MOF was established as $39.7 \mathrm{~m}^{2} \mathrm{~g}^{-1}$ to $\mathrm{N}_{2}$ gas at $77 \mathrm{~K}$. Upon the addition of the $\mathrm{Hg}^{2+}$ and $\mathrm{CH}_{3} \mathrm{Hg}^{+}$, photoluminescence (PL) response at $620 \mathrm{~nm}$ was linearly enhanced between 1-60 $\mu \mathrm{M}$ and 1-80 $\mu \mathrm{M}$ with a LODs of $220 \mathrm{nM}$ and $440 \mathrm{nM}$. Moreover, BA-EuMOF showed higher selectivity over other competing mono- and di-valent cations in real time river water applications.

MOFs composed of other lanthanide metal nodes have also been engaged in the $\mathrm{Hg}^{2+}$ discrimination. By reacting the organic ligand " $4,4^{\prime}, 4^{\prime \prime}$-s-triazine-1,3,5-triyltri-p-aminobenzoic acid $\left(\mathrm{H}_{3} \mathrm{TATAB}\right)$ " with lanthanide metals $(\mathrm{Ln}=\mathrm{Eu}, \mathrm{Tb}, \mathrm{Sm}$, Dy and $\mathrm{Gd})$, the $\operatorname{Ln}(\mathrm{TATAB}) \cdot(\mathrm{DMF})_{4}\left(\mathrm{H}_{2} \mathrm{O}\right)(\mathrm{MeOH})_{0.5} \mathrm{MOF}$ sere produced in quantitative yields and were interrogated towards metal ions detection [79]. Wherein, only the TbTATAB in 
water showed selective sensitivity to $\mathrm{Hg}^{2+}$ but not the other lanthanide ions (Eu, Sm, Dy and Gd) containing MOFs. During $\mathrm{Hg}^{2+}$ detection, luminescence of TbTATAB at $494,544,587$, and $622 \mathrm{~nm}$ (quantum yield $=77.48 \%$ ) was quenched linearly from 0 to $50 \mu \mathrm{M}$ with a LOD of $4.4 \mathrm{nM}$. This work also demonstrated $\mathrm{Hg}^{2+}$ detection in real water samples (river water, drinking water, and tap water), but information on the nanostructure and BET surface area were missing. Recently, Li et al. developed two MOFs, namely $\left\{\left[\mathrm{Tb}_{\mathbf{2}}(\mathbf{b p d a})_{3}\left(\mathrm{H}_{2} \mathrm{O}\right)_{3}\right] \cdot \mathrm{H}_{\mathbf{2}} \mathrm{O}\right\}_{\mathrm{n}}$ and $\left\{\left[\mathrm{Dy} \mathbf{y}_{\mathbf{2}}(\mathrm{bpda})_{3}\left(\mathrm{H}_{\mathbf{2}} \mathrm{O}\right)_{3}\right] \cdot \mathrm{H}_{\mathbf{2}} \mathrm{O}\right\}_{\mathbf{n}}$, by reacting 2,2'-bipyridine4, $4^{\prime}$-dicarboxylic acid $\left(\mathrm{H}_{2}\right.$ bpda) with $\mathrm{LnCl}_{3} \cdot 6 \mathrm{H}_{2} \mathrm{O}(\mathrm{Ln}=\mathrm{Tb}$ and $\mathrm{Dy})$ and engaged them in sensory investigations [80]. The $\left\{\left[\mathrm{Dy} \mathbf{y}_{2}(\mathbf{b p d a})_{3}\left(\mathrm{H}_{2} \mathbf{O}\right)_{3}\right] \cdot \mathbf{H}_{\mathbf{2}} \mathrm{O}\right.$ showed fluorescent quenching with $\mathrm{Hg}^{2+}$ at $489,543,582$, and $620 \mathrm{~nm}\left(\lambda_{\text {ex }}=310 \mathrm{~nm}\right)$ with a $\mathrm{K}_{\mathrm{SV}}$ value of $20,406 \mathrm{M}^{-1}$ and a LOD of $7.2 \mathrm{nM}$. This work requires additional investigations on the BET surface area and interference studies.

Researches in $\mathrm{Hg}^{2+}$ sensing using zinc containing MOFs were also described as follows. Morsali's research group proposed a double solvent sensing method (DSSM) to detect $\mathrm{Hg}^{2+}$ with great accuracy by using a zinc-based MOF [Zn(OBA)-(DPT) 0.5$] \cdot \mathrm{DMF}$, namely TMU-34(-2H), where OBA, DPT, and DMF represent 4, $4^{\prime}$-oxybis(benzoic acid), 3,6-di(pyridin-4-yl)-1,2,4,5-tetrazine, and N, N-dimethylformamide, respectively [81]. The BET specific surface area of TMU-34(-2H) to $\mathrm{N}_{2}$ gas at $77 \mathrm{~K}$ was $667 \mathrm{~m}^{2} \mathrm{~g}^{-1}$ and was able to adsorb $201 \mathrm{~cm}^{3} \mathrm{~g}^{-1}$ of $\mathrm{N}_{2}$ gas. In the presence of $\mathrm{Hg}^{2+}$, the TMU-34(-2H) displayed 1Dtransduction signals of $243 \%$ PL enhancement in water at $648 \mathrm{~nm}\left(\lambda_{\mathrm{ex}}=504 \mathrm{~nm}\right)$ and $90 \%$ PL quenching in acetonitrile at $618 \mathrm{~nm}\left(\lambda_{\mathrm{ex}}=458 \mathrm{~nm}\right)$ with estimated LODs as $1.8 \mu \mathrm{M}$ and $6.9 \mu \mathrm{M}$, correspondingly, within 15 seconds. However, both solvents suffered interfering effects from other ions. Therefore, DSSM tactic was proposed to improve the sensitivity to $\mathrm{Hg}^{2+}$ by combining water and acetonitrile. Wherein, the sensing factor of $\mathrm{Hg}^{2+}$ was found as 41 by plotting 2D sensing curve, which was higher than that of all other metal ions with sensing factors between $0-2$. Thus, the interfering effects was eliminated. However, its applicability is still in question due to the lack of mechanistic aspects. Thereafter an anionic MOF, namely Zn-TPTC (TPTC represents $\left[2,2^{\prime}: 6^{\prime}, 2^{\prime \prime}\right.$-Terpyridine]-4, $4^{\prime}, 4^{\prime \prime}$-tricarboxylic acid), was presented for luminescent detection of $\mathrm{Hg}^{2+}$ [82]. Upon addition of $\mathrm{Hg}^{2+}$, the Zn-TPTC displayed linear PL quenching at $492 \mathrm{~nm}$ in a concentration range of 1 to $100 \mu \mathrm{M}$ and an estimated LOD of $3.7 \mathrm{nM}$. The ' $\mathrm{N}^{\prime}$ atoms of the MOF may interact with $\mathrm{Hg}^{2+}$ because of the greater affinity. There is no information regarding the BET surface area as well as the competing and application studies.

Subsequently, Pankajakshan et al. described $\mathrm{Hg}^{2+}$ sensing ability of $\left\{\left[\mathbf{Z n}\left(\mathbf{4}, \mathbf{4}^{\prime}\right.\right.\right.$-AP) (5-AIA)]. (DMF) 0.5 $_{n}$, (where 4, $4^{\prime}$ AP $=4,4^{\prime}$-azopyridine, 5-AIA and DMF represent deprotonated 5-amino isophthalic acid and $\mathrm{N}, \mathrm{N}^{\prime}$-dimethylformamide), via PL quenching at $405 \mathrm{~nm}$ in aqueous solution [83]. The MOF probe possessed a QY value of $11 \%$ and BET surface area of $173 \mathrm{~m}^{2} \mathrm{~g}^{-1}$. It was stable in $\mathrm{pH}$ range 4 to 11 and exhibited a linear PL quenching response to $\mathrm{Hg}^{2+}$ in a concentration range of $9.99 \mu \mathrm{M}$ to $20 \mathrm{mM}$. Moreover, the MOF displayed a high selectivity to $\mathrm{Hg}^{2+}$ over a wide range of competing mono-, di-, and tri-valent cationic species with a LOD down to $10^{-11} \mathrm{M}$ and an estimated $\mathrm{K}_{\mathrm{SV}}$ value of $1.011 \times 10^{9} \mathrm{M}^{-1} \mathrm{~s}^{-1}$. In fact, the sensitivity was attributed to a specific interaction between $\mathrm{Hg}^{2+}$ and the free standing $-\mathrm{N}=\mathrm{N}-$ of $4,4^{\prime}$-azopyridine. This work undoubtedly can be considered exceptional because of its performance in the real time $\mathrm{Hg}^{2+}$ detection (in seawater, river water, tap water, drinking water, and single crystals of MOF on an aluminum foil). Thereafter Khatun and co-workers developed the luminescent pillared paddle wheel MOF-Zn $\mathbf{n}_{\mathbf{2}} \mathbf{( N D C}_{\mathbf{2}}$ (DPTTZ) with naphthalene dicarboxylate (NDC) antenna and $\mathrm{N}, \mathrm{N}^{\prime}$-di(4pyridyl)thiazolo-[5,4-d]thiazole (DPTTZ) pillars, which detected $\mathrm{Hg}^{2+}$ via red-shifts in PL emission [84]. In addition, MOF-Zn $\mathbf{n}_{\mathbf{2}}(\mathbf{1}, \mathbf{4}-\mathbf{B D C})_{\mathbf{2}} \mathbf{( D P T T Z}_{\mathbf{2}}$ was also synthesized for comparison, where the 1,4-BDC represents 1,4-benzenedicarboxylic acid. The BET surface area and pore volumes of MOFs-Zn $\mathbf{n}_{\mathbf{2}}(\mathbf{N D C})_{\mathbf{2}}$ (DPTTZ) and $\mathbf{Z n}_{\mathbf{2}}(\mathbf{1}, \mathbf{4}-\mathbf{B D C})_{\mathbf{2}}(\mathrm{DPTTZ})_{\mathbf{2}}$ to $\mathrm{CO}_{2}$ were estimated as $106.8 \mathrm{~m}^{2} \mathrm{~g}^{-1}, 113.4 \mathrm{~m}^{2} \mathrm{~g}^{-1}$ and $6.6 \times 10^{-2} \mathrm{~cm}^{3} \mathrm{~g}^{-1}, 7.8 \times 10^{-2} \mathrm{~cm}^{3} \mathrm{~g}^{-1}$, respectively. The $\mathbf{Z n}_{\mathbf{2}} \mathbf{~}^{\text {NDC }} \mathbf{2}_{\mathbf{2}}$ (DPTTZ) in DMF showed an exceptional selectivity only to $\mathrm{Hg}^{2+}$ among all ions via bathochromic PL shift from $410 \mathrm{~nm}$ to $450 \mathrm{~nm}$. Although 
lacking experimental evidences, it was speculated that the PL change could be attributed to the interaction between $\mathrm{Hg}^{2+}$ and DPTTZ group. This work requires further attention regarding the LOD, competing studies, and real time applications. Recently, Zn-based MOF-ZnAPA with 5-aminoisophthalic acid ( $\left.\mathrm{H}_{2} \mathrm{APA}\right)$ organic linkers was demonstrated for $\mathrm{Hg}^{2+}$ detection by means of fluorescence quenching in water [85]. Wherein, PL emission of MOF at $405 \mathrm{~nm}$ was linearly quenched during exposure to $\mathrm{Hg}^{2+}$ in a concentration range of $0-100 \mu \mathrm{M}$ with a LOD of $0.12 \mu \mathrm{M}$. This might be due to the binding affinity of $\mathrm{Hg}^{2+}$ to ' $\mathrm{N}^{\prime}$ atom of amino group. This work showed a great selectivity over many other competing mono- and di-valent cationic species; however, it still needs to put more focus on the BET surface area and real applications.

The Cd-based MOFs were also engaged in discrimination of $\mathrm{Hg}^{2+}$, in parallel to $\mathrm{Zn}$-based MOFs. For example, $\mathrm{Wu}$ and co-workers constructed a $\mathrm{Cd}$ comprising 3D MOF- $\left\{\left[\mathrm{Cd}_{1.5}\left(\mathrm{C}_{18} \mathrm{H}_{10} \mathrm{O}_{10}\right)\right] \cdot\left(\mathrm{H}_{3} \mathrm{O}\right)\left(\mathrm{H}_{2} \mathrm{O}\right)_{3}\right\}_{n}$-Cd-EDDA with dual emission and utilized it in ratiometric detection of $\mathrm{Hg}^{2+}$ in pure water [86]. By hydrothermally reacting 5,5'-[ethane1,2-diylbis(oxy)]diisophthalic acid ( $\mathrm{H}_{4}$ EDDA) with $\mathrm{Cd}\left(\mathrm{ClO}_{4}\right)_{2} \cdot 6 \mathrm{H}_{2} \mathrm{O}$, the Cd-EDDA was produced with $80 \%$ yield. Upon addition of $\mathrm{Hg}^{2+}$ to the Cd-EDDA, intensity of PL emission at $350 \mathrm{~nm}$ decreased significantly $\left(\mathrm{K}_{\mathrm{SV}}=4.3 \times 10^{3} \mathrm{M}^{-1}\right)$ accompanied with a new PL peak at $410 \mathrm{~nm}$ with a linear response (within $15 \mathrm{~s}$ ) between $4-25 \mu \mathrm{M}$ and a calculated LOD of $2 \mathrm{nM}$, which was lower than the permitted level. Be noted that the Cd-EDDA displayed great selectivity over a wide range of metal ions by means of crystallinity destruction and was not reversible with $\mathrm{Na}_{2} \mathrm{~S}$. Thereby the probe behaves like a chemodosimeter. Information regarding the BET surface area and real time applicability requires further investigations. Subsequently, a MOF, namely $\left.\left[\left(\mathbf{M e}_{2} \mathbf{N H}_{2}\right) \mathbf{C d}_{3}(\mathbf{O H})\left(\mathbf{H}_{2} \mathbf{O}\right)_{3}(\mathrm{TATAB})_{2}\right](\mathrm{DMA})_{6}\right]$, was formed as yellow crystals through solvothermally reacting $\mathrm{Cd}\left(\mathrm{NO}_{3}\right)_{2} \cdot 6 \mathrm{H}_{2} \mathrm{O}$ and $4,4^{\prime}, 4^{\prime \prime}$-striazin-1,3,5-triyltri-p-aminobenzoic acid ( $\left.\mathrm{H}_{3} \mathrm{TATAB}\right)$ in DMA (N,N-dimethylacetamide), methanol, and $\mathrm{HCl}$ at $95{ }^{\circ} \mathrm{C}$ for 3 days and was consumed towards luminescent $\mathrm{Hg}^{2+}$ detection in water [87]. Due to the binding between ' $\mathrm{N}^{\prime}$ atoms of amino and triazine groups, PL emission at $365 \mathrm{~nm}$ was quenched in the presence of $\mathrm{Hg}^{2+}$. However, the selectivity was significantly affected by $\mathrm{Fe}^{3+}$. Moreover, there was no details regarding the BET surface area and applicability. Recently, interaction of $\mathrm{Cd}\left(\mathrm{ClO}_{4}\right)_{2} \cdot 6 \mathrm{H}_{2} \mathrm{O}$ with 2-aminoterephthalic acid $\left(\mathrm{NH}_{2}-\mathrm{H}_{2} \mathrm{BDC}\right)$ by microwave synthetic was used as actic to derive the $\mathrm{Cd}^{2+}$-comprising $\mathrm{MOF}-\mathrm{NH}_{2}-\mathrm{Cd}-\mathrm{BDC}$, which was applied in sensing of $\mathrm{Hg}^{2+}$ via PL quenching at $427 \mathrm{~nm}$ [88]. The $-\mathrm{NH}_{2}$ group of $\mathbf{N H}_{\mathbf{2}}-\mathbf{C d - B D C}$ reacted with $\mathrm{Hg}^{2+}$ and led to linearly quenched emission in a concentration range from 1 to $20 \mu \mathrm{M}$ and a $\mathrm{K}_{\mathrm{SV}}$ value of $28.0 \times 10^{3} \mathrm{M}^{-1}$ and a LOD of $0.58 \mu \mathrm{M}$. Though the work seems to be comparatively good with respect to earlier reports, it still lacks information on the BET surface area, real time applicability, and competing studies.

The ferrous $\left(\mathrm{Fe}^{2+}\right)$ comprising MOF nanoparticles, namely Fe(II)-MOF-NPs, were developed via solvothermal reaction of $\mathrm{FeSO}_{4} \cdot 7 \mathrm{H}_{2} \mathrm{O}$ with nano linkers (synthesized via refluxing 1, 2-phenylenediamine and 5-aminoisophthalic acid) and were engaged in colorimetric and PL detection of $\mathrm{Hg}^{2+}$ [89]. The nanoparticles have a size in the range between 100 to $250 \mathrm{~nm}$ and possess magnetic properties as well. During addition of $\mathrm{Hg}^{2+}, \mathrm{PL}$ emission at $416 \mathrm{~nm}$ displayed a 'turn-on' response and was red-shifted to $422 \mathrm{~nm}$. The absorption peak at $427 \mathrm{~nm}$ was also enhanced and red-shifted to $456 \mathrm{~nm}$ accompanied with changes in colour from yellow to colorless. Both absorption and PL showed a linear response in a concentration range from $1 \mathrm{nM}$ to $1 \mu \mathrm{M}$ and LODs of 1.17 and $1.14 \mathrm{nM}$ and limit of quantifications (LOQs) of 1.59 and $1.48 \mathrm{nM}$, respectively. Moreover, the Fe(II)-MOF-NPs in DMSO were also effective in discrimination of $\mathrm{Hg}^{2+}$ in competing and real environment (tap, mineral, river, sea, and waste water). Based on above results, the Fe(II)-MOF-NPs can be an excellent candidate for the discrimination of $\mathrm{Hg}^{2+}$, but mechanistic investigations and BET adsorption studies must be conducted to move towards $\mathrm{Hg}^{2+}$ removal studies. Towards sensing of $\mathrm{Hg}^{2+}, \mathrm{Li}$ and co-workers presented the hydrostable brominefunctionalized Mn-based MOF- $\left\{\left[\mathrm{Mn}_{\mathbf{2}}\right.\right.$ (Bript) $\mathbf{2}_{\mathbf{2}}\left(\mathbf{4}, \mathbf{4}^{\prime} \text {-bpy).5(DMF)] }\left(\mathrm{H}_{\mathbf{2}} \mathrm{O}\right)\right\}_{\mathrm{n}}$, where $\mathrm{H}_{2} \mathrm{Bript}$, 4,4'-bpy, and DMF represent 4-Bromoisophthalic acid, 4,4'-bipyridine, and dimethylfor- 
mamide, respectively [90]. The BET surface area of the MOF was established as $210 \mathrm{~m}^{2} \mathrm{~g}^{-1}$ and was further reduced to $33 \mathrm{~m}^{2} \mathrm{~g}^{-1}$ upon loading of $\mathrm{Hg}^{2+}$. Due to the binding affinity between $\mathrm{Br}$ atom and $\mathrm{Hg}^{2+}$, PL emission at $468 \mathrm{~nm}$ was linearly quenched $\left(\mathrm{K}_{\mathrm{Sv}}=1390.5 \mathrm{M}^{-1}\right)$ from 0 to $0.03 \mathrm{M}$ with an estimated LOD of $48 \mu \mathrm{M}$. The MOF showed high selectivity toward $\mathrm{Hg}^{2+}$ (in water) among variety of competing species. However, studies on the real time applicability and LODs need more focus before proceeding further. To this track, Song et al. reported highly selective sensing of $\mathrm{Hg}^{2+}$ using $\mathrm{Ag}$ coordinated MOF [91]. Wherein, they developed three $\mathrm{Ag}^{+} / \mathrm{Cu}^{2+}$ comprising MOFs, namely $\left[\mathbf{A g}\left(\mathbf{2}, 4^{\prime}-\mathbf{H p d c}\right)\left(4,4^{\prime}-\mathbf{b p y}\right)\right]_{\mathbf{n}}$, $\left[\mathrm{Ag}\left(2,2^{\prime}-\mathrm{Hpdc}\right)\left(4,4^{\prime}-\mathrm{bpy}\right) 0.5\right]_{\mathrm{n}}$, and $\left[\mathrm{Cu}\left(2,2^{\prime}-\mathrm{Hpdc}_{2}(\mathbf{1}, 4-\mathrm{bib})\right]_{\mathrm{n}}\right.$, via hydrothermal method, where 2,4'-Hpdc, 2,2'-Hpdc, 4,4'-bpy, and 1,4-bib represent 2,4'-biphenyldicarboxylic acid, 2,2'-biphenyldicarboxylic acid, 4,4'-bipyridine, and 1,4-bis(1-imidazolyl) benzene, respectively. Among them, only the $\left[\operatorname{Ag}\left(2,4^{\prime}-\mathbf{H p d c}\right)\left(4,4^{\prime}-\mathbf{b p y}\right)\right]_{n}$ in water showed selectivity to $\mathrm{Hg}^{2+}$ via 'turn-on' response with PL emission at $401 \mathrm{~nm}$. Note that the $\mathrm{Fe}^{3+}$ showed PL quenching in the selectivity studies as seen in Figure 4 . Due to the binding affinity between 2,4'-Hpdc to $\mathrm{Hg}^{2+}$, PL emission of the MOF (in water) was enhanced linearly between $\mathrm{Hg}^{2+}$ concentrations from 0 to $100 \mu \mathrm{M}$ with a LOD of $9.63 \mathrm{nM}$. However, it still requires optimization for BET surface area, competing analysis, and real sample applications.

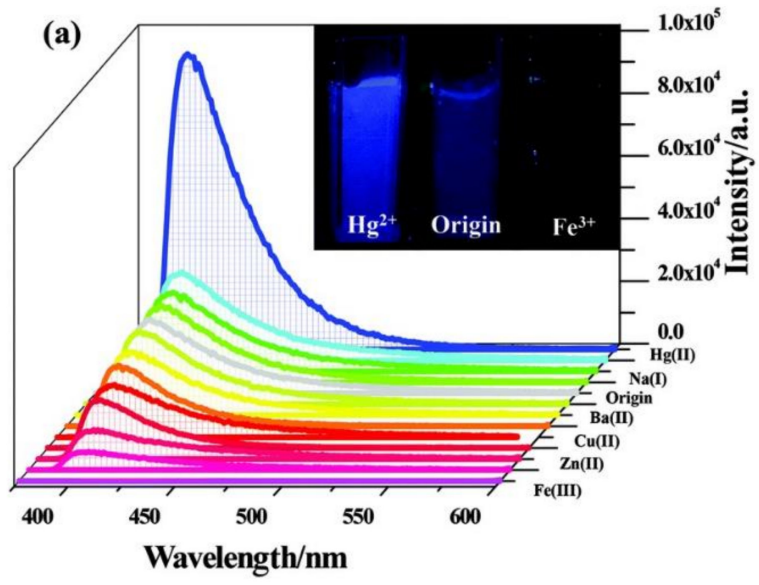

(b)

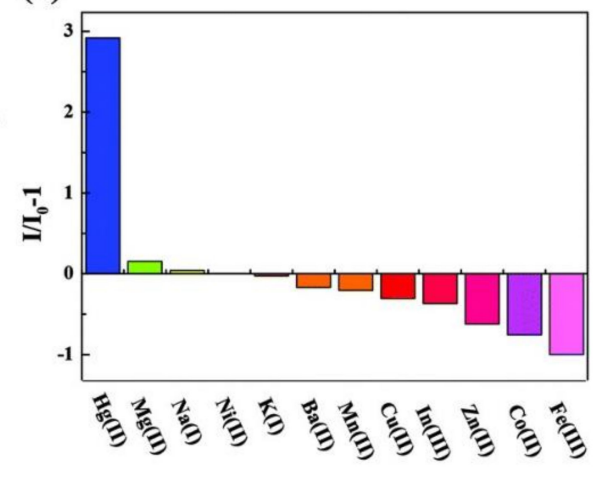

Figure 4. (a) Suspension-state PL spectra (inset: the images under UV-light irradiation at $365 \mathrm{~nm}$ ) and (b) the relative intensities of $\left[\mathbf{A g}\left(\mathbf{2}, \mathbf{4}^{\prime}-\mathbf{H p d c}\right)\left(\mathbf{4}, \mathbf{4}^{\prime}-\mathbf{b p y}\right)\right]_{\mathrm{n}}$ at $401 \mathrm{~nm}$ dispersed in aqueous solutions containing different metal ions $(50 \mu \mathrm{M})$ when excited at $300 \mathrm{~nm}$ (reproduced with the permission from Ref [91]).

Many MOFs were also involved in detection of multiple analytes other than $\mathrm{Hg}^{2+}$ as detailed in the following. For example, $4,4^{\prime}$-(benzothiadiazole-4,7-diyl)dibenzoic acid ligand comprising MOFs, such as $\left[\mathrm{Mn}_{4}\left(\mathrm{C}_{20} \mathrm{H}_{10} \mathbf{N}_{2} \mathrm{O}_{4} \mathrm{~S}\right)_{2}-(\mathrm{HCOO})_{4}(\mathrm{DEF})_{2}\right]$ and $\left[\mathrm{Pb}\left(\mathrm{C}_{20} \mathbf{H}_{10} \mathbf{N}_{2} \mathrm{O}_{4} \mathrm{~S}\right)(\mathrm{DMF})\right]$ (where DEF and DMF represent $\mathrm{N}, \mathrm{N}^{\prime}$-diethylformamide and $\mathrm{N}, \mathrm{N}^{\prime}$-dimethylformamide; solvothermally synthesized), were described for the sensing of $\mathrm{Hg}^{2+}$ and $\mathrm{Tl}^{3+}$ metal cations and chromate, dichromate, and permanganate anions [92]. Detection of the metal ions was attributed to the interaction of ' $\mathrm{S}$ ' atom with metal cations. Moreover, PL emission at $500 \mathrm{~nm}$ was quenched rapidly with LODs down to parts per billion/parts per million (ppb/ppm) in the presence of these analytes. Be noted that both MOFs can be used to detect $\mathrm{Hg}^{2+}$ in samples free of $\mathrm{Tl}^{3+}$. Thus, these MOFs can be accounted as $\mathrm{Hg}^{2+}$ sensors. However, they are non-selective. Thereafter a ratiometric $\mathrm{Hg}^{2+}$ sensor was proposed by using MOF-[Zn(tpbpc) 2 - solvent prepared via solvothermal tactic, where Htpbpc $\left(4^{\prime}-\left[4,2^{\prime} ; 6^{\prime}, 4^{\prime \prime}\right]\right.$-terpyridin- $4^{\prime}$-yl-biphenyl-4-carboxylic acid and DMF solvent were used as an organic linker with $\mathrm{Zn}$ metal nodes [93]. This Zn-MOF was also demonstrated for detection of $\mathrm{CrO}_{4}{ }^{2-}$ and $\mathrm{Cr}_{2} \mathrm{O}_{7}{ }^{2-}$ species in water via PL quenching at $414 \mathrm{~nm}$. Above sensory results may arise from interactions between pyridine ' $\mathrm{N}$ ' atoms and $\mathrm{Hg}^{2+}$ or by inhibition of energy transfer processes by $\mathrm{CrO}_{4}{ }^{2-}$ and $\mathrm{Cr}_{2} \mathrm{O}_{7}{ }^{2-}$ ions. During addition of $\mathrm{Hg}^{2+}$ ions from 0 to $1200 \mu \mathrm{M}$, PL emission peak at $414 \mathrm{~nm}$ was quenched linearly with a LOD of $0.32 \mu \mathrm{M}$, accompanied with appearance of a new peak at $500 \mathrm{~nm}$ (green emission under UV lamp $\lambda_{\text {ex }}=365 \mathrm{~nm}$ ). However, during competing studies, the selectivity may be affected in the presence of $\mathrm{Cr}(\mathrm{VI})$ ions 
$\left(\mathrm{CrO}_{4}{ }^{2-}\right.$ and $\left.\mathrm{Cr}_{2} \mathrm{O}_{7}{ }^{2}\right)$. Thus, more interrogations are required due to lack of information on the selectivity, BET surface area and practical applications.

$\mathrm{Ma}$ 's research group developed the stable dye-incorporated MOF- $\left[\left(\mathrm{CH}_{3}\right)_{2} \mathbf{N H}_{2}\right]\left[\mathbf{I n}(\mathrm{TNB})_{4 / 3}\right]$. (2DMF) $\left(3 \mathrm{H}_{2} \mathrm{O}\right)$ via a solvothermal method, where $\mathrm{H}_{3} \mathrm{TNB}\left(4,4^{\prime}, 4^{\prime \prime}\right.$-nitrilotribenzoicacid) was used as an organic linker and then incorporated with a dye 4-[p-(dimethylamino)styryl]-1ethylpyridinium (DSM) to provide the MOF-DSM system [94]. The MOF-DSM system displayed sensing ability towards $\mathrm{Hg}^{2+}, \mathrm{Cr}_{2} \mathrm{O}_{7}^{2-}$, and a wide variety of nitro-compounds. The BET surface area of MOF and MOF-DSM systems were estimated as $491 \mathrm{~m}^{2} \mathrm{~g}^{-1}$ and $236 \mathrm{~m}^{2} \mathrm{~g}^{-1}$, respectively. During discrimination of $\mathrm{Hg}^{2+}$, PL emission peaks of MOF-DSM (in water) at 478 and $630 \mathrm{~nm}$ were linearly quenched between $1-10 \mu \mathrm{M}$ with an estimated LOD of $1.75 \mathrm{ppb}$ and a $\mathrm{K}_{\mathrm{SV}}$ value of $1.48 \times 10^{5} \mathrm{M}^{-1}$. The energy transfer efficiency of the $\pi-\pi^{*}$ transitions diminished due to the binding affinity between $\mathrm{Hg}^{2+}$ and ' $\mathrm{N}^{\prime}$ atoms of DSM. The MOF-DSM was found to be more effective in aqueous detection of $\mathrm{Cr}_{2} \mathrm{O}_{7}{ }^{2-}$ and vapour/aqueous detection of nitro-compounds. Subsequently, Li et al. derived the Co-based MOF-[Co (NPDC)(bpee)] D DMF $\cdot 2 \mathrm{H}_{2} \mathrm{O}$ (where NPDC and bpee represent 2-nitro phenylenedicarboxylate and 1,2-bis(4-bipyridyl) ethylene) by means of the solvothermal tactic and established sensing ability towards $\mathrm{Hg}^{2+}$ and $\mathrm{MnO}_{4}{ }^{-}$[95]. This MOF in water displayed PL quenching in the presence of $\mathrm{MnO}_{4}{ }^{-}$and PL enhancement at $471 \mathrm{~nm}$ for $\mathrm{Hg}^{2+}$ ions. The linear response for $\mathrm{Hg}^{2+}$ ions by this MOF was found to be 1-120 $\mu \mathrm{M}$ with a LOD of $4.1 \mu \mathrm{M}$. However, this work still contains mechanistic flaws with non-optimal LODs and lacks information in applicability as well. To this track, Yang and co-workers synthesized two Cd-based MOFs, namely $\mathbf{C d}(\mathrm{L})(\text { atpa) }]_{\mathbf{n}}$ and $\left[\mathrm{Cd}(\mathrm{L})(\mathrm{tbta})\left(\mathrm{H}_{2} \mathrm{O}\right)\right]_{\mathbf{n}}$ (where $\mathrm{H}_{2}$ atpa, $\mathrm{H}_{2}$ tbta, and L represent 2-aminoterephthalic acid, tetrabromoterephthalic acid, and 1,4-bis(benz-imidazol-1-yl)-2-butene, respectively) via a hydrothermal method and utilized them as dual luminescent sensors $\left(\mathrm{Cu}^{2+}\right.$ and $\mathrm{Cr}_{2} \mathrm{O}_{7}{ }^{2-}$ by $\left[\mathbf{C d}(\mathbf{L})(\text { atpa) }]_{n}\right.$, and $\mathrm{Hg}^{2+}$ and $\mathrm{Cr}_{2} \mathrm{O}_{7}{ }^{2-}$ by $\left[\mathbf{C d}(\mathbf{L})(\mathrm{tbta})\left(\mathrm{H}_{2} \mathrm{O}\right)\right]_{\mathrm{n}}$ in water [96]. PL intensity of $\left[\mathrm{Cd}(\mathrm{L})(\mathrm{tbta})\left(\mathrm{H}_{2} \mathrm{O}\right)\right]_{\mathrm{n}}$ at $294 \mathrm{~nm}$ was linearly quenched during addition of $\mathrm{Hg}^{2+}$ from 0 to $0.25 \mathrm{mM}$ with a LOD of $0.043 \mu \mathrm{M}$ and a $\mathrm{K}_{\mathrm{SV}}$ value of $1.72 \times 10^{5} \mathrm{M}^{-1}$. Moreover, fluorescence of $\left[\mathrm{Cd}(\mathrm{L})(\mathrm{tbta})\left(\mathrm{H}_{2} \mathrm{O}\right)\right]_{\mathrm{n}}$ in water at $294 \mathrm{~nm}$ was also quenched in the presence of $\mathrm{Cr}_{2} \mathrm{O}_{7}{ }^{2-}$. This work did not provide any details on the BET surface area, discriminative information between $\mathrm{Hg}^{2+}$ and $\mathrm{Cr}_{2} \mathrm{O}_{7}{ }^{2-}\left(\mathrm{Cr}^{6+}\right)$, and practicality.

Subsequently, 2,6-naphthalenedicarboxylic acid (NP) and 1,5 dihydroxy-2,6-naphthalen edicarboxylic (DNP) were conjugated with lanthanide cations $\left(\mathrm{La}^{3+}\right.$ and $\left.\mathrm{Ce}^{3+}\right)$ to produce luminescent MOFs, namely AUBM-2 (Ce) and AUBM-2(La) with NP ligand and AUBM3(Ce) and AUBM-3(La) with DNP ligand. They were engaged in sensory studies [97]. Wherein, upon excitation at 300 and $370 \mathrm{~nm}$, the AUBM-2 (Ce) and AUBM-3(Ce) displayed sensory responses to $\mathrm{Hg}^{2+}, \mathrm{Cr}^{3+}, \mathrm{Pb}^{2+}, \mathrm{Cd}^{2+}$, and $\mathrm{As}^{3+}$ by means of fluorescent enhancement or quenching responses. This study requires further optimization for $\mathrm{Hg}^{2+}$ analyte detection. Next, Ren et al. proposed utilization of MOF nanosheet amino-MIL-53(Al) (hydrothermally synthesized by reacting $\mathrm{AlCl}_{3} \cdot 6 \mathrm{H}_{2} \mathrm{O}$ with 2-amino-terephthalic acid) towards luminescent detection of $\mathrm{Hg}^{2+}$ and glutathione (GSH) [98]. Emission of amino-MIL-53(Al) nanosheets at $435 \mathrm{~nm}$ (in water) was linearly quenched by $\mathrm{Hg}^{2+}$ with concentrations between $1.96 \mathrm{nM}$ to $38.27 \mu \mathrm{M}$ and a detection limit of $0.23 \mathrm{nM}$. Furthermore, luminescent quenching was partially restored by addition of GSH (linear range: $210 \mathrm{nM}$ to $15.25 \mu \mathrm{M}$ and LOD $=8.11 \mathrm{nM}$ ). However, this work still lacks of information about the BET surface area. Solvothermally synthesized Cd-based MOFs [(Cd(II)BPDC) $\left.)_{0.5}(\mathbf{L} 1)\left(\mathbf{N O}_{3}\right)\right] \cdot 3.4 \mathrm{DMF}$ (where BPDC, L1, and DMF represent 4,4'-biphenyldicarboxylic acid, 1-(3,5-di(1H-imidazol-1-yl)phenyl)-1H-imidazole), and Dimethylformamide, respectively) and $\left[\left(\mathbf{C d}_{\mathbf{2}}(\mathbf{4}-\mathrm{tp}-3-\mathbf{l a d})(\mathbf{1}, \mathbf{4}-\mathbf{B D C})_{2}\right\} \cdot \mathbf{2} \mathbf{M e C N}\right)_{\mathbf{n}}$ (where 4-tp-3-lad, 4-BDC, and MeCN represent 2,3,5,6-tetra(pyridin-4-yl)-bicyclo [2.2.0]hexane, 1 , deprotonated 1,4-benzenedicarboxylic acid, and acetonitrile, respectively) were also proposed towards the detection of $\mathrm{Hg}^{2+}$ and nitro-explosives via fluorescence quenching $[99,100]$. However, due to insufficient information regarding the BET surface area, competing studies, and practicality, these reports are not impressive. Later, Su et al. re-

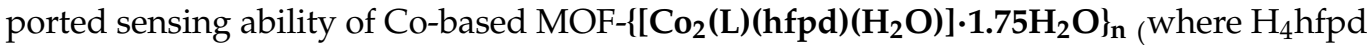
and $\mathrm{L}$ represent $4,4^{\prime}$-(hexa-fluoroisopropylidene)diphthalic acid and 4,4'-bis(imidazol-1yl)-biphenyl) to $\mathrm{Hg}^{2+}$ and acetylacetone via luminescent quenching responses [101]. This 
hydrothermally synthesized MOF showed luminescence quenching in the presence of $0-200 \mu \mathrm{M} \mathrm{Hg}^{2+}$ with a $\mathrm{K}_{\mathrm{SV}}$ of $6497 \mathrm{M}^{-1}$ and a LOD of $4 \mu \mathrm{M}$. However, this work requires further interrogations on the BET surface area, nano/micro-structure, competing studies, and practicality.

\section{Metal Coordinated Polymers as Luminescent $\mathrm{Hg}^{2+}$ Sensors}

In addition to MOFs, metal containing coordination polymers were proposed towards luminescent sensing of $\mathrm{Hg}^{2+}$ [100]. For instance, Sun's research group developed $\mathrm{Zn}$ - and Cd-based coordination polymers-[Zn(TPDC-2 $\left.\left.\mathrm{CH}_{3}\right)\left(\mathbf{H}_{2} \mathbf{O}\right)_{2}\right] \cdot \mathbf{H}_{2} \mathbf{O}$ and $[\mathrm{Cd}(\mathrm{TPDC}-$ $\left.\left.2 \mathbf{C H}_{3}\right)\left(\mathbf{H}_{2} \mathbf{O}\right)_{4}\right] \cdot \mathbf{H}_{2} \mathrm{O}$ via solvothermally reacting $2^{\prime}, 5^{\prime}$-dimethyl-[1, $1^{\prime}: 4^{\prime}, 1^{\prime \prime}$-terphenyl $-4,4^{\prime \prime}$ dicarboxylic acid $\left(\mathrm{H}_{2}\right.$ TPDC-2 $\left.\mathrm{CH}_{3}\right)$ with $\mathrm{Zn}^{2+}$ and $\mathrm{Cd}^{2+}$ ions, separately, and engaged them in sensory interrogations towards metal ions [102]. Emission of the [Zn(TPDC$\left.\left.2 \mathrm{CH}_{3}\right)\left(\mathbf{H}_{2} \mathbf{O}\right)_{2}\right] \cdot \mathbf{H}_{2} \mathrm{O}$ metal polymer at $380 \mathrm{~nm}$ (in water) was linearly quenched between 1-10 femtomole (fM) with a LOD of $3.6 \mathrm{fM}$. The solid chelation-enhanced fluorescence quenching (CHEQ) effect can be attributed to coordination between carboxyl group and $\mathrm{Hg}^{2+}$. However, this report did not provide any information regarding the BET surface area and practicality. Next, the Eu/IPA CPNPs (by solvothermal tactic) were prepared by reacting $\mathrm{Eu}^{3+}$ comprising coordination polymer nanoparticles (CPNPs) with isophthalic acid (IPA) bridging ligands and were employed in $\mathrm{Hg}^{2+}$ detection [103]. Initially, absorbance band of Eu/IPA CPNPs in Tris-HCl buffer ( $25 \mathrm{mM}, \mathrm{pH} 7.0)$ was overlapped with imidazole-4,5-dicarboxylic acid ( $\mathrm{Im})$, thus emission intensity at $615 \mathrm{~nm}$ was quenched due to the inner filter effect (IFE). During addition of $\mathrm{Hg}^{2+}$, the IFE was supressed and recovery of emission at $615 \mathrm{~nm}$ was observed. The linear correlation of $\mathrm{Hg}^{2+}$ ranged between $2 \mathrm{nM}$ to $2 \mu \mathrm{M}$ with a LOD of $2 \mathrm{nM}$. Effectiveness of the probe was further demonstrated with applicability in biological fluid samples. Nevertheless, information regarding BET surface area must be evaluated for its exceptional applicability.

Towards the development of metal coordination polymers for $\mathrm{Hg}^{2+}$ sensors, $\mathrm{Li}$ et al. described the solvothermally synthesized Zn-based 3D coordination polymer- $\left\{\left[\mathbf{Z n}_{\mathbf{2}} \mathbf{( 1 , 4 -}\right.\right.$ bpyvna)(1,3,5-BTC)(OH)] $\left.\mathbf{H}_{2} \mathbf{O}\right\}_{\mathbf{n}}$ (where 1,4-bpyvna and 1,3,5- $\mathrm{H}_{3} \mathrm{BTC}$ represent 1,4-bis(2(pyridin-4-yl)vinyl)naphthalene and 1,3,5-benzene-tricarboxylic acid, respectively) as a $\mathrm{Hg}^{2+}$ sensor [104]. Due to the interactive effect of 1,4-bpyvna with $\mathrm{Hg}^{2+}$, the $\left\{\left[\mathbf{Z n}_{\mathbf{2}} \mathbf{( 1 , 4 -}\right.\right.$ bpyvna)(1,3,5-BTC)(OH)] $\left.\cdot \mathbf{H}_{2} \mathbf{O}\right\}_{n}$ in DMF displayed fluorescence quenching at 444 and $472 \mathrm{~nm}$ as seen in Figure 5.

A linear response of the polymer was found from 0 to $0.018 \mathrm{ppm}$ with a LOD of $0.057 \mathrm{ppm}$. A fluorescent colour change from blue to yellow was also observed. However, further interrogations for the BET surface area and real time applications are still required. Subsequently, Zhang and co-workers presented $\mathrm{Hg}^{2+}$ sensing ability of hydrothermally synthesized fluorescent coordination polymer, namely $\left[\mathbf{Z n}\left(\mathbf{H}_{3} \mathbf{T T A}\right)\left(\mathbf{H}_{2} \mathbf{O}\right)_{2}\right] \cdot \mathbf{2} \mathbf{H}_{2} \mathbf{O}$ (where $\mathrm{H}_{3}$ TTA represents $\left[2,2^{\prime}: 6^{\prime}, 2^{\prime \prime}\right.$-terpyridine]-4, $4^{\prime}, 4^{\prime \prime}$-tricarboxylic acid)), in aqueous solution [105]. Emission band at $500 \mathrm{~nm}$ was quenched in the presence of $\mathrm{Hg}^{2+}$ with a $\mathrm{K}_{\mathrm{SV}}$ value of $4695 \mathrm{M}^{-1}$. This work is incomplete due to lack of information in the BET surface area, LODs, and practicality. Utilization of $\mathrm{Zn}$ - and $\mathrm{Cd}$-based luminescent coordination polymers towards the quantitation of $\mathrm{Hg}^{2+}$ and $\mathrm{Cr}_{2} \mathrm{O}_{7}{ }^{2-}$ has been reported by many research groups [106-108]. Since $\mathrm{Cr}_{2} \mathrm{O}_{7}{ }^{2-}$ is a well-known source of $\mathrm{Cr}^{6+}$ ions, discrimination between them are not available in those reports. Therefore, those works cannot be considered as exceptional $\mathrm{Hg}^{2+}$ sensor studies. Similarly, Lin et al. demonstrated $\mathrm{Pb}^{2+}$ and $\mathrm{Hg}^{2+}$ sensing ability of $\mathrm{Eu}^{3+}$ containing coordination polymer, namely $\left\{\left[\mathrm{Ln}_{\mathbf{2}}(\mathrm{PBA})_{3}\left(\mathrm{H}_{2} \mathbf{O}\right)_{3}\right] \cdot \mathrm{DMF} \cdot \mathbf{3} \mathbf{H}_{2} \mathbf{O}\right\}_{\mathbf{n}}$, in DMF and aqueous media, where PBA, DMF, and $\mathrm{H}_{2} \mathrm{O}$ represent deprotonated 5-(4-pyridin-3-yl-benzoylamino)-isophthalic acid, Dimethylformamide, and water molecules, respectively [109]. Wherein, the polymer can be used to detect $\mathrm{Hg}^{2+}$ in samples free of $\mathrm{Pb}^{2+}$. Thus, these MOFs can be accounted as $\mathrm{Hg}^{2+}$ sensors. However, they are non-selective. 


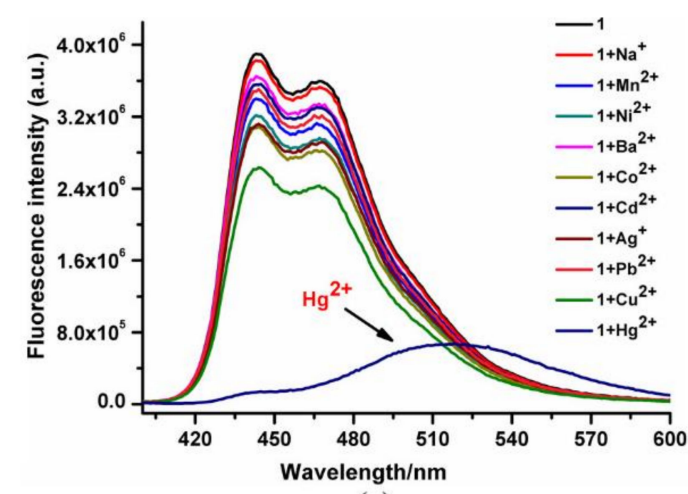

(a)

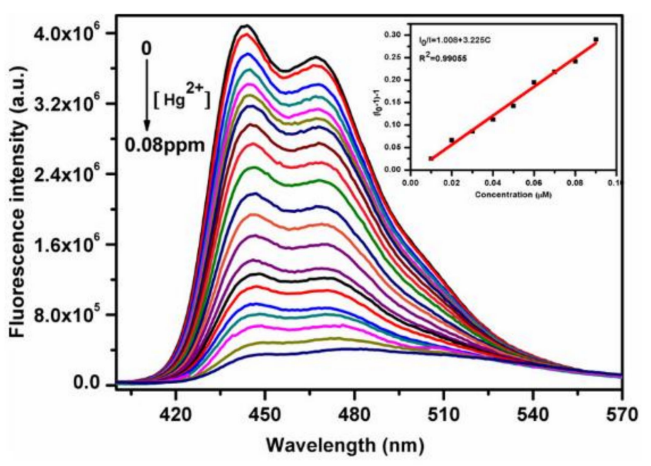

(c)

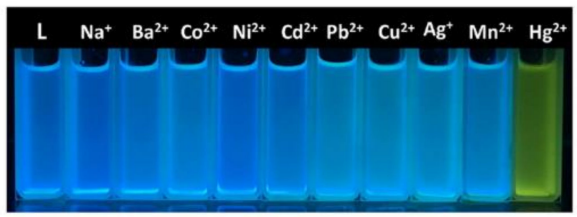

(b)

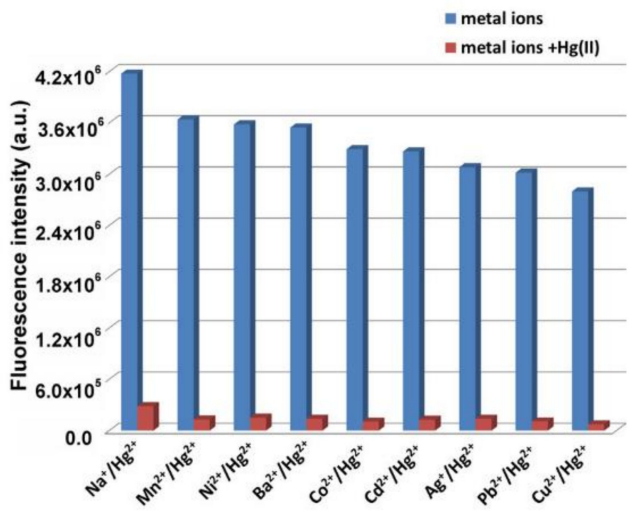

(d)

Figure 5. (a) Emission spectra of $\left\{\left[\mathrm{Zn2}(1,4-\text {-bpyvna)(1,3,5-BTC)(OH)]·H2O }\}_{\mathrm{n}}\right.\right.$ in DMF in the absence/presence of Mn+ ions. (b) The colours of the suspensions of $\left\{\left[\mathbf{Z n 2}(\mathbf{1}, \mathbf{4}-\text { bpyvna) (1,3,5-BTC)(OH)]·H2O }\}_{\mathbf{n}}\right.\right.$ with different metal ions under UV light. (c) Emission spectra of $\left\{[\mathbf{Z n 2 ( 1 , 4 - b p y v n a ) ( 1 , 3 , 5 - B T C ) ( O H ) ] \cdot H 2 O}\}_{\mathbf{n}}\right.$ in the presence of increasing $\mathrm{Hg}^{2+}$ concentrations $\left(0-0.08\right.$ ppm) in DMF. Inset: linear relation between the quenching efficiency and the concentration of $\mathrm{Hg}^{2+}$ in the range of 0-0.018 ppm. (d) Fluorescence intensities of \{[Zn2(1,4-bpyvna)(1,3,5-BTC)(OH)]·H2O $\}_{\mathbf{n}}$ immersed in the DMF solution of metal ion (blue colour) or mixed Hg2+ and metal ions (red colour) under an excitation of $389 \mathrm{~nm}$ (Reproduced with the permission from Ref [104]).

In addition to metal coordination polymer-based $\mathrm{Hg}^{2+}$ sensor, Rachuri and co-workers reported a luminescent coordination polymer, namely $\left[\mathrm{Zn}\left(\mu_{2}-\mathbf{1 H}\right.\right.$-ade) $\left.\left(\mu_{2}-\mathbf{S O}_{4}\right)\right]$ (by solvothermal reaction of adinine (HAde) and $\left.\mathrm{Zn}\left(\mathrm{SO}_{4}\right) \cdot 7 \mathrm{H}_{2} \mathrm{O}\right)$, as discussed in the following [110]. In the report, fluorescence intensity of the $\left[\mathbf{Z n}\left(\boldsymbol{\mu}_{\mathbf{2}} \mathbf{- 1 H}\right.\right.$-ade) $\left.\left(\boldsymbol{\mu}_{2}-\mathbf{S O}_{4}\right)\right]$ at $395 \mathrm{~nm}$ (in water) was linearly quenched between $0-1 \mathrm{mM}$ of $\mathrm{Hg}^{2+}$ with a LOD of $70 \mathrm{nM}$ and a $\mathrm{K}_{\mathrm{SV}}$ value of $7.7 \times 10^{3} \mathrm{M}^{-1}$. Moreover, this polymer also has an additional advantage that it showed selective sensing of the 2,4,6-trinitrophenol (TNP) in aqueous medium. The underlying mechanism of detection of $\mathrm{Hg}^{2+}$ was attributed to the interaction with basic sites ( $\mathrm{N}$ atoms) of the adenine and TNP through the resonance energy transfer (RET). It should be noted that this work also described the $\mathrm{Hg}^{2+}$ detection in paper strips, therefore, it can be extended for effective $\mathrm{Hg}^{2+}$ removal in real samples with directed BET surface area analysis. Thereafter, Zhu et al. demonstrated $\mathrm{Hg}^{2+}$ sensing utility of two luminescent coordination polymers, namely $[\mathbf{C d}(\mathrm{L})(\mathbf{N T A})]_{\mathbf{n}}$ and [Ni(L)(NPTA) $\left.\cdot \mathrm{H}_{\mathbf{2}} \mathrm{O}\right]_{\mathbf{n}}$ (obtained by solvothermal method, where $\mathrm{L}, \mathrm{H}_{2} \mathrm{NTA}$, and $\mathrm{H}_{2} \mathrm{NPTA}$ represent 1,6-bis(benzimidazol-1-yl)hexane, 2-nitroterephthalic acid, and 3-nitrophthalic acid, respectively) [111]. Emission peaks at $292 \mathrm{~nm}$ and $295 \mathrm{~nm}$ of the polymers [Cd(L)(NTA) $]_{\mathbf{n}}$ and $\left[\mathrm{Ni}(\mathrm{L})(\mathrm{NPTA}) \cdot \mathrm{H}_{2} \mathrm{O}\right]_{\mathrm{n}}$ (in water), respectively, were linearly quenched by $\mathrm{Hg}^{2+}$ in a concentration range between 1-200 $\mu \mathrm{M}$ with corresponding LODs of $3.05 \mu \mathrm{M}$ and $2.29 \mu \mathrm{M}$ and $\mathrm{K}_{\mathrm{Sv}}$ values of $3565 \mathrm{M}^{-1}$ for 1 and $7432 \mathrm{M}^{-1}$. In addition, both polymers displayed selectivity 
only to acetylacetone among all solvents. However, this work requires information on the BET surface area, competing studies, mechanistic investigations, and practicality.

\section{MOFs Holding Composites for Optical Recognition of $\mathbf{H g}^{2+}$}

To enhance sensing ability of MOFs to $\mathrm{Hg}^{2+}$, researchers also proposed to synthesize MOFs comprising composites as detailed in the following. A metal-polydopamine framework (MPDA - a dopamine loaded Co-based MOF developed by sonochemical reaction of $\mathrm{Co}\left(\mathrm{NO}_{3}\right)_{2}$ and 2-methylimidazole to afford ZIF-67 primarily) was reported as a fluorescent quencher towards the detection of $\mathrm{Hg}^{2+}$ and $\mathrm{Ag}^{+}$via exonuclease III signal amplification activity with pico-molar level LODs (1.3 pM and $34 \mathrm{pM}$, respectively) [112]. Upon addition of $\mathrm{Hg}^{2+}$ to MPDA-T-rich ssDNA (T-rich ssDNA represents thymine rich single stranded Deoxyribonucleic acid) system, 'turn-on' PL emission enhancement at $520 \mathrm{~nm}$ was observed with a linear response from 0 to $2 \mathrm{nM}$ and a LOD of $1.3 \mathrm{pM}$. The quenched luminescence of MPDA conjugated with T-rich ssDNA was recovered through $\mathrm{T}-\mathrm{Hg}^{2+}-\mathrm{T}$ complexation during addition of $\mathrm{Hg}^{2+}$. This work was also well demonstrated in tap and river water applications. To this way, Huang and co-workers reported $\mathrm{Cu}$-based MOFs as a hybrid sensory system with C-rich or T-rich DNA probes to detect the $\mathrm{Ag}^{+}, \mathrm{Hg}^{2+}$, and thiol comprising species at nanomolar-level via $\mathrm{T}-\mathrm{Hg}^{2+}-\mathrm{T}$ complexation $[113,114]$. Wherein, Huang et al. developed a MOF, namely $\left[\mathrm{Cu}_{4}(\mathbf{D c b b})_{\mathbf{4}}(\mathbf{D p s})_{2}\left(\mathbf{H}_{2} \mathbf{O}\right)_{2}\right]_{\mathbf{n}}$ (by reacting $\mathrm{H}_{2} \mathrm{DcbbBr}=$ 1-(3,5-dicarboxybenzyl)-4,4'-bipyridinium bromide and Dps $\left(4,4^{\prime}\right.$-dipyridyl sulfide) with $\left.\mathrm{Cu}\left(\mathrm{NO}_{3}\right)_{2} \cdot 3 \mathrm{H}_{2} \mathrm{O}\right)$, to detect $\mathrm{Ag}^{+}, \mathrm{Hg}^{2+}$, and biothiols with nM LODs [113]. Similarly, the $\mathrm{MOF}$, namely $\left[\mathrm{Cu}(\mathbf{C d c b p})\left(\mathbf{H}_{2} \mathbf{O}\right)_{2} \cdot \mathbf{2 H}_{2} \mathbf{O}\right]_{\text {n }}$ (synthesized by reacting $\mathrm{H}_{3} \mathrm{CdcbpBr}$ (3carboxyl-(3,5-dicarboxybenzyl)-pyridinium bromide) with $\mathrm{CuSO}_{4} \cdot 5 \mathrm{H}_{2} \mathrm{O}$ ) was engaged in detection of $\mathrm{Hg}^{2+}$ and biothiols with nM LODs [114]. In both cases, the MOF tended to form a hybrid system initially with fluorescent dye loaded thymine rich (T-rich) DNA (labelled as P-DNA) which led to fluorescent quenching. It was then recovered upon addition of metal ions, $\mathrm{Hg}^{2+}$ in particular, via $\mathrm{T}^{-\mathrm{Hg}^{2+}}-\mathrm{T}$ complexation. The above hybrid MOFs-DNA systembased detection of $\mathrm{Hg}^{2+}$ and biothiols and the corresponding mechanism are illustrated in Figure 6. Following the same strategy, $\mathrm{Zr}$ - and Ce-based MOFs (UIO-66-- $\mathbf{N H}_{\mathbf{2}}$ and Ce/TBC) were also demonstrated to discriminate $\mathrm{Hg}^{2+}$ with nanomolar LODs $[115,116]$. Wherein the Ce/TBC (also noted as mixed-valence state cerium-based metal-organic framework (MVC-MOF) combined with thymine-rich ssDNA was engaged in colorimetric peroxidase like sensors to detect $\mathrm{Hg}^{2+}$ using oxidase substrate 3,3',5,5'-tetramethylbenzidine [116]. Results of $\mathrm{Hg}^{2+}$ detection showed a linear response in a concentration range of 0.05 to 6 $\mu \mathrm{M}$ with a LOD of $10.5 \mathrm{nM}$ and were further supported by environmental water analysis. In fact, many MOF-DNA hybrid systems were reported for detection of metal ions, aminoacids, and nucleic acids [117,118], which make the strategy as precise one.

Recently, gold nanoclusters composited MOFs, namely AuNCs/MIL-68(In)- $\mathbf{N H}_{2} / \mathrm{Cys}$ and AuNCs@UIO-66, were demonstrated in discrimination of $\mathrm{Hg}^{2+}[119,120]$. To develop the AuNCs/MIL-68(In)-NH2/Cys, MIL-68(In)- $\mathbf{N H}_{2}$ was first solvothermally synthesized by reacting $\mathrm{In}\left(\mathrm{NO}_{3}\right)_{3} \cdot \mathrm{xH}_{2} \mathrm{O}$ with 2-Aminoterephthalic acid $\left(\mathrm{H}_{2} \mathrm{ATA}\right)$ followed by evenly dispersing the AuNCs on its surface. The AuNCs exhibited emission bands at $438 \mathrm{~nm}$ and $668 \mathrm{~nm}\left(\lambda_{\mathrm{ex}}=370 \mathrm{~nm}\right)$. By adding cysteine into above mixture, the AuNCs/MIL68(In)- $\mathrm{NH}_{2}$ /Cys was produced with enhanced emission [119]. Upon addition of $\mathrm{Hg}^{2+}$ to the AuNCs/MIL-68(In)-NH2/Cys at pH 7.4 (phosphate buffer), emission at $638 \mathrm{~nm}$ was quenched without affecting the peak at $438 \mathrm{~nm}$. Due to the binding affinity of $\mathrm{Hg}^{2+}$ with thiol (-SH) of cysteine, PL quenching exhibited two linear responses (with a concentration range from $20 \mathrm{pM}$ to $0.2 \mu \mathrm{M}$ and from $0.2 \mu \mathrm{M}$ to $60 \mu \mathrm{M}$ ) with a LOD of $6.7 \mathrm{pM}$, which was further supported by real water analysis and microfluidic paper device. Subsequently, the UIO-66 was obtained by solvothermally reacting zirconium chloride with 1,4-benzenedicarboxylic acid $\left(\mathrm{H}_{2} \mathrm{BDC}\right)$. The synthesized UIO-66 was then conjugated with AuNCs to afford AuNCs@UIO-66 with 11\% quantum yield [120]. PL emission of the AuNCs@UIO-66 at pH 7.2 was observed at $650 \mathrm{~nm}$ and was quenched linearly by $\mathrm{Hg}^{2+}$ with concentrations from $800 \mathrm{nM}$ to $10 \mu \mathrm{M}$ and a LOD of $77 \mathrm{pM}$. The emission quenching 
was attributed to the $\mathrm{Au}-\mathrm{Hg}$ amalgamation via interactive amino groups of bovine serum albumin (BSA) present over AuNCs surface. The applicability of the sensory study was also successfully demonstrated in tap and river water which can be accounted as a good candidate for $\mathrm{Hg}^{2+}$ discrimination.

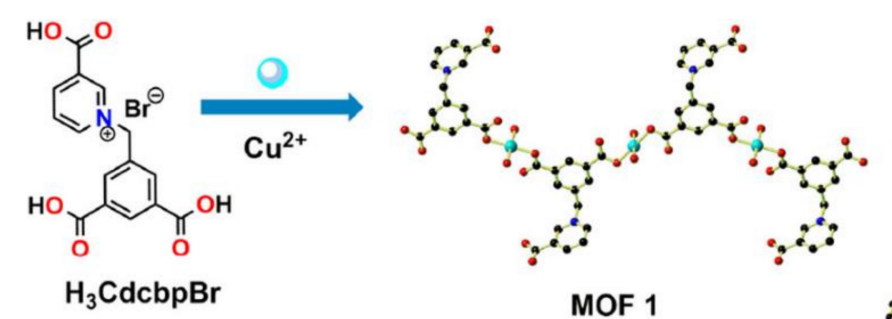

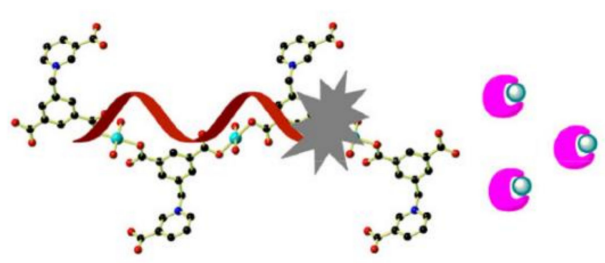

Fluorescence quenched
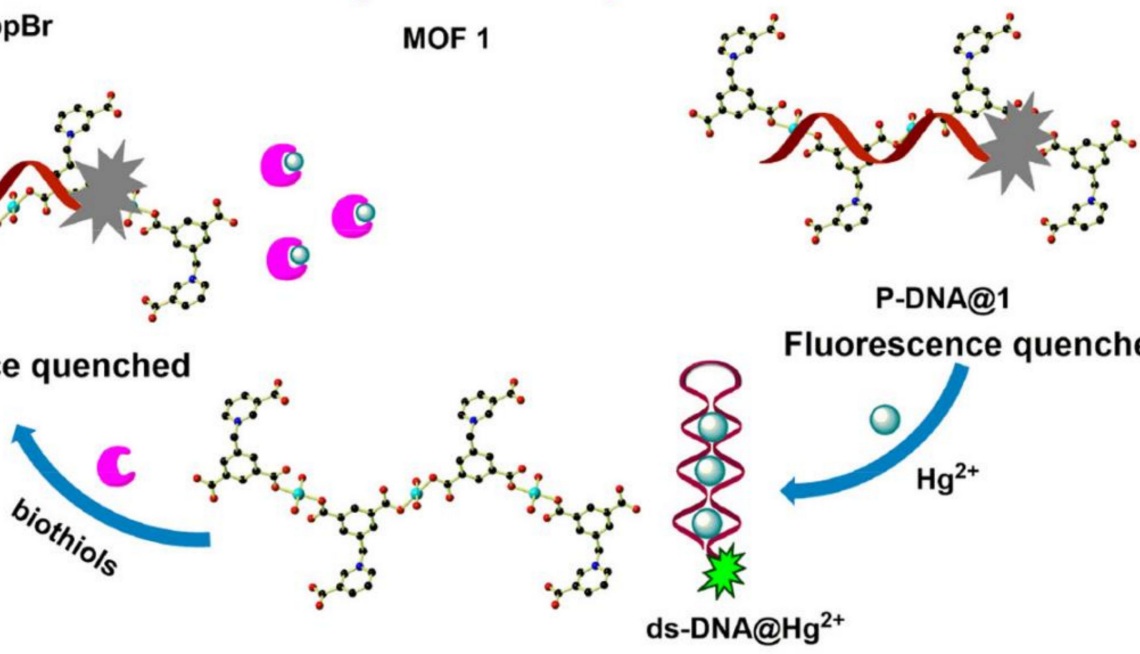

Fluorescence recovery

Figure 6. The proposed $\mathrm{Hg}^{2+}$ and biothiols detection mechanism based on the P-DNA@1 hybrid (Reproduced with the permission from Ref [114]).

To this track, Marieeswaran and co-workers presented $\mathrm{Hg}^{2+}$ sensing ability of the MOF containing composite consisted of magnetic nanoscale metal-organic framework (MNMOF) conjugated with fluorescein amidite (FAM)-labeled ssDNA [121]. The MNMOF was developed by one-pot reaction between $\mathrm{Fe}_{3} \mathrm{O}_{4}$ nano-spheres (synthesized hydrothermally), $\mathrm{FeCl}_{3} \cdot 6 \mathrm{H}_{2} \mathrm{O}$, and 2-aminoterephthalic acid. Emission intensity at $495 \mathrm{~nm}$ (in Tris- $\mathrm{HCl}$ buffer) was quenched up to $62 \%$ with adsorption of FAM-labeled ssDNA on the MNMOF. Addition of $\mathrm{Hg}^{2+}$ further lowered the emission quenching at $495 \mathrm{~nm}$ down to $52 \%$ via $\mathrm{T}-\mathrm{Hg}^{2+}-\mathrm{T}$ complexation. The linear regression of $\mathrm{Hg}^{2+}$ detection was between 2-20 nM with a LOD of $8 \mathrm{nM}$. This work was also demonstrated in environmental water samples. However, the BET surface area information and competing studies still need to be updated. In addition to the MOF-DNA hybrid system, $\mathrm{Hu}$ and co-workers revealed the utilization of the $\{[\mathbf{C u}(\mathbf{D c b b})(\mathbf{B p e})] \cdot \mathbf{C l}\}_{\mathbf{n}}$ (where $\mathrm{H}_{2} \mathrm{DcbbBr}$ and Bpe represent 1-(3,5-dicarboxybenzyl)-4,4'-bipyridinium bromide and trans-1,2-bis(4-pyridyl)ethylene, respectively) towards sequential quantitation of $\mathrm{Hg}^{2+}$ and $\mathrm{I}^{-}$via the $\mathrm{T}-\mathrm{Hg}^{2+}-\mathrm{T}$ motif and "off-on-off" fluorescence response [122]. Detection of $\mathrm{Hg}^{2+}$ and I" was verified by circular dichroism $(\mathrm{CD})$ and the underlying mechanism was clarified by fluorescence anisotropy, binding constant, and simulation studies. LODs for $\mathrm{Hg}^{2+}$ and I' sensors were estimated as 3.2 and $3.3 \mathrm{nM}$, respectively. Though the sensor showed high selectivity, it can be considered a supplementary work due to the similar $\mathrm{T}-\mathrm{Hg}^{2+}-\mathrm{T}$ motif approach.

The AuNP@MOF composite nanoparticles were used in colorimetric $\mathrm{Hg}^{2+}$ assay via gold amalgam-triggered reductase mimetic activity in aqueous medium [123]. The AuNP@MOF composite was developed by immobilizing Au NPs over the porous surface of iron-5,10,15,20-tetrakis (4-carboxyl)-21H,23H-porphyrin-based MOF- (Fe-TCPP-MOF) and was utilized in colorimetric sensing of $\mathrm{Hg}^{2+}$. Wherein, $\mathrm{Hg}^{2+}$ triggered the Au-mediated 
catalytic reduction of methylene blue and turned the blue colour to colourless, which was accompanied with quenching in absorbance peak of methylene blue at $665 \mathrm{~nm}$ as shown in

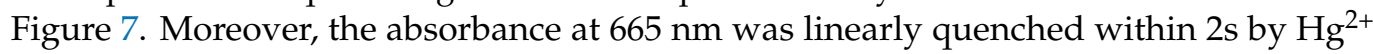
with concentrations from 200-400 pM and a LOD of 103 pM. Apart from lack of the BET surface area information, the competing studies, tap and river water investigations attested the utility of the AuNP@MOF in $\mathrm{Hg}^{2+}$ detection.
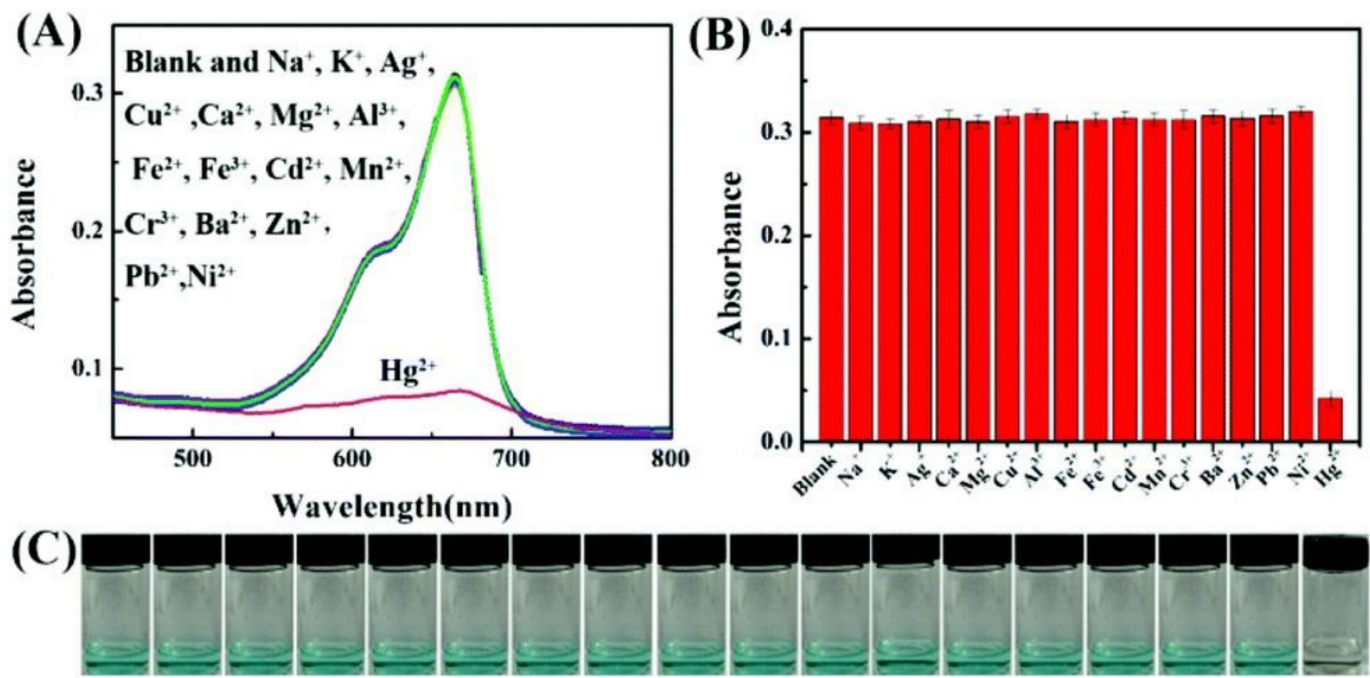

Figure 7. Selectivity of the sensing method by AuNP@MOF to other metal ions. Concentrations of $\mathrm{Hg}^{2+}$ and other metal ions $\left(\mathrm{Na}^{+}, \mathrm{K}^{+}, \mathrm{Ag}^{+}, \mathrm{Ca}^{2+}, \mathrm{Mg}^{2+}, \mathrm{Cu}^{2+}, \mathrm{Al}^{3+}, \mathrm{Fe}^{3+}, \mathrm{Fe}^{2+}, \mathrm{Cd}^{2+}, \mathrm{Mn}^{2+}, \mathrm{Cr}^{3+}, \mathrm{Ba}^{2+}, \mathrm{Zn}^{2+}, \mathrm{Pb}^{2+}\right.$ and $\mathrm{Ni}^{2+}$ ) were $1 \mathrm{nM}$ and $10 \mathrm{nM}$, respectively. (A) The UV spectra of the sensing system in response to various metal ions; (B) The UV absorbance of the sensing system at $665 \mathrm{~nm}$ towards various metal ions; $(\mathbf{C})$ photographs of the sensing system responding to various metal ions (Reproduced with the permission from Ref [123]).

In this light, Zhang et al. deposited Au nanoparticles on titanium-based MOF ( $\mathbf{N H}_{2}$ MIL-125(Ti)) by solvothermal reaction between 2-aminoterephthalate and tetrabutyl titanate) to afford Au@ $\mathbf{N H}_{2}-\mathbf{M I L - 1 2 5}$ (Ti) for colorimetric detection of $\mathrm{H}_{2} \mathrm{O}_{2}$, cysteine, and $\mathrm{Hg}^{2+}$ via peroxidase-like activity using 3,3',5,5'-tetramethylbenzidine (TMB-catalyst) [124]. The Au@NH $\mathbf{2}$-MIL-125(Ti) and TMB showed a blue colour and a "turn-on" absorbance response at $652 \mathrm{~nm}$ in the presence of $\mathrm{H}_{2} \mathrm{O}_{2}$ via peroxidase like mimic. Upon addition of cysteine to above sensory system, absorbance at $652 \mathrm{~nm}$ was quenched accompanied with disappearance of the blue colour. However, the blue colour and absorbance peak were recovered by adding $\mathrm{Hg}^{2+}$. The $\mathrm{Hg}^{2+}$ detection showed a linear response in concentrations from 1 to $5 \mu \mathrm{M}$ with a LOD of $100 \mathrm{nM}$ and was authenticated by real sample analysis. A masking tactic with EDTA was proposed in this report to avoid the interference effect from other metal ions, however, this work required more complicated detection procedures.

A “CDs/AuNCs@ZIF-8" composite consisted of zeolitic imidazolate framework-8 (ZIF-8) encapsulated with carbon dots (CDs) and gold nanoclusters was produced and utilized in detection of $\mathrm{Hg}^{2+}$ [125]. The CDs/AuNCs@ZIF-8 in aqueous medium displayed emission bands at 440 and $640 \mathrm{~nm}\left(\lambda_{\mathrm{ex}}=360 \mathrm{~nm}\right)$ due to the encapsulated CDs and AuNCs. In the presence of $\mathrm{Hg}^{2+}, \mathrm{PL}$ peak at $640 \mathrm{~nm}$ was quenched but emission band at 440 $\mathrm{nm}$ was not affected. Therefore, it was noted as a ratiometric sensor. Due to the $\mathrm{Au}-\mathrm{Hg}$ amalgamation, the probe showed linear ratiometric response $\left(\mathrm{I}_{640} / \mathrm{I}_{440}\right)$ between $3-30 \mathrm{nM}$ with a LOD of $1 \mathrm{nM}$ accompanied with visualization of red blue emission colour changes under UV-irradiation. This work was also demonstrated in tap and river water samples. Following the ratiometric sensing approach, Yang et al. constructed a ratiometric sensor MOF/CdTe QDs via physically mixing CdTe QDs $\left(\lambda_{\mathrm{em}}=605 \mathrm{~nm}\right)$ with MOF (Fe-MIL$\mathbf{8 8 N H} \mathrm{NH}_{2}, \lambda_{\mathrm{em}}=425 \mathrm{~nm}$ ) towards $\mathrm{Hg}^{2+}$ and $\mathrm{Cu}^{2+}$ discrimination [126]. During detection of metal analytes, ratiometric responses at $\mathrm{I}_{425} / \mathrm{I}_{605}$ due to the strong binding interaction 
between CdTe QDs and metal ions were evaluated by monitoring the colour changes (from pink to blue). Although this work was well supported by paper-based analysis, lake water, fruit juice, and red wine samples, but it lacks information in competing studies.

\section{MOFs in Electrochemical Recognition of $\mathbf{H g}^{2+}$}

Similar to many inorganic electrochemical sensors [127], MOFs were also engaged in electrochemical-based detection of $\mathrm{Hg}^{2+}$ as described subsequently. For example, Zhang et al. demonstrated electrochemical sensing of $\mathrm{Hg}^{2+}$ in the presence of glucose by using the $\mathrm{Cu}^{2+}$ anchored MOFs as enzyme free catalyst [128]. MOFs were firstly synthesized By solvothermally reacting amino terephthalic acid $\left(\mathrm{NH}_{2}-\mathrm{BDC}\right)$ with $\mathrm{Cu}\left(\mathrm{NO}_{3}\right)_{2}$. The as-synthesized MOFs were then combined with Au NPs and sDNA to obtain the sDNA/MOF-Au probe. The cDNA/GO@Au/GCE electrode was immersed in the mixed solution of sDNA/MOF-Au and $\mathrm{Hg}^{2+}$ at certain concentration for $\mathrm{Hg}^{2+}$ sensing. The

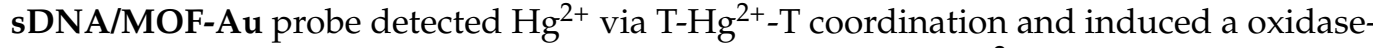
like catalytic response. This work showed a linear response to $\mathrm{Hg}^{2+}$ in concentrations from $0.10 \mathrm{aM}$ to $100 \mathrm{nM}\left(\mathrm{aM}=\right.$ attomole $\left.=10^{-18} \mathrm{M}\right)$ with a LOD of $0.001 \mathrm{aM}$. Moreover, this work was also demonstrated in dairy product samples, which was impressive. However, careful optimization is required to attain the reproducible results. Recently, the ZIF-8 was synthesized via hydrothermal reaction of $\mathrm{Zn}\left(\mathrm{NO}_{3}\right)_{2} \cdot 4 \mathrm{H}_{2} \mathrm{O}$ and 2-methylimidazole and employed in electrochemical discrimination of $\mathrm{Hg}^{2+}$ by coupling with $\mathrm{Ag}$ and $\mathrm{Au}$ nanoparticles [129]. This work also involved the electrochemical aptasensor based on the Au electrode (AE). Signals were obtained from the "APT/Ag@Au/ZIF-8/AE" aptasensor by means of differential pulse voltammetry (DPV) and electro-chemical impedance spectroscopy (EIS). Due to the T-Hg-T complexation from $\mathrm{T}$ rich aptamer, $\mathrm{Hg}^{2+}$ detection became feasible. Linear responses were observed from detection of $\mathrm{Hg}^{2+}$ in concentrations from $1.0 \times 10^{-16}$ to $1.0 \times 10^{-12} \mathrm{M}$ and from $5.0 \times 10^{-15}$ to $1.0 \times 10^{-12} \mathrm{M}$ with LODs of $1.8 \pm 0.04 \times 10^{-17} \mathrm{M}$ and $1.3 \pm 0.01 \times 10^{-16} \mathrm{M}$ by DPV and EIS, respectively. This work was well supported by real water samples, thereby can be considered a report in $\mathrm{T}-\mathrm{Hg}^{2+}-\mathrm{T}$ motif featured electrochemical sensors.

Similar results were reported from many MOFs-based electrochemical sensors with $\mathrm{fM}$ LODs [130-132]. Wherein, the Cu-based MOFs (Cu-MOFs), thioether side groups attached Zr-based MOFs (S-Zr-MOFs), and 2D-Co-based MOFs (PPF-3 nanosheets) were engaged in the fabrication of Cu-MOFs/Au, S-Zr-MOF/SPE (SPE represents screen printed electrode), and anchor-Au NPs@PPF-3 attached DNB/depAu/GCE (Au NPs, anchor, anchor, DNB, and depAu/GCE represent gold nanoparticles, dibenzocyclooctyne (DBCO), 3D DNA "nanosafe-box", and gold nanoparticle-coated glassy carbon electrode, represtively) electrodes towards the specific detection of $\mathrm{Hg}^{2+}$ ions. The GCE/AuNPs/DNA 2 sensor was incubated in a mixture of $\mathbf{C u}-\mathbf{M O F} / \mathrm{DNA}_{1}$ probes (T-rich DNA used in study) and $\mathrm{Hg}^{2+}$. It demonstrated a linear DPV response from $10 \mathrm{fM}$ to $100 \mathrm{nM}$ with a LOD of $4.8 \mathrm{fM}$ and also real time applications [130]. Similarly, the S-Zr-MOF/SPE showed a linear differential pulse anodic stripping voltammetry (DPASV) response for $\mathrm{Hg}^{2+}$ between $0.03 \mathrm{nM}$ to $3 \mu \mathrm{M}$ with a LOD of $7.3 \mathrm{fM}$ via multiple $\mathrm{Hg}-\mathrm{S}$ interaction (by thio-ether side chains) and $\mathrm{T}-\mathrm{Hg}^{2+}-\mathrm{T}$ formation [131]. By dropping the anchor-AuNPs@PPF-3 [the PPF-3 was synthesized by solvothermally reacting $\mathrm{Co}\left(\mathrm{NO}_{3}\right)_{2} \cdot 6 \mathrm{H}_{2} \mathrm{O}, 5,10,15,20$-tetrakis(4-carboxyl-phenyl)-porphyrin (TCPP), and $4^{\prime}$-bipyridine (BPY)] over the surface of DNB/depAu/GCE, the proposed electrode fabrication was completed. The electrode was subjected to $\mathrm{Hg}^{2+}$ detection to reveal a linear DPV response between $0.1 \mathrm{pM}$ to $10 \mathrm{nM}$ with a LOD of $33 \mathrm{fM}$ [132]. Next, the $\mathrm{Cu}-\mathrm{MOF}$-mediated $\mathrm{Hg}^{2+}$ detection by means of differential pulse voltammetry (DPV) and cyclic voltammetry $(\mathrm{CV})$ tactics in $0.1 \mathrm{M}$ phosphate buffer $(\mathrm{PB})$ at $\mathrm{pH} 9$ was reported by Singh and co-workers [133]. In the report, $\mathrm{CuNO}_{3} \cdot 3 \mathrm{H}_{2} \mathrm{O}$ and 2-aminoterephthalic acid were solvothermally reacted to afford porous $\mathbf{C u}-\mathbf{M O F}$ nanoparticles, which could absorb large amount of $\mathrm{Hg}^{2+}$. Through coupling with the GCE, the $\mathrm{Cu}-\mathrm{MOF}$ detected $\mathrm{Hg}^{2+}$ linearly in concentrations from 0.1 to $50 \mathrm{nM}$ with a LOD of $0.0633 \mathrm{nM}$. Reliability of this work was well demonstrated by the real tuna-fish and tap water samples investigations. 
Thereafter Kokkinos and co-workers proposed utilization of the Ca-MOF modified working electrodes towards 3D-printed lab-in-a-syringe voltammetric cell mediated electrochemical detection of $\mathrm{Hg}^{2+}$ [134]. The Ca-MOF, namely [Ca( $\left.\left.\mathbf{H}_{4} \mathbf{L}\right)(\mathbf{D M A})_{2}\right] \cdot 2 \mathrm{DMA}$, where $\mathrm{H}_{6} \mathrm{~L}$ and DMA represent $\mathrm{N}, \mathrm{N}^{\prime}$-bis(2,4-dicarboxyphenyl)-oxalamide and $\mathrm{N}, \mathrm{N}$-dimethylaceta mide), showed exceptional selectivity to $\mathrm{Hg}^{2+}$. Moreover, the voltammetric lab-in-a-syringe device consisted of a vessel assimilating two thermoplastic conductive electrodes (act as counter and pseudo-reference electrodes) was fabricated by a single-step process. A small detachable 3D-printed syringe loaded with a graphite paste/Ca-MOF mixture was used as a working electrode. The Ca-MOF participated in the ion exchange to form "Hg@CaMOF". The device showed a linear response to $\mathrm{Hg}^{2+}$ with concentrations between $2-40 \mu \mathrm{g} \mathrm{L}^{-1}$ and a LOD of $0.6 \mu \mathrm{g} \mathrm{L}^{-1}$. Practicality of this work was also demonstrated in the fish oil and bottle water samples.

In contrast to direct electrochemical sensors, Zhang et al. proposed the MOF-involved light driven electrochemical (photoelectrochemical; $\mathrm{PEC}$ ) sensor for $\mathrm{Hg}^{2+}$ discrimination as described next [135]. Firstly, $\mathrm{Co}\left(\mathrm{NO}_{3}\right)_{2} \cdot 6 \mathrm{H}_{2} \mathrm{O}$ and 2-methylimidazole were solvothermally reacted to afford the ZIF-67. The ZIF-67 was then reacted with $\mathrm{Cd}\left(\mathrm{NO}_{3}\right)_{2} \cdot 4 \mathrm{H}_{2} \mathrm{O}$ and thioacetamide (TAA) to yield the CoSx@CdS nanocomposites (CdS nanoparticles were grown over the surface of cobalt sulfide (CoSx) by using ZIF-67 polyhedrons as the sacrificial templates and cobalt precursors). The synthesized composite was drop casted on the ITO electrodes to engage in the photoelectrochemical sensing of $\mathrm{Hg}^{2+}$ as illustrated in Figure 8.

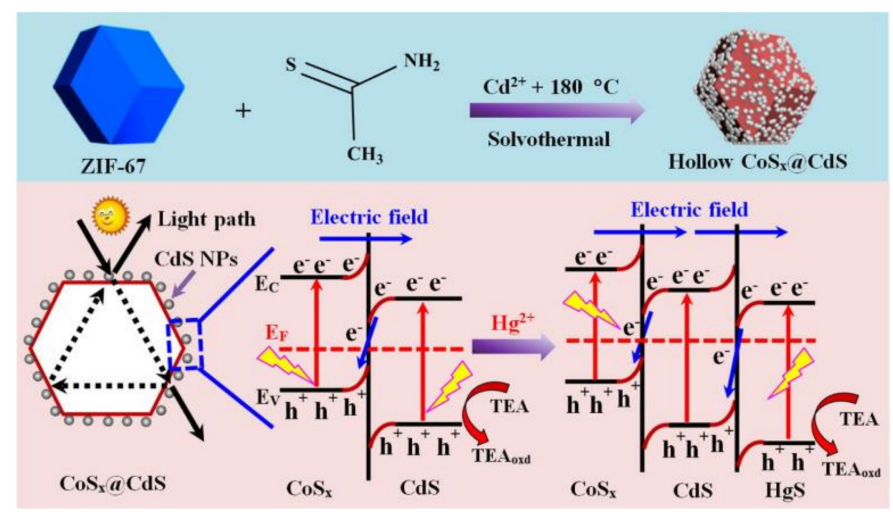

Figure 8. Synthetic process of hollow $\operatorname{CoS}_{\mathbf{x}}$ polyhedrons and $\operatorname{CoS}_{\mathbf{x}} @ \mathbf{C d S}$ composites and the mechanism of photocurrent responses of $\mathbf{C o S}_{\mathbf{x}} @ \mathbf{C d S}$ composites, showing the band structures of $\mathrm{CoS}_{\mathbf{x}} @ \mathbf{C d S} / \mathrm{HgS}$ composites and charge separation under the visible-light illumination (Reproduced with the permission from Ref [135]).

In the presence of $\mathrm{Hg}^{2+}$ ions in PBS ( $\mathrm{pH}$ 7.4) containing 0.15 M triethanolamine (TEA) (see Figure 8), carrier transport and photocurrent of the device were improved and enhanced under illumination due to the combined $\mathrm{CoS}_{\mathrm{x}}$ and $\mathrm{CdS}$ components. In fact, the ion-exchange reaction took place to trigger in-situ generation of $\operatorname{CoS}_{\mathbf{x}} @ \mathbf{C d S} / \mathbf{H g S}$ (new Z-scheme heterojunction photocatalyst) during the detection process. This sensor showed a linear response to $\mathrm{Hg}^{2+}$ with concentrations between $0.010-1000 \mathrm{nM}$ and a LOD of $2 \mathrm{pM}$. It was also validated by tap and lake water analysis.

\section{MOFs in Removal of $\mathrm{Hg}^{2+}$}

Other than optical and electrochemical recognition of metal analytes, MOFs were also engaged in the selective removal heavy metal ions [136]. In this section, removal/extraction of $\mathrm{Hg}^{2+}$ in particular was described in detail. Many Zr-based MOFs displayed great adsorption capacity to $\mathrm{Hg}^{2+}$ due to their porous nature. For example, Kahkha and co-workers described the consumption of mesoporous porphyrinic containing Zr-MOF-PCN-222/MOF545 for effective pipette-tip solid-phase extraction of $\mathrm{Hg}^{2+}$ [137]. The MOF was solvothermally synthesized by reacting meso-tetrakis(4-carboxyphenyl)porphyrin $\left(\mathrm{H}_{2} \mathrm{TCPP}\right)$ and $\mathrm{ZrOCl}_{2} \cdot 8 \mathrm{H}_{2} \mathrm{O}$. The as-synthesized MOF was then inserted into a Bio Plas pipette-tip at- 
tached to a $2000-\mu \mathrm{L}$ micro pipette for $\mathrm{Hg}^{2+}$ adsorption. It was shown that $2 \mathrm{mg}$ of MOFsorbent was enough to accomplish extraction and desorption of $\mathrm{Hg}^{2+}$ up to 15 cycles at $\mathrm{pH}$ 5 by using $10 \% \mathrm{HCl}$ as eluting solvent (fixed at $15 \mu \mathrm{L}$ volume). A LOD of this method was estimated as $20 \mathrm{ng} \mathrm{L}^{-1}$ with an adsorption capacity (contrast to other ions), enrichment factor, and total extraction time of $35.5 \mathrm{mg} \mathrm{g}^{-1}, 120$-fold, and $7 \mathrm{~min}$, respectively. This work was demonstrated for $\mathrm{Hg}^{2+}$ determination in the fish samples, however, information regarding the BET surface area and Langmuir/Freundlich isotherms requires further interrogations. Hasankola et al. engaged the MOF-PCN-221 (synthesized by solvothermal reaction), which comprised of 5,10,15,20-tetrakis(4-carboxyphenyl) porphyrin $\left(\mathrm{H}_{2} \mathrm{TCPP}\right)$ organic linker and ' $\mathrm{Zr}^{\prime}$ metal node, towards selective removal of $\mathrm{Hg}^{2+}$ [138]. Wherein the time required for $\mathrm{Hg}^{2+}$ adsorption was $30 \mathrm{~min}$ at an optimal $\mathrm{pH}$ of 7.1 and an adsorption capacity of PCN-221 was established as $233 \mathrm{mg} \mathrm{g}^{-1}$. Be noted that the adsorption process of $\mathrm{Hg}^{2+}$ by PCN-221 can be properly interpreted with the pseudo-second-order kinetic model (with $\mathrm{R}^{2}=0.99$ ) and followed the Langmuir model adsorption isotherms for $\mathrm{Hg}^{2+}$. Investigations on the $\mathrm{Hg}^{2+}$ adsorption mechanism indicated that $\mathrm{Hg}^{2+}$ could not be replace with $\mathrm{Zr}$ ions. For the desorption process, $0.01 \mathrm{M} \mathrm{HNO}_{3}$ was used. This work requires more investigations for the BET surface area, practicality, and structural features.

$\mathrm{Li}$ et al. described the utilization of porous and highly defective Zr-based MOF-UIO$66-\mathrm{Zr}_{6}(\mathrm{OH})_{4} \mathrm{O}_{4}(\mathrm{BDC})_{6}$ (where $\mathrm{BDC}$ represents benzene-1,4-dicarboxylate), namely UIO66-50Benz (Benz represents benzene-1,4-dicarboxylate), for $\mathrm{Hg}^{2+}$ removal [139]. By means of topotactic transformations of MOFs and ligand extraction process, $\mathrm{ZrOx}$ (obtained by immersion of UIO-66-50Benz in $10 \mathrm{~mol} \mathrm{~L}^{-1} \mathrm{NaOH}$ ), ZrOxyPhos (obtained by immersion of UIO-66-50Benz in $210 \mathrm{mM} \mathrm{Na}_{3} \mathrm{PO}_{4}$ ), and ZrSulf (obtained by immersion of UIO-6650Benz in $250 \mathrm{mg}$ of $\mathrm{Na}_{2} \mathrm{~S}$ solution in $10 \mathrm{~mL}$ ) were developed and engaged in $\mathrm{Hg}^{2+}$ removal as seen in Figure 9.
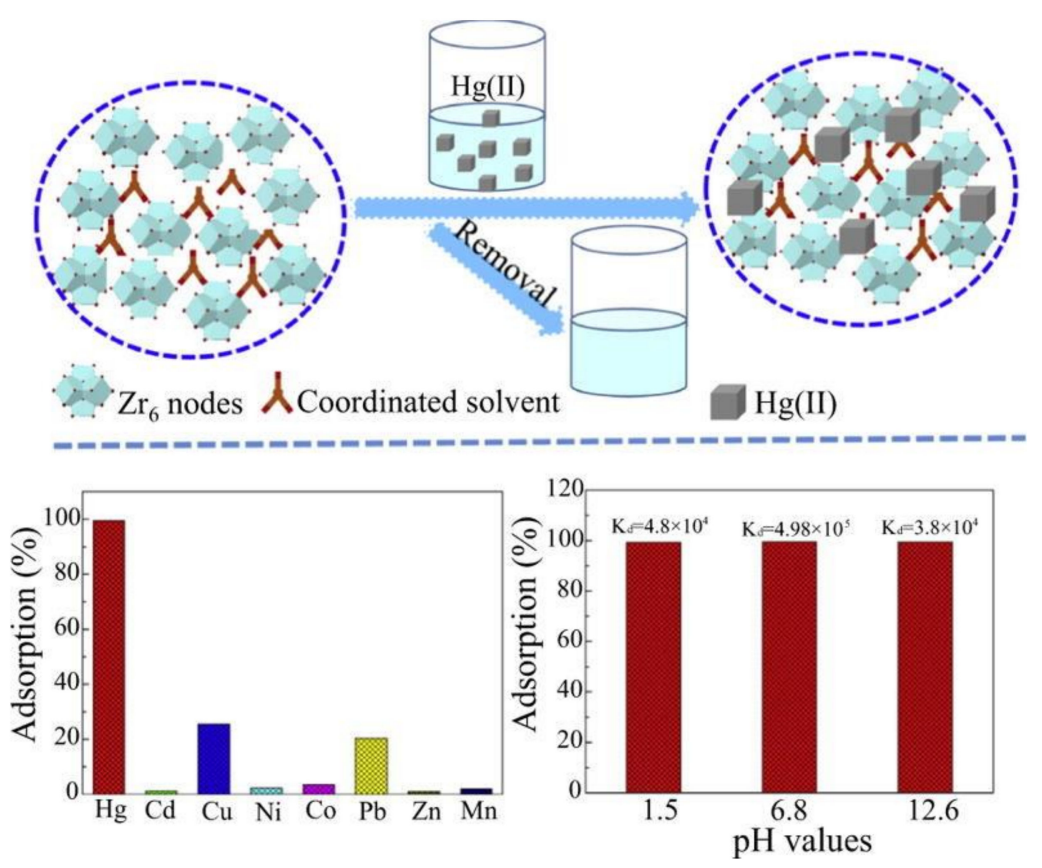

Figure 9. Schematic of the utilization of highly defective Zr-based porous MOFs- ZrOx, ZrOxyPhos, and ZrSulf towards $\mathrm{Hg}^{2+}$ removal and excellent $\mathrm{Hg}^{2+}$ removal performance by ZrSulf compared to other metal ions and at different $\mathrm{pH}$ ranges; coordinated solvents $\mathrm{NaOH}, \mathrm{Na}_{3} \mathrm{PO}_{4}$, and $\mathrm{Na}_{2} \mathrm{~S}$ were used to afford $\mathrm{ZrOx}$, ZrOxyPhos, and $\mathrm{ZrSulf}$, respectively. (Reproduced with the permission from $\operatorname{Ref}[139])$.

The BET surface area of ZrOx, ZrOxyPhos, and ZrSulf were estimated as 430, 290, and $560 \mathrm{~m}^{2} \mathrm{~g}^{-1}$, correspondingly, which also confirmed the high effectiveness of ZrSulf. Among these materials, ZrSulf possessed the fastest adsorption kinetics $\left(1.1 \times 10^{-2} \mathrm{~g}(\mathrm{mg} \mathrm{min})^{-1}\right.$ and 
the highest adsorption capacity of $824 \mathrm{mg} \mathrm{g}^{-1}$. The distribution coefficient $\left(K_{d}\right)$ of $\mathbf{Z r S u l f}$ to $\mathrm{Hg}^{2+}$ was estimated as $4.98 \times 10^{5} \mathrm{~mL} \mathrm{~g}^{-1}$ at $\mathrm{pH} 6.8$ Moreover, it was reusable for more than five cycles after washing with $\mathrm{HCl}$ and thio-urea. The high selectivity of $\mathrm{Hg}^{2+}$ was attributed to the covalent bond formation with sulfur-based functionality. From kinetic studies, it was established that the adsorption followed the pseudo-second order model and, at the same time, controlled by the film diffusion and pore diffusion. This material can be considered as a good candidate for $\mathrm{Hg}^{2+}$ removal in terms of its adsorption capacity and practicality.

Subsequently, Leus and co-workers solvothermally synthesized the thiolated $\mathrm{Zr}$ based MOF-UIO-66-(SH) 2 (by reacting $\mathrm{ZrOCl}_{2} \cdot 8 \mathrm{H}_{2} \mathrm{O}$ and 2,5-dimercaptoterephthalic acid$\left.\left(\mathrm{H}_{2} \mathrm{BDC}-2,5 \mathrm{SH}\right)\right)$ and applied it for selective removal of $\mathrm{Hg}$ species [140]. The Langmuir surface area of UIO-66-(SH) 2 was estimated as $499 \mathrm{~m}^{2} \mathrm{~g}^{-1}$. The UIO-66-(SH) 2 showed a maximum $\mathrm{Hg}^{2+}$ adsorption capacity of $236.4 \mathrm{mg} \mathrm{g}^{-1}$ between $\mathrm{pH} 3.0-5.0$. Due to the presence of -SH group, adsorption of $\mathrm{Hg}^{2+}$ showed the best fit with Langmuir isotherm and followed the pseudo-second order kinetics. Moreover, adsorption and desorption of $\mathrm{Hg}^{2+}$ can be extended up to three cycles by using $1 \mathrm{M} \mathrm{HCl}$ and $0.66 \mathrm{M}$ thiourea. This work was also applied in waste water-based $\mathrm{Hg}^{2+}$ removal. The use of thiolated UIO-66-SH (an archetypal thiolated $\mathrm{Zr}$-based MOF- $\mathrm{Zr}_{6}(\mathrm{OH})_{4} \mathrm{O}_{4}(\mathrm{BDC})_{6}$, where BDC represents benzene1,4-dicarboxylate) towards $\mathrm{Hg}$ species removal applications was also demonstrated by $\mathrm{Li}$ and co-workers [141]. However, the presence of $\mathrm{Zn}^{2+}$ and $\mathrm{Pb}^{2+}$ may reduce the adsorption of $\mathrm{Hg}^{2+}$ by UIO-66-SH.

Next, Fu et al. employed the post-functionalized UIO-66- $\mathbf{N H}_{\mathbf{2}}$ (Zr-based MOF) with 2,5-Dimercapto-1,3,4-thiadiazole to produce the UIO-66-DMTD for effective removal of $\mathrm{Hg}^{2+}$ in water [142]. Due to the $\mathrm{Hg}^{2+}$ adsorption over the MOF surface, the calculated BET surface area of UIO-66-DMTD-Hg decreased from $651 \mathrm{~m}^{2} \mathrm{~g}^{-1}$ to $42 \mathrm{~m}^{2} \mathrm{~g}^{-1}$, thereby confirming the adsorbing ability of the proposed MOFs. The maximum adsorption of $\mathrm{Hg}^{2+}$ was $670.5 \mathrm{mg} \mathrm{g}^{-1}$ at $\mathrm{pH}$ 3. The adsorption kinetic followed the pseudo-second-order and was linearly fitted with Langmuir isotherm. Moreover, selectivity to $\mathrm{Hg}^{2+}$ by the UIO-66-DMTD and its analogous (UIO-66- $\mathbf{N H}_{2}$ and $\mathrm{UIO}-66-\mathrm{SO}_{3} \mathrm{H}$ ) was higher than that of other species as seen in Figure 10.

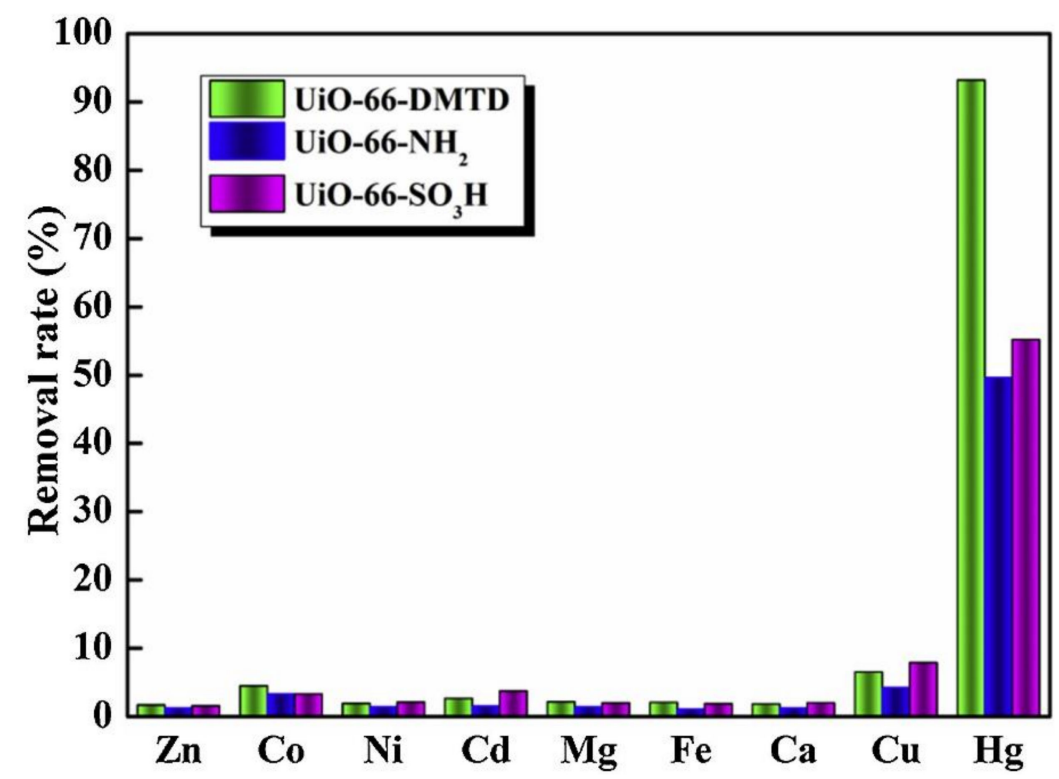

Figure 10. Selective removal of $\mathrm{Hg}^{2+}$ by UIO-66- $\mathrm{NH}_{2}$, UIO-66- $\mathrm{SO}_{3} \mathrm{H}$ and UIO-66-DMTD (Reproduced with the permission from Ref [142]).

At a fixed $\mathrm{Hg}^{2+}$ removal time of $120 \mathrm{~min}$, recyclable usage of the UIO-66-DMTD was found to be effective up to 10 times. The $\mathrm{Hg}^{2+}$ removal is highly fascinated and can be effective in the lab wastewater-based extraction due to the high affinity of thiol (-SH) group to $\mathrm{Hg}^{2+}$. 
Similar to the MOF-UIO-66-(SH) 2 [140], Ding and co-workers proposed the Zr-based MOF-Zr-DMBD (synthesized by reacting 2,5-Dimercapto-1,4-benzenedicarboxylic acid $\left(\mathrm{H}_{2} \mathrm{DMBD}\right)$ and $\left.\mathrm{ZrCl}_{4}\right)$ for $\mathrm{Hg}^{2+}$ removal [143]. However, due to a high degree of similarity to the UIO-66-(SH) ${ }_{2}$-based research, this work will not be further discussed. Regarding the effectiveness of thiol functionalized or thiol comprising MOFs towards removal of $\mathrm{Hg}^{2+}$ species, $\mathrm{Li}$ et al. described the utilization of dense thiol arrays containing $\mathrm{Zr}$ based MOF, namely ZrOMTP (via reacting 4,4', $4^{\prime \prime}, 4^{\prime \prime \prime}$-(pyrene-1,3,6,8-tetrayl)tetrakis(2,6dimercaptobenzoic acid)( $\left.\mathrm{H}_{4} \mathrm{OMTP}\right)$ with $\left.\mathrm{ZrCl}_{4}\right)$, in Ref. [144]. The BET surface area of ZrOMTP to $\mathrm{N}_{2}$ gas was estimated as $1290 \mathrm{~m}^{2} \mathrm{~g}^{-1}$ and the distribution coefficient $\left(K_{d}\right)$ for $\mathrm{Hg}^{2+}$ was calculated as $1.60 \times 10^{8} \mathrm{~mL} \mathrm{~g}^{-1}$, which is far better than that of other thiol containing MOFs. This could be attributed to the dense thiol arrays present in ZrOMTP framework. Adsorption of $\mathrm{Hg}^{2+}$ followed the first order kinetic model and was best fitted with Langmuir isotherms. Moreover, this MOFs lowered $\mathrm{Hg}$-based contaminants from ppm to below the allowed drinkable limit of $2 \mathrm{ppb}$.

Highly dense alkyl thiol comprising MOF-Zr-MSA was developed by hydrothermally reacting $\mathrm{ZrCl}_{4}$ and mercaptosuccinic acid (HOOC-CHSH-CH$-\mathrm{COOH}, \mathrm{MSA}$ ) in aqueous phase and was engaged in $\mathrm{Hg}^{2+}$ removal [145]. The Zr-MSA showed an adsorption efficiency of $99.99 \%$ to $\mathrm{Hg}^{2+}$ in a $\mathrm{pH}$ range of $0-7 \mathrm{pH}$ within 5 min and was reusable (with $6 \mathrm{M} \mathrm{HCl}$ ) for up to five cycles. Moreover, the Zr-MSA showed a maximum adsorption capacity of $734 \mathrm{mg} \mathrm{g}^{-1}$ and a $K_{d}$ value of $1.82 \times 10^{8} \mathrm{~mL} \mathrm{~g}^{-1}$, which was best correlated with Langmuir isotherm. Due to the higher affinity of $-\mathrm{SH}$ to $\mathrm{Hg}^{2+}$, this work reduced the $\mathrm{Hg}$ content from $10,000 \mathrm{ppb}$ to $0.11 \mathrm{ppb}$, which was far below the drinking water limit. In addition to thiol containing MOFs, the Zr-MOFs (Zr-MOFs-SH(O)) was synthesized by one-pot reaction of $\mathrm{ZrCl}_{4}$, meso-tetra(4-carboxyphenyl)porphine $\left(\mathrm{H}_{2} \mathrm{TCPP}\right)$, and modulators-mercaptoacetic acid (MAA) or alpha lipoic acid (ALA) - and was employed in $\mathrm{Hg}^{2+}$ adsorption [146]. For comparison, the $\mathbf{Z r - M O F s - S H ( P )}$ was synthesized via postsynthetic modification of the $\mathrm{Zr}$-MOFs-SH(O) and was engaged in adsorption studies. Due to the higher -SH content in the Zr-MOFs-SH(O), it showed a higher adsorption capacity (for $\mathrm{Hg}^{2+}$ ) of $843.6 \mathrm{mg} \mathrm{g}^{-1}$ than that of the Zr-MOFs-SH(P) $\left(138.5 \mathrm{mg} \mathrm{g}^{-1}\right)$. $\mathrm{Hg}^{2+}$ adsorption of the Zr-MOFs-SH(O) followed the pseudo-second-order kinetic model and was best fitted with Langmuir isotherm. In addition, this study showed good selectivity, recyclability, and chemical stability. By functionalizing the $\mathbf{N H}_{2}$-UIO-66 with L-cysteine, the Cys-UIO-66 was obtained and was used for $\mathrm{Hg}^{2+}$ removal from solution [147]. The Cys-UIO-66 showed a maximum adsorption capacity of $350.14 \mathrm{mg} \mathrm{g}^{-1}$ (after $180 \mathrm{~min}$ ) at pH 5.0 of $\mathrm{Hg}^{2+}$ adsorption which followed the pseudo-second-order model and was fitted with Langmuir isotherm. Due to the -SH (from cysteine) affinity to $\mathrm{Hg}^{2+}$, reusability of $\mathrm{Hg}^{2+}$ adsorption/desorption was up to five cycles (with $0.1 \mathrm{M} \mathrm{HNO}_{3}$ and $1 \%$ thiourea solution). In terms of the capacity and time consumption, this study could need more improvements. By following the similar approach, Liu and co-workers presented the cysteamine functionalized MOFs-MIL-101-SH (Cr) and UIO-66-SH ( $\mathrm{Zr}$ ) for $\mathrm{Hg}^{2+}$ removal [148]. The MOFs showed adsorption capacities of 10 and $250 \mathrm{mg} \mathrm{g}^{-1}$ at $\mathrm{pH}$ of 5, respectively, with certain reusability.

By utilizing four different types of organic ligands with bulky sulphur side chains, four Zr-based MOFs, namely Zr-L1, Zr-L2, Zr-L3, and Zr-L4 (Zr(IV)-carboxylate frameworks; where L1-L4 represents the deprotonated four thioether-equipped carboxylic acid linker molecules), were constructed for selective removal of $\mathrm{Hg}^{2+}$ ions [149]. The $K_{d} s$ values of Zr-L1, Zr-L2, Zr-L3, and Zr-L4 were estimated as $1.95 \times 10^{3} \mathrm{~mL} \mathrm{~g}^{-1}, 1.47 \times 10^{4} \mathrm{~mL} \mathrm{~g}^{-1}$, $4.47 \times 10^{3} \mathrm{~mL} \mathrm{~g}^{-1}$, and $2.40 \times 10^{4} \mathrm{~mL} \mathrm{~g}^{-1}$, respectively. Moreover, $\mathrm{Hg}$ adsorption of $\mathbf{Z r}$-L1, Zr-L2, Zr-L3, and Zr-L4 followed the Langmuir isotherm with capacities of $193 \mathrm{mg} \mathrm{g}^{-1}$, $275 \mathrm{mg} \mathrm{g}^{-1}, 245 \mathrm{mg} \mathrm{g}^{-1}$, and $322 \mathrm{mg} \mathrm{g}^{-1}$ at $\mathrm{pH} 6.8$, correspondingly. However, this work needs further investigations on interference studies and real time applications. The $\mathrm{Zr}$ based MOF-DUT-67 (Zr) synthesized by solvothermal reaction of zirconium chloride with 2, 5-thiophene-dicarboxylic acid showed removal efficiencies for $\mathrm{Hg}^{2+}$ and $\mathrm{CH}_{3} \mathrm{Hg}^{+}$from $69 \%$ to $90 \%$ and from $30 \%$ to $77 \%$, respectively [150]. At pH 6, the DUT-67 (Zr) showed 
a great efficiency to $\mathrm{Hg}^{2+}$ and $\mathrm{CH}_{3} \mathrm{Hg}^{+}$with adsorption capacities of $0.0451 \mathrm{mg} \mathrm{g}^{-1}$ and $0.0374 \mathrm{mg} \mathrm{g}^{-1}$, respectively. The adsorption followed the pseudo-second-order kinetic model. This work was also demonstrated in river and lake water samples, but mechanism and interference studies require further investigations. The $\mathrm{ZrO}_{2}$-based (MOF)-808 synthesized by a sol-gel method was grafted with amidoxime $(\mathrm{AO})$ via wet-chemistry process to afford MOF-808/AO, which was used in $\mathrm{Hg}^{2+}$ removal and displayed high efficiencies [151]. In particular, the MOF-808/AO showed a higher adsorption efficiency in all pHs. The BET surface area of MOF-808 and MOF-808/AO were established as 2152 and $1899 \mathrm{~m}^{2} \mathrm{~g}^{-1}$, respectively. Moreover, adsorption capacities of MOF-808 and MOF808/AO towards $\mathrm{Hg}^{2+}$ were estimated as $383.8 \mathrm{mg} \mathrm{g}^{-1}$ and $343.6 \mathrm{mg} \mathrm{g}^{-1}$ (at $70 \mathrm{~min}$ ), correspondingly. The $\mathrm{Hg}^{2+}$ adsorption in both MOFs followed the pseudo-second-order kinetic model and was fitted with Langmuir isotherms. This work requires more efforts to obtain additional information on the mechanism, interference effect, and real time analysis.

The $\mathrm{Zr}$-based MOFs and $\mathrm{Zn}$-metal nodes comprising MOFs were also engaged in $\mathrm{Hg}^{2+}$ removal as detailed next. The $\mathrm{Zn}_{2}(\mathrm{DHBDC})(\mathrm{DMF})_{2} \cdot\left(\mathrm{H}_{2} \mathrm{O}\right)_{2}$, namely MOF-74-Zn, was synthesized by solvothermally reacting $\mathrm{ZnNO}_{3}$ and 2,5-dihydroxy-1,4-benzenedicarboxylic acid (DHBDC) and was applied in $\mathrm{Hg}^{2+}$ removal [152]. The MOF-74-Zn showed a maximum adsorption capacity of $63 \mathrm{mg} \mathrm{g}^{-1}$ (for $\mathrm{Hg}^{2+}$ at $\mathrm{pH} 6$ in $90 \mathrm{~min}$ ). The $\mathrm{Hg}^{2+}$ adsorption followed the pseudo-second-order kinetic model but was best fitted with the Langmuir isotherm rather than the Freundlich isotherm. The -OH group was directly involved in adsorption of $\mathrm{Hg}^{2+}$. However, this work showed a minimum adsorption capacity and lacked information on the interference effect. Wang and co-workers presented the $\mathrm{Zn}$ based MOF, namely NTOU-4 (hydro(solvo)thermally synthesized by reacting $\mathrm{ZnNO}_{3}$ with 1H-1,2,4-triazole-3,5-diamine and 1,4-benzenedicarboxylate organic linkers) for $\mathrm{Hg}^{2+}$ removal applications [153]. The NTOU-4 showed an adsorption capacity of $163 \mathrm{mg} \mathrm{g}^{-1}$ at $30 \mathrm{~min}$ and was operable between $\mathrm{pH} 3-11$. However, the underlying mechanism, kinetic model, and isotherm studies require further clarification. Next, Esrafili et al. described the utilization of dual functionalized Zn-based MOF, namely TMU-32S (synthesized by incorporation of different percentile of N1,N3-di(pyridine-4-yl) malonamide in TMU-32 (a $\mathrm{Zn}$ containing MOF with urea linkers)), towards $\mathrm{Hg}^{2+}$ adsorption and removal [154]. Due to the strong binding forces produced by urea and malonamide functional units, the TMU-32S showed a high adsorption capacity of $1428 \mathrm{mg} \mathrm{g}^{-1}$ (in just $17 \mathrm{~min}$ ) and became more efficient at $\mathrm{pH}$ 4.4. The system followed the linear pseudo-second-order model and was linearly fitted with the Langmuir isotherm. Moreover, the material showed adsorption and desorption (with $0.2 \mathrm{M}$ of EDTA) up to three cycles with $65 \%$ efficiency. This work requires more studies regarding the interference effect with several metal analytes.

Subsequently, the Cu-based MOFs were authorized as efficient adsorbents for $\mathrm{Hg}^{2+}$ removal as described next. Wu et al. developed the copper and 3,30,5,50-azobenzenetetracarbo xylic acid containing porous MOF, namely JUC-62, for $\mathrm{Hg}^{2+}$ removal in tea and mushroom samples [155]. The adsorption capacity of the JUC-62 to $\mathrm{Hg}^{2+}$ was established as $836.7 \mathrm{mg} \mathrm{g}^{-1}$ at pH 4.6 in $15 \mathrm{~min}$ in aqueous media. This work followed the pseudosecond-order model and was fitted with Langmuir adsorption isotherm. Moreover, it was reusable with EDTA up to four cycles. However, further interrogations are required on the interference studies. Mon and co-workers described utilization of a Cu-based MOF, namely $\left\{\mathbf{C u}_{4}{ }_{4}{ }^{\mathrm{II}}[(\mathbf{S}, \mathbf{S}) \text {-methox }]_{2}\right\} .5 \mathbf{H}_{\mathbf{2}} \mathrm{O}$ (where methox represents bis[(S)-methionine]oxalyl diamide), for $\mathrm{HgCl}_{2}$ removal studies [156]. This microporous MOF was decorated with thioalkyl chains, thereby was able to adsorb $\mathrm{HgCl}_{2}$ efficiently to afford the $\mathrm{HgCl}_{2} \mathrm{~S}_{2}$ adduct. This MOF adsorbed $99.95 \%$ of $\mathrm{HgCl}_{2}$ within 15 min and reduced the $\mathrm{Hg}^{2+}$ concentration from $10 \mathrm{ppm}$ to below $2 \mathrm{ppb}$ in drinking water. However, this work lacked information on the reusability, kinetic studies, and real applications. Next, the polysulfides functionalized benzene-1,3,5-tricarboxylic acid and $\mathrm{Cu}$ containing $\mathbf{S}_{\mathbf{x}}-\mathbf{M O F}$ (where MOF represents $\mathrm{Cu}$ BTC (by solvothermal tactic) and $S_{x}{ }^{2-}, X=3,4,6$ ) were described for efficient adsorption of $\mathrm{Hg}^{2+}$ [157]. Among these materials, the $\mathbf{S}_{4}-\mathbf{M O F}$ displayed great selectivity to $\mathrm{Hg}^{2+}$ with a LOD of $0.13 \mu \mathrm{g} \mathrm{L}^{-1}$ and a linear response from $30-200 \mu \mathrm{g} \mathrm{L}^{-1}$ at $\mathrm{pH} 6$ in $30 \mathrm{~min}$. The $\mathbf{S}_{4^{-}}$ 
MOF showed different adsorbing capacities to different metal ions in the following orders: $\mathrm{Hg}(\mathrm{II})>>\mathrm{Pb}(\mathrm{II})>\mathrm{Zn}(\mathrm{II})>\mathrm{Ni}$ (II) $>\mathrm{Co}(\mathrm{II})$. By means of $\mathrm{Hg}^{2+}-\mathrm{S}$ bonding, adsorption was efficient and applicable in sea, tap, and wastewater. However, information regarding kinetic studies is still missing. A copper metallacycle complex, namely $\mathbf{C u}_{\mathbf{2}}\left(\mathbf{P D M A} \mathbf{2}_{\mathbf{2}}\right.$ (DMF) (comprised of 3,3'-((1E,1'E)-(pyrimidine-4,6-diylbis(2-methylhydrazin-2-yl-1-ylidene)) bis (methanylylidene)dibenzoic acid $\left(\mathrm{H}_{2} \mathrm{PDMA}\right)$ ), was demonstrated for $\mathrm{Hg}^{2+}$ removal [158]. Due to the multi ' $\mathrm{N}^{\prime}$ binding sites, the MOF showed an adsorption efficiency of $61.4 \%$ for $\mathrm{Hg}^{2+}$ (among $\mathrm{Hg}^{2+}, \mathrm{Mn}^{2+}, \mathrm{Cd}^{2+}, \mathrm{Pb}^{2+}$ ions) with an adsorption capacity of $300 \mathrm{mg} \mathrm{g}^{-1}$. Moreover, this MOF was reusable with EDTA. The $\mathrm{Hg}^{2+}$ adsorption followed the pseudosecond-order kinetic model. Xu and co-workers proposed utilization of the SH@Cu-MOF towards adsorption of $\mathrm{Hg}^{2+}$ and $\mathrm{Hg}^{(0)}$ species by grafting dithioglycol from the postsynthetic modified Cu-MOF (Cu with 5-aminoisophthalic) [159]. Though the material seems to be impressive compared to others reports, however, its adsorption capacity $\left(173 \mathrm{mg} \mathrm{g}^{-1}\right.$ in $6 \mathrm{~h}$ ) was not up to standard. However, this work does point to a new direction for future development of the Cu-based MOFs.

Liang and co-workers described utilization of the sulfur-functionalized Co-based MOF, namely FJI-H12 (composed of NCS ${ }^{-}, \mathrm{Co}(\mathrm{II})$ and 2,4,6-tri(1-imidazolyl)-1,3,5-triazine (Timt)), for $\mathrm{Hg}^{2+}$ removal in water [160]. The FJI-H12 showed a $K_{d}$ value of $1.85 \times 10^{6} \mathrm{~mL} \mathrm{~g}^{-1}$ with an adsorption capacity of $439.8 \mathrm{mg} \mathrm{g}^{-1}$ at $\mathrm{pH} 7$. The adsorption was efficient because of the $\mathrm{Hg}^{2+}$ to $\mathrm{S}$ (of $\mathrm{SCN}^{-}$) affinity and it could be applied for continuous removal purpose. Moreover, this work followed the pseudo-second-order kinetic model and was also reusable, thereby is attested a nice work. Jiang et al. designed a stable sulfur containing Cobased MOF $\left\{\left[\mathrm{Co}_{3}\left(\mu_{3}-\mathrm{OH}\right)(\mathrm{DMTDC})_{3}(\mathrm{INT})_{3}\right]-\left[\mathrm{Co}_{2}(\mathrm{OH})\left(\mathrm{H}_{2} \mathrm{O}\right)_{2}\right]\left(\mathrm{NO}_{3}\right)_{19}-\left(\mathrm{H}_{2} \mathrm{O}\right)_{7}(\mathrm{DMA})_{11}\right\}_{\mathrm{n}}$, namely NENU-401 (where DMTDC, INT, DMF, and DMA represent 3,4-dimethylthieno[2,3b]thiophene-2,5-dicarboxylic acid, isonicotinate, N,N-dimethylformamide, and N,N-dimeth ylacetamide), via introducing an INT group in NENU-400- $\left\{\left[\mathrm{Co}_{3}\left(\mu_{3}-\mathrm{OH}\right)\left(\mathrm{H}_{2} \mathrm{O}\right)_{3}(\mathrm{DMTDC})_{3}\right]\right.$ $\left.\left(\mathrm{NO}_{3}\right)_{10}-\left(\mathrm{H}_{2} \mathrm{O}\right)_{6}(\mathrm{DMF})_{6}\right\}$ and utilized it successfully in $\mathrm{Hg}^{2+}$ removal [161]. Unlike the NENU-400, which collapsed easily during $\mathrm{Hg}^{2+}$ adsorption, the NENU-401 preserved its structural features, thereby was highly applicable for $\mathrm{Hg}^{2+}$ extraction. The $K_{d}$ value of NENU-401 at $25^{\circ} \mathrm{C}$ was estimated as $8.3 \times 10^{6} \mathrm{~mL} \mathrm{~g}^{-1}$ with an adsorption capacity of $596.57 \mathrm{mg} \mathrm{g}^{-1}$ in $10 \mathrm{~min}$. The NENU-401 performed far better than many thiol containing MOFs. Moreover, $\mathrm{Hg}^{2+}$ extraction by the NENU-401 was recovered up to $90 \%$ of its original by thioglycol solution and was reusable for more than four cycles because of the effective coordination between $\mathrm{Hg}^{2+}$ and ' $-\mathrm{S}^{\prime}$ atom. Note that the NENU-401-based $\mathrm{Hg}^{2+}$ extraction followed the pseudo-second-order kinetic model and was linearly fitted with Langmuir isotherm. This work demonstrated an impressive approach to improve the structural stability of MOFs. Moreover, it also displayed certain selectivity to $\mathrm{Pb}^{2+}$ (nearly $70 \%$ ) but still required further optimization. Recently, Sun's research group proposed employment of the sulfur-rich two-dimensional (2D) Co-based MOF nanosheets, namely 2D-NCS $\left(\left\{\left[\mathrm{Co}(\mathrm{NCS})_{2}(\mathrm{pyz})_{2}\right]\right\}_{n}\right.$; where pyz represents pyrazine), for exceptional removal of $\mathrm{HgCl}_{2}$ [162]. The BET surface area of $2 \mathrm{D}-\mathrm{NCS}$ to $\mathrm{N}_{2}$ gas at $77 \mathrm{~K}$ was established as $365 \mathrm{~m}^{2} \mathrm{~g}^{-1}$ with a maximum adsorption capacity of $1698 \mathrm{mg} \mathrm{g}^{-1}$ in $15 \mathrm{~min}$ and a $K_{d}$ value of $2.26 \times 10^{6} \mathrm{~mL} \mathrm{~g}^{-1}$. The MOF nanosheets reduced $\mathrm{Hg}^{2+}$ concentrations from $10 \mathrm{ppm}$ to $1 \mathrm{ppb}$ within $15 \mathrm{~min}$ and were also effective in environmental samples between $\mathrm{pH}$ 4-9. This work followed the pseudo-second-order model and was fitted with Langmuir isotherm. Due to the strong $\mathrm{Hg}-\mathrm{S}$ interactions, extraction was efficient up to five cycles (by thioglycol solution) and could be further tuned towards development of 3D materials for future environmental remediation. Similar to the FJI-H12 [152], another Co-based MOF$\left[\mathrm{Co}_{3}(\mathrm{SCN})_{6}(\mathrm{TPMA})_{4}\right] \mathrm{n}$, namely FJI-H30 (synthesized by solvothermally refluxing TPMA (tris(pyridin-4-ylmethyl)amine) and $\mathrm{Co}(\mathrm{SCN})_{2}$ ), was engaged in $\mathrm{Hg}^{2+}$ adsorption [163]. Due to the exceptional interaction between $\mathrm{SCN}^{-}$groups to $\mathrm{Hg}^{2+}$, its maximum adsorption capacity reached $705 \mathrm{mg} \mathrm{g}^{-1}$ with negligible interference. The BET surface area of FJI-H30 to $\mathrm{CO}_{2}$ gas at $195 \mathrm{~K}$ was determined as $221 \mathrm{~m}^{2} \mathrm{~g}^{-1}$. This material showed a $K_{d}$ value of $1.84 \times 10^{5} \mathrm{~mL} \mathrm{~g}^{-1}$ and operated efficiently between $\mathrm{pH} 4-9$ with regeneration (by KSCN 
solution) of $>90 \%$ up to three cycles. This work followed the pseudo-second-order model and was fitted with Langmuir isotherm. It can be applied in industrial waste water, thereby is considered a nice work.

Halder et al. engaged the thiocyanato ligand $\left(\mathrm{SCN}^{-}\right)$comprising Ni-based 3D MOF, namely [Ni(3-bpd) $\left.\mathbf{2}_{2}(\mathbf{N C S})_{2}\right]_{\mathbf{n}}$ (where 3 bpd represents 1,4-bis(3-pyridyl)-2,3-diaza1,3-butadiene), for effective removal of $\mathrm{Hg}^{2+}$ in aqueous solution [164]. Because the uncoordinated $\mathrm{S}$ atom of $\mathrm{SCN}^{-}$was strongly bonded with $\mathrm{Hg}^{2+}$ and formed the mercuric thiocyanate adduct, therefore, a great adsorption capacity of $713 \mathrm{mg} \mathrm{g}^{-1}$ was achieved. Nevertheless, this work still requires further optimization for the interference effect, adsorption kinetics, and practicality. A post-synthetic modified tactic was proposed to develop the thiol (-SH) functionalized In-based MOF, namely SH-MIL-68(In) (primarily $\mathbf{N H}_{2}-\mathbf{M I L}-68(\mathbf{I n})$ obtained by solvothermally reacting 2-amino-benzene-1, 4-dicarboxylic acid $\left(\mathrm{NH}_{2}-\mathrm{H}_{2} \mathrm{BDC}\right)$ with $\mathrm{In}\left(\mathrm{NO}_{3}\right)_{3}$ followed by post-synthetic modification), towards $\mathrm{Hg}^{2+}$ extraction [165]. The SH-MIL-68(In) showed a highest $\mathrm{Hg}^{2+}$ adsorption capacity of $450 \mathrm{mg} \mathrm{g}^{-1}$ and a large adsorption rate (rate constant $k_{2}=1.25 \mathrm{~g} \mathrm{mg}^{-1} \mathrm{~min}^{-1}$ ). As seen in Figure 11, the adsorption process took place within $2 \mathrm{~min}$ at $\mathrm{pH} 4$ due to the presence of free -SH group.

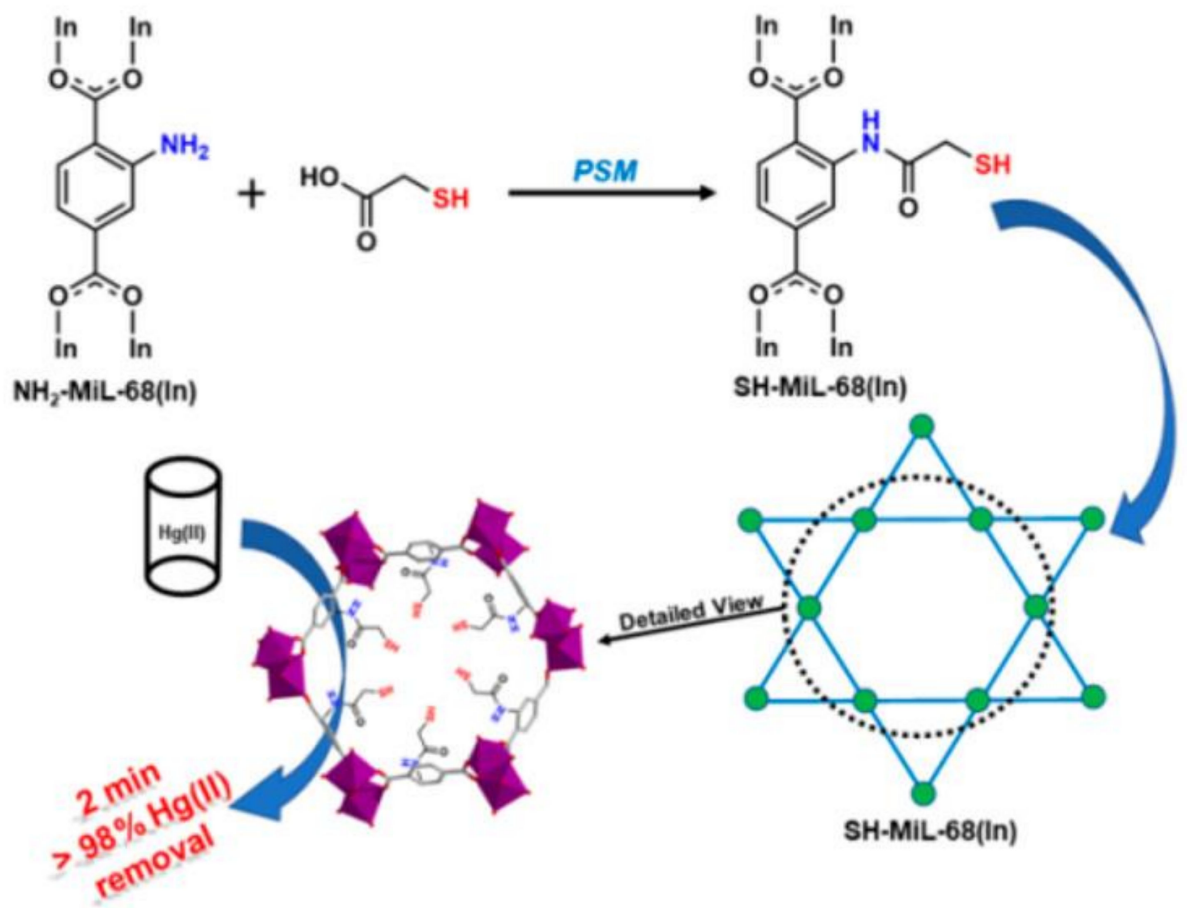

Figure 11. Schematic of post-synthetic modification of $\mathrm{NH}_{2}-\mathrm{MIL}-68(\mathrm{In})$ to afford SH-MIL-68(In) and its utilization in $\mathrm{Hg}^{2+}$ extraction (Reproduced with the permission from Ref [165]).

The material was reusable (in the presence of $0.01 \mathrm{M} \mathrm{HCl}, 0.1 \%$ thiourea) up to five cycles. This work followed the pseudo-second-order model and was linearly fitted with Langmuir isotherm. It is an impressive work considering its short process time and negligible interferences. However, real time applicability still needs to be demonstrated. By means of diffusion and solvothermal strategies, $\mathrm{Li}$ et al. developed three thioether-based MOFs, namely $\left[\left(\mathrm{ZnCl}_{2}\right)_{3}\left(\mathrm{~L}_{1}\right)_{2} \cdot \chi \text { (solvent) }\right]_{n}-(1),\left[\left(\mathrm{Cu}_{2} \mathrm{I}_{3} \mathrm{O}_{2}\right)_{4}\left(\mathrm{CH}_{4} \mathrm{~N}_{0.5}\right)_{4}\left(\mathrm{~L}_{1}\right)_{4}(\mathrm{DMA})_{4} \cdot 3\left(\mathrm{H}_{2} \mathrm{O}\right) \cdot \chi \text { (solvent) }\right]_{n}-(2)$, and $\left[\left(\mathrm{CuBr}_{2}\right)_{2}\left(\mathrm{~L}_{2}\right)_{2} \mathrm{CH}_{3} \mathrm{CN} \cdot \chi_{\chi} \text { (solvent) }\right]_{n}-(3)$ (where $\mathrm{L}_{1}$ and $\mathrm{L}_{2}$ represent $1,3,5$-tris ((pyridin-4ylthio)methyl)benzene and 2,4,6-trimethoxy-1,3,5-tris((pyridin-4-ylthio) methyl)benzene; DMA $=$ Dimethylacetamide) to utilize them for effective removal of $\mathrm{Hg}^{2+}$ in water [166]. These MOFs removed $90 \%$ of $\mathrm{Hg}^{2+}$ within 5 min at optimum pHs 4 and 5 . The maximum adsorption capacities of MOFs (1), (2), and (3) were estimated to be $362.3 \mathrm{mg} \mathrm{g}^{-1}, 227.4 \mathrm{mg} \mathrm{g}^{-1}$, and $341.7 \mathrm{mg} \mathrm{g}^{-1}$, respectively. The observed higher efficiencies to $\mathrm{Hg}^{2+}$ was attributed to the strong binding between $\mathrm{Hg}$-S. They were reusable up to five cycles (with $\mathrm{Na}_{2} \mathrm{~S}$ ). This work followed the pseudo-second-order model and was linearly correlated with the Langmuir 
isotherm. This work is considered a good one because of the negligible interference effect, but further optimization is required to improve the adsorption capacity.

The bi-metallic MOFs were also employed in $\mathrm{Hg}^{2+}$ removal/extraction as described next. Han and co-workers constructed the heterometallic metal-organic framework (HMOF): $\left\{\left[\left(\mathrm{CH}_{3}\right)_{2} \mathrm{NH}_{2}\right] \mathrm{InCu}_{4} \mathrm{~L}_{4} \cdot{ }_{x} \mathrm{~S}\right\}_{n}$, namely BUT-52 (where L represents 6,6'-dithiodinicotinic acid), to engage in $\mathrm{Hg}^{2+}$ removal, in which $\mathrm{In}(\mathrm{COO})_{4}$ and $\mathrm{Cu}_{6} \mathrm{~S}_{6}$ clusters were rationally embedded [167]. The BET surface area of BUT-52 to $\mathrm{N}_{2}$ gas at $77 \mathrm{~K}$ was $126.2 \mathrm{~cm}^{3} \mathrm{~g}^{-1}$. It showed $92 \%$ of mercury removal efficiency in ethanol. This work requires further optimization in anti-interference, $\mathrm{pH}$, time, and real time application studies. Mon et al. described utilization of the $\mathrm{Ca}$ and $\mathrm{Cu}$-based porous bimetallic MOF, namely $\left\{\mathrm{Ca}^{\mathrm{II}} \mathrm{Cu}^{\mathrm{II}}{ }_{6}[(\mathrm{~S}, \mathbf{S})\right.$ methox $\left.]_{3}(\mathrm{OH})_{2}\left(\mathrm{H}_{\mathbf{2}} \mathrm{O}\right)\right\} \cdot \mathbf{1 6}_{\mathbf{2}} \mathrm{O}$ (where methox represents bis[(S)-methionine]oxalyl diamide), for $\mathrm{Hg}^{2+}$ and $\mathrm{CH}_{3} \mathrm{Hg}^{+}$removal in aqueous media [168]. This BioMOF reduced $\mathrm{Hg}^{2+}$ and $\mathrm{CH}_{3} \mathrm{Hg}^{+}$contents from $10 \mathrm{ppm}$ to 5 and $27 \mathrm{ppb}$, respectively, with corresponding adsorbing ability of $99.95 \%$ and $99.0 \%$ (via $\mathrm{Hg}-\mathrm{S}$ interactions) for dissolved $\mathrm{HgCl}_{2}$ and $\mathrm{CH}_{3} \mathrm{HgCl}$ salts. However, optimization is required to study the adsorption kinetics and real applications. In parallel with MOFs-based extraction/removal of $\mathrm{Hg}^{2+}$, a few MOFs were also reported in multiple heavy metal ions, including $\mathrm{Hg}^{2+}$ [169-173]. Though those reports demonstrated effective removal of $\mathrm{Hg}^{2+}$, but they were also affected by interfering effects from other ions. To avoid the interfering effects, complicated masking procedure is required. Therefore, those reports will not be discussed in this review.

\section{MOFs Comprised Composites for $\mathbf{H g}^{2+}$ Removal}

Compared to MOFs, composites comprised of MOFs also become effective in $\mathrm{Hg}^{2+}$ removal [174]. For example, the Pt NPs encapsulated UIO-66-- $\mathbf{N H}_{2}$-(denoted as Pt NP@UIO66- $\mathbf{N H}_{2}$ ) was engaged in facile colorimetric detection and removal of $\mathrm{Hg}^{2+}$ in water [175]. The Pt NP@UIO-66-NH displayed a linear colorimetric response from 0 to $10 \mathrm{nM}$ with a LOD $0.35 \mathrm{nM}$ due to the peroxidase like activity which took place in the presence of 3,3',5,5' -tetramethylbenzidine and $\mathrm{H}_{2} \mathrm{O}_{2}$. Moreover, the Pt NP@UIO-66- $\mathbf{N H}_{\mathbf{2}}$ was used as an adsorbent for $\mathrm{Hg}^{2+}$ with a maximum adsorption capacity of $206.25 \mathrm{mg} \mathrm{g}^{-1}$. This material showed $\mathrm{Hg}^{2+}$ removal of $99 \%$ and reduced $\mathrm{Hg}^{2+}$ concentrations from $5 \mathrm{ppm}$ to $2.39 \mathrm{ppb}$. Reusability of this composite was established up to four cycles by $\mathrm{Na}_{2} \mathrm{~S}$. This work followed the pseudo-second-order model and was linearly fitted with the Langmuir isotherm. With respect to multiple applications, this work is considered a nice one. The mercapto-functionalized $\mathrm{Zr}-\mathrm{MOF} /$ melamine sponge composite (Zr-MOF-SH/MF) was proposed for removal of $\mathrm{Hg}^{2+}$ from water [176]. Firstly, zirconium chloride $\left(\mathrm{ZrCl}_{4}\right)$ was reacted with meso-tetra(4-carboxyphenyl)porphine $\left(\mathrm{H}_{2} \mathrm{TCPP}\right)$. The product was then interacted with mercaptoacetic acid to afford PCN-224-MAA, which formed the composite structure with melamine sponge. In particular, the PCN-224-MAA/MF (where MAA and MF represent mercaptoacetic acid and melamine formaldehyde) showed great ability for $\mathrm{Hg}^{2+}$ removal (among other heavy metal ions) with a maximum adsorption capacity of $412.5 \mathrm{mg} \mathrm{g}^{-1}$ at $\mathrm{pH} 3$ as seen in Figure 12. Due to the $\mathrm{Hg}-\mathrm{S}$ interactions, the removal process was found to be efficient and effective. The presence of melamine sponge extended the $\mathrm{Hg}^{2+}$ adsorption cycle up to five times. This work showed more effectiveness in $\mathrm{Hg}^{2+}$ removal from water-oil mixture, but the underlying kinetics require further studies. 

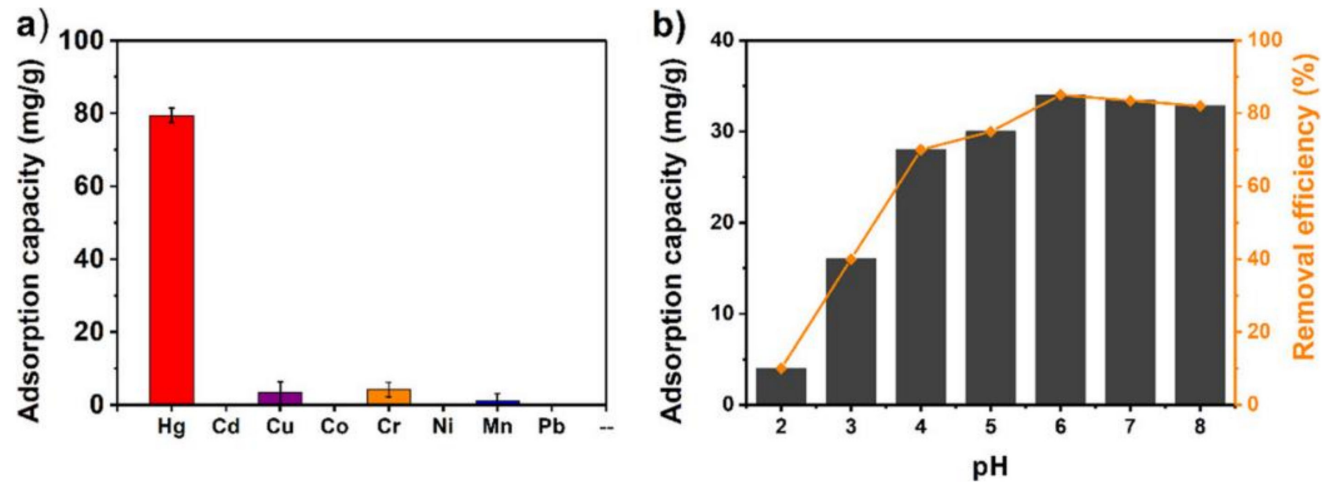

Figure 12. (a) Adsorption of mixed heavy metal ions (concentration of each ion was $100 \mathrm{mg} \mathrm{L}^{-1}$ on the PCN-224-MAA/MF composite at $\mathrm{pH} 3$. (b) Effect of $\mathrm{pH}$ on the removal of $\mathrm{Hg}^{2+}$ ions with an initial concentration of $20 \mathrm{mg} \mathrm{L}^{-1}$ on a PCN-224-MAA/MF (Reproduced with the permission from Ref [176]).

Novel ZnS-ZIF-8 monolith was explored in $\mathrm{Hg}^{2+}$ capture in wastewater [177]. The ZIF-8 filter paper was first developed by reacting $\mathrm{Zn}\left(\mathrm{NO}_{3}\right)_{2} \cdot 6 \mathrm{H}_{2} \mathrm{O}$ with 2-methylimidazole followed by sulfurization to obtain the ZnS-ZIF-8 monolith, which possessed a hierarchical porous crystalline structure. At an optimum value of $\mathrm{pH}$, the monolith showed a maximum adsorption capacity of $925.9 \mathrm{mg} \mathrm{g}^{-1}$ with recyclability with $\mathrm{Na}_{2} \mathrm{~S}$. The efficiency was found to be high because of the effective $\mathrm{Hg}-\mathrm{S}$ interaction. This work followed the pseudo-second-order kinetic and was correlated with Langmuir isotherm. This work is considered a nice one in terms of its selectivity and applicability. Nosike and co-workers proposed utilization of the $\mathrm{Fe}_{3} \mathrm{O}_{4} @ \mathrm{ZIF}-\mathbf{9 0}$-Cysteine composite towards $\mathrm{Hg}^{2+}$ adsorption as detailed below [178]. Wherein, the $\mathrm{Fe}_{3} \mathrm{O}_{4}$ was first embedded into the ZIF-90 (a Zn-based zeoliticimidazolate framework) as a core. Cysteine was then covalently attached to the $\mathrm{Fe}_{3} \mathrm{O}_{4} @ Z$ ZIF-90 via Schiff base reaction and post-synthetic modification strategy to obtain the $\mathrm{Fe}_{3} \mathrm{O}_{4} @ \mathrm{ZIF}-90-C y s t e i n e$. Poly-acrylic acid (PAA) was capped on the above composite to avoid agglomeration of nanoparticles. Because of the pore size and free thiol (-SH) group of cysteine, this composite showed good adsorbing ability to $\mathrm{Hg}^{2+}$ with a maximum capacity of $900 \mathrm{mg} \mathrm{g}^{-1}$ at optimal pH 4. The adsorption followed the pseudo-second-order model. Desorption and regeneration were accomplished with $\mathrm{HCl}(0.1 \mathrm{M})$ up to four cycles. However, the synthetic complications may affect its applicability. Huang et al. described the magnetic MOF composite, namely bi-I-functionalized $\mathrm{Fe}_{3} \mathbf{O}_{4} @ \mathrm{SiO}_{2} @ \mathrm{HKUST} \mathbf{- 1}$ (where HKUST-1 represents Cu-based MOF), with core-shell nanostructures for enhanced removal of $\mathrm{Hg}^{2+}$ in water [179]. The bismuthiol I (1,3,4-thiadiazole-2,5-dithiol, Bi-I) was functionalized over the $\mathrm{Fe}_{3} \mathrm{O}_{4} @ \mathrm{SiO}_{2} @$ HKUST-1 via post-synthetic modification. As shown in Figure 13, the bi-I-functionalized $\mathrm{Fe}_{3} \mathrm{O}_{4} @ \mathrm{SiO}_{2} @$ HKUST-1 displayed high adsorption ability to $\mathrm{Hg}^{2+}$ with a maximum capacity of $264 \mathrm{mg} \mathrm{g}^{-1}$ between $\mathrm{pHs} 2-9$. This work followed the pseudo second order model and was linearly fitted with the Langmuir isotherm. In both composites, the $\mathrm{Fe}_{3} \mathrm{O}_{4}$ was used to afford the magnetic property and played a vital role to improve the adsorption capacity. Performance of the bi-I-functionalized $\mathrm{Fe}_{3} \mathrm{O}_{4} @ \mathrm{SiO}_{2} @$ HKUST-1 was effective in the presence of other competing species. However, the main drawback of this study is that it cannot be reused with any eluent because of the strong $\mathrm{Hg}-\mathrm{S}$ bond and the hydrolysis of Bi-I. Thereby this material can only be consumed for one-time removal of $\mathrm{Hg}^{2+}$ ions in water. 


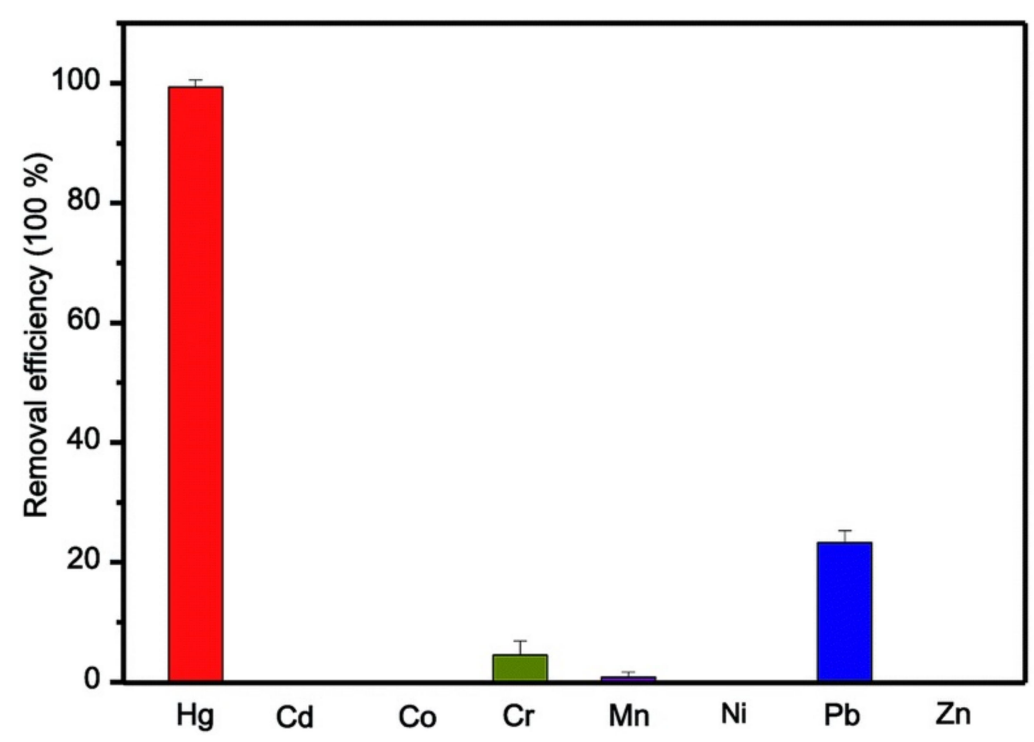

Figure 13. Selectivity of bi-I-functionalized $\mathrm{Fe}_{3} \mathrm{O}_{4} @ \mathrm{SiO}_{2} @ \mathrm{HKUST}-1$ for $\mathrm{Hg}^{2+}$ conditions: each ion of $10 \mathrm{mg} \mathrm{L}^{-1}$ and $\mathrm{pH} 3$ (reproduced with the permission from Ref [179]).

Liang and co-workers reported incorporation of $\operatorname{In}_{2} \mathrm{~S}_{3}$ nanoparticles into the MIL-101 (a Cr-based MOF) to afford the $\mathbf{I n}_{2} \mathbf{S}_{3} @ \mathbf{M I L}-\mathbf{1 0 1}$ for effective removal of $\mathrm{Hg}^{2+}$ with an efficiency of $99.95 \%$ within a minute [180]. The BET surface area of the $\mathbf{I n}_{2} \mathbf{S}_{3} @ \mathbf{M I L}-101$ to $\mathrm{N}_{2}$ gas at $77 \mathrm{~K}$ was $1476 \mathrm{~m}^{2} \mathrm{~g}^{-1}$ with a maximum adsorption capacity of $518.2 \mathrm{mg} \mathrm{g}^{-1}$ for $\mathrm{Hg}^{2+}$. This work followed the pseudo second order kinetic model and was linearly correlated with the Langmuir isotherm. The strong affinity between $\mathrm{Hg}^{2+}$ to $\mathrm{S}$ was the main reason for high efficiency of the $\mathbf{I n}_{2} \mathbf{S}_{3} @ \mathbf{M I L}-\mathbf{1 0 1}$, which was able to reduce $\mathrm{Hg}^{2+}$ concentrations from $10 \mathrm{ppm}$ to $1.75 \mathrm{ppb}$. Moreover, the composite operated between pHs 3 to 8 and was effective in the presence of competing species. By using $0.1 \mathrm{M} \mathrm{KCl}$ solution, the materials can be recycled up to three times, thereby is noted a remarkable work. In fact, incorporation of $\operatorname{In}_{2} \mathrm{~S}_{3}$ nanoparticles improves the adsorption ability of MIL-101 to $\mathrm{Hg}^{2+}$ ions. Similar to selective removal of $\mathrm{Hg}$ species, the MOF containing composites were also engaged in adsorption and capture of $\mathrm{Pb}^{2+}$ [181-183]. However, those reports will not be discussed in this review due to the possible interference effects.

\section{MOFs and Its Analogous in Elemental Mercury $\left(\mathrm{Hg}^{0}\right)$ Adsorption}

Due to the high toxic effect of elemental mercury $\left(\mathrm{Hg}^{0}\right)$ from flue gas, its adsorption and separation is in high demand. Moreover, feasible utilization of MOFs and its analogous have been predicted theoretically $[184,185]$. For example, Zhao et al. reported $\mathrm{Hg}^{0}$ removal from flue gas of iron and steel by using the MIL-101(Cr). Performance of the MIL-101(Cr) was compared to the Cu-BTC (BTC represents benzene-1,3,5-tricarboxylate), UIO-66, and activated carbon [186]. Wherein, $\mathrm{Hg}^{0}$ was primarily adsorbed over the surface of MIL101(Cr) and was oxidized by the open metal site $\mathrm{Cr}^{3+}$. Be noted that the MIL-101(Cr) captured $88 \%$ of $\mathrm{Hg}^{0}$ at $250{ }^{\circ} \mathrm{C}$ and also showed good thermal and chemical stability. Exceptional adsorption ability of the MIl-101(Cr) was further demonstrated by Dong and co-workers through $\mathrm{Hg}^{0}$ removal from the coal-fired boiler flue gas experiment [187]. Simulation studies also agreed with the experimental results, in which $\mathrm{Hg}^{0}$ adsorption over the MIL-101(Cr) surface followed the pseudo-second-order model as shown in Figure 14. Moreover, the MIl-101(Cr) showed the Langmuir-type rate expression with an estimated equilibrium adsorption capacity for the MOF-sorbent of $25.656 \mu^{-g^{-1}}$ at $200{ }^{\circ} \mathrm{C}$. Thus, the MIL-101(Cr) is considered a potential candidate for $\mathrm{Hg}^{0}$ removal. 


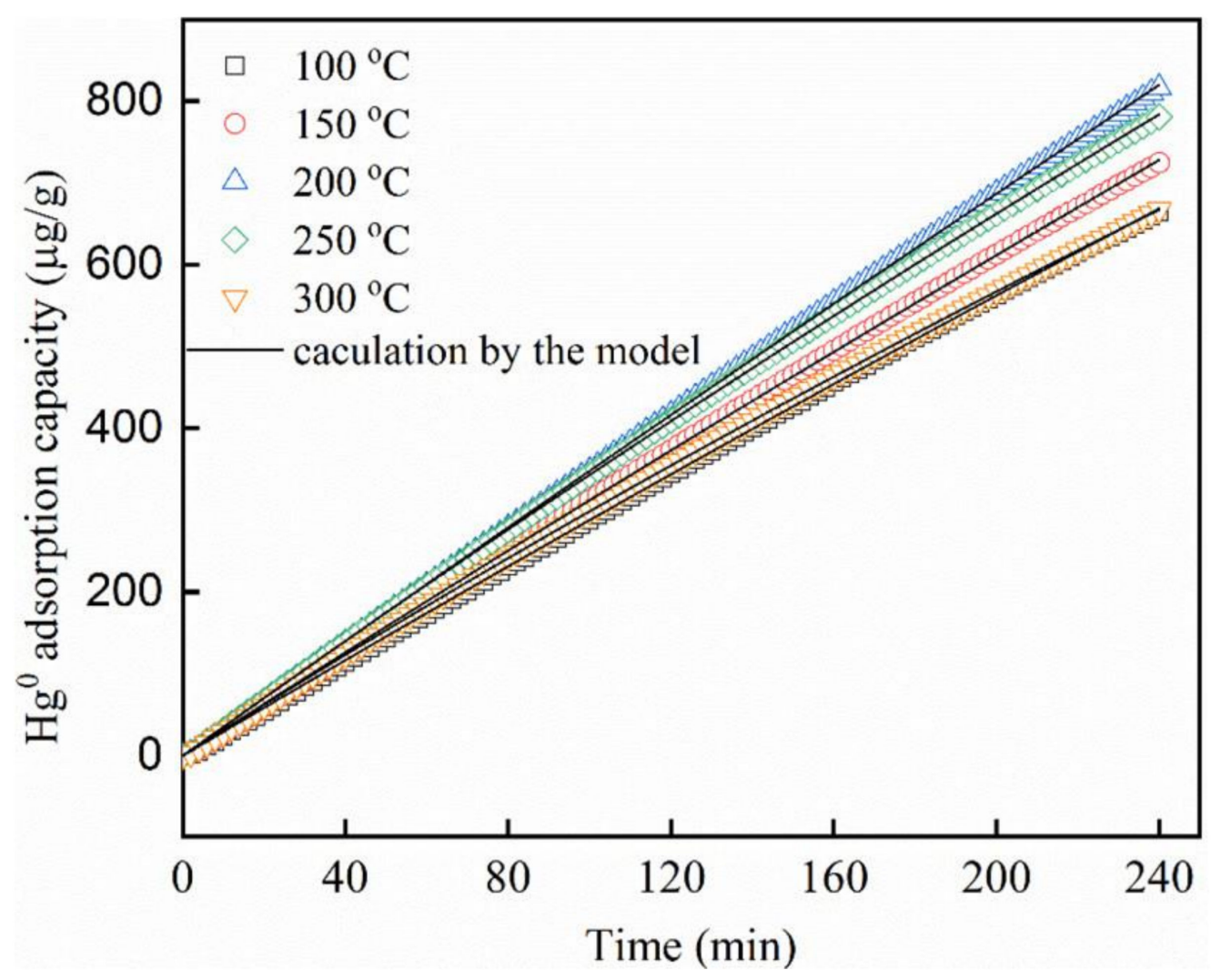

Figure 14. Simulation of $\mathrm{Hg}^{0}$ adsorption on MIL-101(Cr) by the pseudo-second-order model. Reaction conditions: $\mathrm{N}_{2}+5 \% \mathrm{O}_{2}$, inlet concentration of $\mathrm{Hg}^{0}=203 \mu \mathrm{g} \mathrm{m}{ }^{-3}$, gas hourly space velocity $(\mathrm{GHSV})=8 \times 10^{5} \mathrm{~h}^{-1}, 200^{\circ} \mathrm{C}$ (reproduced with the permission from Ref [187]).

Utilization of the Cu-BTC (BTC represents benzene-1,3,5-tricarboxylate) for $\mathrm{Hg}^{0}$ removal from sintering gas was discussed by Chen and co-workers [188]. The Cu-BTC showed great efficiency in the presence of $15 \mathrm{ppm} \mathrm{HCl}$ with the combination of $\mathrm{O}_{2}$. The chemisorbed $\mathrm{O}_{2}$ (over $\mathrm{Cu}^{2+}$ surface) oxidized the $\mathrm{Hg}^{0}$ to $\mathrm{Hg}^{2+}$, which was then converted to $\mathrm{HgCl}_{2}$ in the presence of $\mathrm{HCl}$. Moreover, the inhibition effect of $\mathrm{SO}_{2}$ was overcome by $\mathrm{HCl}$, thereby the $\mathbf{C u}-\mathbf{B T C}$ is noted a material with good performance for $\mathrm{Hg}^{0}$ adsorption The $\mathrm{MnO}_{\mathrm{x}}$ loaded on the MIL-100(Fe) $\left(77.4 \%\right.$ efficiency at $250{ }^{\circ} \mathrm{C}$; GHSV $\left.=18,000 \mathrm{~h}^{-1}\right)$ and $\alpha-\mathrm{MnO}_{2}$ anchored MIL-96(Al) were reported for $\mathrm{Hg}^{0}$ removal from flue gas $[189,190]$. Because the presence of both $\mathrm{MnO}_{\mathrm{x}}$ and $\alpha-\mathrm{MnO}_{2}$ can enhance adsorption of $\mathrm{Hg}^{0}$ and oxidation process, therefore, such composited MOFs can be engaged for environmental remediation. Subsequently, Yang et al. reported the nanosized CuSe functionalized $\mathrm{Zn}$-comprising zeolitic imidazolate framework-8 (CuSe/ZIF-8) for $\mathrm{Hg}^{0}$ adsorption and removal studies [191]. The as-prepared CuSe/ZIF-8 with the $80 \%$ mass ratio of CuSe to ZIF-8 (to afford 0.8NC-ZIF) displayed an equilibrium $\mathrm{Hg}^{0}$ adsorption capacity with an average rate of $309.8 \mathrm{mg} \mathrm{g}^{-1}$ and $105.3 \mu \mathrm{g} \mathrm{g}^{-1} \mathrm{~min}^{-1}$, correspondingly, which were far better than that of the reported metal sulfide and activated carbon sorbents. The HgSe, which is more stable than $\mathrm{HgS}$, can be easily formed because of the strong affinity between $\mathrm{Hg}$ and $\mathrm{Se}^{2-}$ (from CuSe). The composite can be used for continuous removal of $\mathrm{Hg}^{0}$, thereby is considered an exceptional material. Following the similar approach, the Se functionalized MIL-101-Cr (Se/MIL-101-Cr) was proposed for $\mathrm{Hg}^{0}$ removal [192]. By means of stable and water-insoluble HgSe formation, the Se/MIL-101-Cr showed a maximum $\mathrm{Hg}$ adsorption capacity of $48.19 \mathrm{mg} \mathrm{g}^{-1}$, which was far better than commercially activated carbon. Moreover, the adsorption rate reached a value of $44.8 \mu \mathrm{g} \mathrm{g}^{-1} \mathrm{~min}^{-1}$ and became more-effective in flue gas atmosphere containing $\mathrm{SO}_{2}, \mathrm{NO}$, and $\mathrm{H}_{2} \mathrm{O}$. Thus, it is noted as a nice candidate for $\mathrm{Hg}^{0}$ sorption. 
Zhao and co-workers reported $\mathrm{Hg}^{0}$ removal by combining Ag NPs with the Zr-based MOF-UIO-66 [193]. The adsorption capacity reached a value of $3.7 \mathrm{mg} \mathrm{g}^{-1}$ at $50^{\circ} \mathrm{C}$ because of the significant synergistic effect of Ag NPs over the UIO-66. Removal of $\mathrm{Hg}^{0}$ was attributed to the Ag amalgam formation and channel adsorption at low temperature. At high temperature, removal of $\mathrm{Hg}^{0}$ was driven by the Ag-activated oxygen oxidation and channel capture. Zhang et al. proposed the consumption of the Mn-Ce loaded MOF (MnCe@MOF) for removal of $\mathrm{Hg}^{2+}$ and NO from flue gas at low temperature [194]. However, this study reported a possible interfering effect of $\mathrm{NO}$ over $\mathrm{Hg}^{0}$ adsorption.

\section{MOFs for Simultaneous Detection and Removal of $\mathbf{H g}^{2+}$}

As suggested by earlier studies $[153,175]$, MOFs were also engaged in simultaneous detection and removal studies as discussed in this section. For instance, Rudd et al. demonstrated heavy metal ions sensing and removal using solvothermally synthesized $\mathrm{Zn}$ based luminescent MOFs, namely $\mathrm{Zn}_{2}$ (ofdc) ${ }_{2}$ (tppe)-LMOFs-261, $\mathrm{Zn}_{2}$ (hfdc) ${ }_{2}$ (tppe)-LMOFs262, and $\mathrm{Zn}_{2}(\mathrm{dbtdcO})_{2}$ (tppe)-LMOFs-263), where $\mathrm{H}_{2}$ ofdc, $\mathrm{H}_{2} \mathrm{dbtdcO}_{2}$, and tppe represent [9-oxo-9H-fluorene-2,7-dicarboxylic acid], [dibenzo[b,d]thiophene-3,7-dicarboxylic acid5,5-dioxide], and 1,1,2,2-tetrakis(4-(pyridine-4-yl)phenyl)ethane, respectively [195]. Among these MOFs, the LMOFs-263 displayed the highest luminescent selectivity to $\mathrm{Hg}^{2+}$ and $\mathrm{Pb}^{2+}$ with LODs of 3.3 and $19.7 \mathrm{ppb}$, respectively. Moreover, it showed a maximum adsorption capacity of $380 \mathrm{mg} \mathrm{g}^{-1}$ (for $\mathrm{Hg}^{2=}$ within $30 \mathrm{~min}$ ) and the adsorption followed pseudosecond-order kinetics. A $K_{d}$ value of $6.45 \times 10^{5} \mathrm{~mL} \mathrm{~g}^{-1}$ was determined for the LMOFs-263. The effective adsorption was attributed to the strong interaction between $\mathrm{Hg}^{2+}$ and $\mathrm{SO}_{2}{ }^{2-}$ (of $\mathrm{H}_{2} \mathrm{dbtdcO}_{2}$ ) and the pore size. The BET surface area of LMOFs-263 was estimated as $1004 \mathrm{~m}^{2} \mathrm{~g}^{-1}$ to $\mathrm{N}_{2}$ gas at $77 \mathrm{~K}$, however, further investigations are required to overcome the $\mathrm{Pb}^{2+}$ interference. Al-based imidazolate framework, namely NH2-MIL-53(A1), for selective detection and removal of $\mathrm{Hg}^{2+}$ was reported by Zhang and co-workers [196]. Because of the coordination of amino $\left(-\mathrm{NH}_{2}\right)$ group and ligand-to-metal charge transfer (LMCT) effect with $\mathrm{Hg}^{2+}$, fluorescent intensity of the NH2-MIL-53(Al) at $427 \mathrm{~nm}\left(\lambda_{\mathrm{ex}}=330 \mathrm{~nm}\right)$ was linearly quenched between $1-17.3 \mu \mathrm{M}$ with a LOD of $0.15 \mu \mathrm{M}$. In addition, $\mathrm{Hg}^{2+}$ sensing ability of the NH2-MIL-53(Al) was good at $\mathrm{pHs} 4-10$ without any interference. The MOF showed an adsorption capacity of $53.85 \mathrm{mg} \mathrm{g}^{-1}$ (for $\mathrm{Hg}^{2+}$ ) and was reusable with $0.1 \mathrm{M}$ $\mathrm{HCl}$ and $10 \%$ thiourea eluent. This work followed pseudo second order kinetic model and was linearly correlated with the Langmuir isotherm, thereby is a nice probe.

By loading the (bis(4-(dimethylamino)phenyl)methanethione) probe over the Al-based MOF (which was solvothermally synthesized by reacting $\mathrm{Al}\left(\mathrm{NO}_{3}\right)_{3} \cdot 9 \mathrm{H}_{2} \mathrm{O}$ and terephthalic acid), detection and removal of $\mathrm{Hg}^{2+}$ in water and skin-whitening cosmetics was delivered by Radwan and co-workers [197]. These thioketone Al-MOFs monitors (TAM) acted as microporous carriers towards $\mathrm{Hg}^{2+}$ via fluorescent quenching at $470 \mathrm{~nm}$ and enhancement at $610 \mathrm{~nm}$ with a linear range from $2 \mathrm{nM}$ to $2.1 \mu \mathrm{M}$ and a LOD of $4.4 \mathrm{nM}$. Moreover, the thioketone Al-MOF (TAM) nanorods were used in effective adsorption of $\mathrm{Hg}^{2+}$, which showed a maximum adsorption capacity of $1110 \mathrm{mg} \mathrm{g}^{-1}$ with exceptional applicability in water and skin-whitening cosmetics. Shahat et al. engaged the modified amino-functionalized Al-MOF for optical recognition and removal of $\mathrm{Hg}^{2+}$ [198]. $\mathrm{AlCl}_{3} \cdot 6 \mathrm{H}_{2} \mathrm{O}$ and 2-amino terephthalic acid was first solvothermally reacted to yield the MOF-NH2-MIL-101(Al) followed by modification with ninhydrin to obtain the final adduct Nin-NH-MIL-101(Al). The Nin-NH-MIL-101(Al) showed a BET surface area of $896.6 \mathrm{~m}^{2} \mathrm{~g}^{-1}$ for $\mathrm{N}_{2}$ gas at 77K. It was used as a colorimetric sensory probe for $\mathrm{Hg}^{2+}$ with a LOD of $0.494 \mu \mathrm{g} \mathrm{L}^{-1}$ and was further applied in removal studies. The probe displayed a maximum adsorption capacity of $127.4 \mathrm{mg} \mathrm{g}^{-1}$ and was recyclable in the presence of $0.1 \mathrm{M}$ thiourea as shown in Figure 15. This work followed the pseudo second order kinetic model and was linearly fitted Langmuir isotherm. Be noted that the Nin-NH-MIL-101(Al)-based optical detection and removal of $\mathrm{Hg}^{2+}$ was not affected by any interference. 


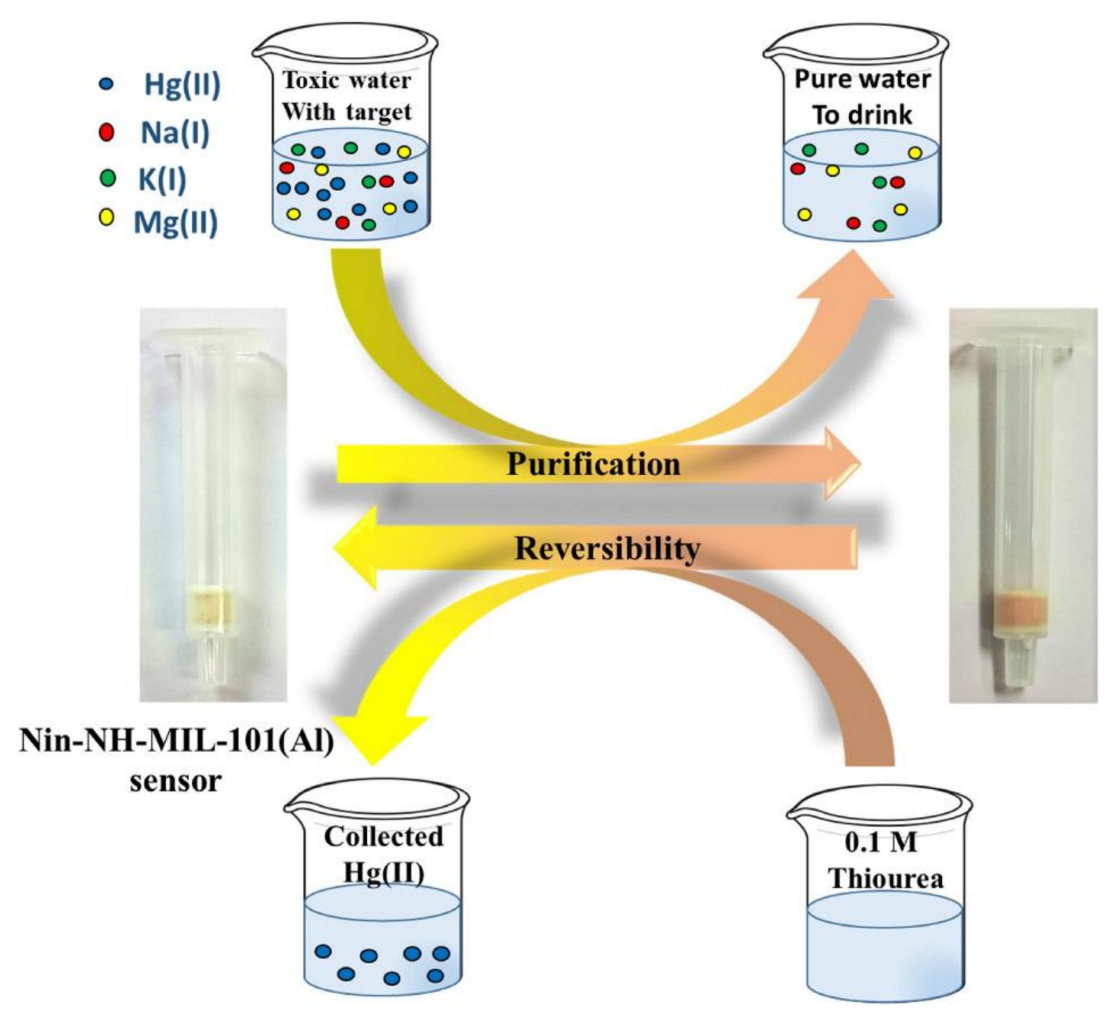

Figure 15. Representative design of the Nin-NH-MIL-101(Al) sensor applied to purification of water polluted with $\mathrm{Hg}(\mathrm{II})$ ions and the reversible process by using $0.1 \mathrm{M}$ thiourea solution for several times (reproduced with the permission from Ref [198]).

By means of hydrothermal reactions, the $\mathrm{Cu}$-based MOFs and amide-functionalized pillar ligands (-NH-CO-), namely TMU-46, 47, and 48, were synthesized and then decorated with suitable functional group malonamide (S) to produce the labelled dual functionalized materials-TMU-46S, TMU-47S, and TMU-48S, respectively. They were applied towards $\mathrm{Hg}^{2+}$ sensing and removal [199]. The BET surface areas of TMU-46S, TMU-47S, and TMU-48S were $510 \mathrm{~m}^{2} \mathrm{~g}^{-1}, 520 \mathrm{~m}^{2} \mathrm{~g}^{-1}$, and $408 \mathrm{~m}^{2} \mathrm{~g}^{-1}$, respectively. Because of the strong coordination of $\mathrm{Hg}$ to $\mathrm{S}$, the TMU-48S displayed the highest selectivity to $\mathrm{Hg}^{2+}$ via fluorescent quenching at $480 \mathrm{~nm}\left(\lambda_{\mathrm{ex}}=330 \mathrm{~nm}\right)$ with a $\mathrm{K}_{\mathrm{SV}}$ value of $86,087 \mathrm{M}^{-1}$. Moreover, the TMU-48S showed a maximum adsorption capacity of $714 \mathrm{mg} \mathrm{g}^{-1}$. However, it also showed some selectivity to $\mathrm{Pb}^{2+}$ and $\mathrm{Ag}^{+}$. The CuS particles (PCuS) were synthesized via wet-treatment of Cu-based MOF- HKUST-1 and were engaged in colorimetric detection of $\mathrm{Hg}^{2+}$ in the presence of $3,3^{\prime}, 5^{\prime}$,5-tetramethylbenzidine (TMB) and $\mathrm{H}_{2} \mathrm{O}_{2}$ (by peroxidase like activity) [200]. The BET surface area of PCuS was calculated to be $35 \mathrm{~m}^{2} \mathrm{~g}^{-1}$ with a linear colorimetric response between 3-40 $\mu \mathrm{M}$ and an established LOD of $0.22 \mu \mathrm{M}$. Moreover, the PCuS showed a maximum adsorption capacity of $2105 \mathrm{mg} \mathrm{g}^{-1}$. The system followed the pseudo second order kinetic and was linearly fitted with the Langmuir isotherm.

A porphyrinic Zr-based MOF, namely PCN-221 (by solvothermal reaction between meso-tetra(4-carboxyphenyl) porphyrin (TCPP) and $\mathrm{ZrCl}_{4}$ ), was proposed for fluorescent sensing and removal of $\mathrm{Hg}^{2+}$ in water [201]. The PCN-221 showed linear quenching at $436 \mathrm{~nm}\left(\lambda_{\mathrm{ex}}=280 \mathrm{~nm}\right)$ in the presence of $\mathrm{Hg}^{2+}$ concentrations from 0 to $300 \mu \mathrm{M}$ with a $\mathrm{K}_{\mathrm{SV}}$ value of $4021.9 \mathrm{M}^{-1}$ and a LOD of $0.01 \mu \mathrm{M}$. Moreover, sensing ability of DMF by PCN-221 was also described in this report with extensive $\mathrm{Hg}^{2+}$ adsorption studies. The PCN-221 displayed a maximum capacity of $233.65 \mathrm{mg} \mathrm{g}^{-1}$ towards $\mathrm{Hg}^{2+}$ adsorption and was highly effective at $\mathrm{pH}$ 7. Three adsorption-desorption cycles were achieved in the presence of $0.2 \mathrm{M} \mathrm{Na}_{2}$ EDTA without any interference effect. This study followed the pseudo second order model and was linearly correlated by the Langmuir isotherm. Recently, a 3D-microporous carbon/Zr-2,5-dimercaptoterephthalic acid MOFs (Zr-DMBD MOFs/3D-KSC) nanocomposite was delivered towards electrochemical detection and 
removal of $\mathrm{Hg}^{2+}$ [202]. Sensitivity of the nanocomposite to $\mathrm{Hg}^{2+}$ was established as

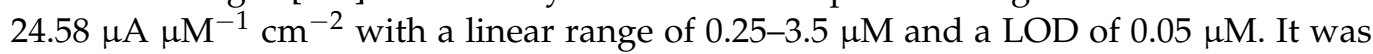
confirmed that specificity and effectiveness of the composite were similar to sensory and other utilities of nanomaterials [203-206]. This may be due to the presence of thiol (-SH) group of 2,5-dimercaptoterephthalic acid, which has great affinity to $\mathrm{Hg}^{2+}$. The $\mathbf{Z r}$-DMBD MOFs/3D-KSC showed a maximum adsorption capacity (for $\mathrm{Hg}^{2+}$ ) of $19.3 \pm 0.52 \mathrm{mg} \mathrm{g}^{-1}$ (within $60 \mathrm{~min}$ at $\mathrm{pH} \mathrm{6}$ ) and was reusable up to five cycles with EDTA. This work was also applied in real water samples. However, information regarding adsorption kinetics still needs to be discussed. Apart from specific $\mathrm{Hg}^{2+}$ sensing/adsorption utilization of MOFs, the Hg-metalated MOF scaffold can be employed for detection of other species. For example, Hg-metalated PCN-222 was reported as fluorescent and visual sensors for cysteine [207], which pointed out the possible future direction of MOFs-based $\mathrm{Hg}^{2+}$ sensors.

\section{Advantages}

Consumption of MOFs and their analogous for selective $\mathrm{Hg}^{2+}$ detection and removal possess many advantages and some restrictions as follows.

1. The majority of MOFs and their derivatives detect or adsorb the $\mathrm{Hg}$ species in aqueous media, therefore, MOFs-based detection and removal experiments could sustain the eco-friendly process via decontaminating the toxic mercury from aquatic environment.

2. Due to the porous nano/micro structural features, MOFs can be tuned towards encapsulation of specific $\mathrm{Hg}$ species, which could be further enhanced by post-synthetic modification or loading of specific groups, such as thiols (-SH).

3. MOFs and their analogous have the advantage of recognition of multiple analytes, including $\mathrm{Hg}^{2+}$, via variations of detection conditions, masking agents, and analyte concentrations.

4. MOFs can act as probes towards recognition and removal of $\mathrm{Hg}$ species through many tactics, such as optical, electrochemical, photoelectrochemical, etc. Thus, they are noted as materials with exceptional advantages.

5. By tuning the compositions to adjust the specific porous surface, many composites comprised of MOFs have unique advantages of capturing $\mathrm{Hg}$ species in the presence of other interfering analytes.

6. MOFs mediated $\mathrm{Hg}$ detection/removal process can be further extended towards recognition of specific bio-analytes, such as glutathione, cysteine, and thiol containing species.

\section{Limitations}

1. Synthesis of designated MOFs and their analogous is still considered a tough task due to certain limitations, such as possible co-adduct formation, suitable tactics, reaction conditions, solvent, etc.

2. Though MOFs display high sensitivity via fluorescence quenching or enhancement, however, many of them are consisted of toxic metals, such as $\mathrm{Al}, \mathrm{Cr}, \mathrm{Zr}$, Lanthanides, etc. Therefore, bioimaging or biological assays of $\mathrm{Hg}^{2+}$ by these MOFs are restricted.

3. MOFs with free thiol (-SH) containing organic linkers also showed selectivity to $\mathrm{Pb}^{2+}, \mathrm{Cd}^{2+}$, and $\mathrm{Ag}^{+}$, thereby limiting high selectivity towards $\mathrm{Hg}$ species via certain interfering effect.

4. Majority of MOFs-based $\mathrm{Hg}^{2+}$ adsorption or removal studies were limited by many factors, such as MOFs concentration, structural stability, porosity, $\mathrm{pH}$, time, operating temperature, suitable eluent, etc. Those factors require further attention.

5. Design and development of certain MOFs comprised composites are also limited by the multiple complicated procedures, which not only increase the cost of the processes but also restrict the commercialization of materials.

6. Complete characterizations of the $\mathrm{Hg}$ assay and removal processes also requires many costly instruments, such as scanning electron microscopy (SEM), powder-X-ray diffraction analyzer (PXRD), elemental analyzer, thermogravimetric analyzer (TGA), 
etc., which limits future research towards development of MOFs-based materials for mercury remediations.

7. Finally, adsorption capacities of a few MOFs were found to be affected by the multiple interference effects and physical/chemical stability of MOFs during the $\mathrm{Hg}$ assays in real samples. Thus, much focus is anticipated to address this problem.

\section{Conclusions and Perspectives}

This review provided valuable information regarding the utilities of MOFs and their analogous towards mercury species $\left(\mathrm{Hg}^{0}, \mathrm{Hg}^{2+}\right.$ and $\left.\mathrm{CH}_{3} \mathrm{Hg}^{+}\right)$detection and removal. By tuning the organic linkers and metal nodes, physical and chemical properties of MOFs can be adjusted to target at specific $\mathrm{Hg}$ species. Most of the MOFs displayed selective sensing responses to $\mathrm{Hg}^{2+}$ via luminescence quenching, which could be extended to adsorption studies in the future. At optimal conditions, MOFs-based adsorption of $\mathrm{Hg}^{2+}$ or $\mathrm{Hg}^{0}$ can be effective, which may pave the way for real time applications. MOFs with free thiol (-SH) or sulfur groups showed high adsorption and removal ability for $\mathrm{Hg}$ species via $\mathrm{Hg}-\mathrm{S}$ bonding, thereby such designs are highly desirable. The pore size and specific surface area can be tuned by modifying the MOF ratios in MOFs containing composites to effectively trap Hg specie. Apart from the above statements, following points need to be addressed to further improve the efficiency of MOFs-based mercury detection and removal.

1. A standardized cost-effective synthetic and purification technique must be proposed to develop MOFs for mercury detection and removal towards reliable environmental remediation.

2. Luminescent MOFs of low toxicity must be developed by using less toxic metal nodes and organic linkers for detecting the presence of $\mathrm{Hg}^{2+}$ ions in biological samples.

3. Fewer reports are available for MOFs-based $\mathrm{Hg}^{2+}$ detection via fluorescent enhancement, thereby such designs require more attention in the future.

4. The underlying mechanisms of MOFs-based electrochemical detection of $\mathrm{Hg}^{2+}$ is not entirely clear, which require more experiments and investigations.

5. The $\mathrm{T}-\mathrm{Hg}^{2+}-\mathrm{T}$ coordination-based $\mathrm{Hg}^{2+}$ detection has already been stabilized in many MOF-DNA hybrid systems. It could be extended towards removal studies, which is currently incomplete.

6. Many MOFs-based mercury detection and removal studies still lack evidence to strongly support the proposed mechanisms. This may require more attention.

7. Following parameters, such as MOFs concentrations, $\mathrm{pH}$, time, eluent solvent, and temperature, must be carefully examined and controlled for mercury removal, which complicate the separation processes. Therefore, development of MOFs that can adsorb $\mathrm{Hg}$ under less optimal conditions is becoming important.

8. Development of MOFs for detection and removal of $\mathrm{CH}_{3} \mathrm{Hg}^{+}$and $\mathrm{Hg}^{0}$ is currently less reported, thereby requiring much attention.

9. Many free thiol (-SH) containing MOFs have been reported for $\mathrm{Hg}^{2+}$ removal. Thus "state-of-the-art" procedure with certain well-known MOFs (such as UIO-66) must be developed towards commercialization.

10. Efficiency of post-synthetic modified MOFs over the unmodified one for mercury removal is still under debate, therefore, more evidence must be provided to support the PSM strategy.

11. Interaction between $\mathrm{Hg}$ to Se produces the water insoluble and stable $\mathrm{HgSe}$ as an adduct, which improves the recyclability of the MOF probe. Thus, such design should be a future-focused research.

12. Some MOFs also demonstrated moderately adsorption of other ions other than efficient mercury removal. This problem needs to be overcome for effective $\mathrm{Hg}$ separation in real samples.

13. There are not many studies available which report both detection and removal of $\mathrm{Hg}^{2+}$ ions. This kind of studies are able to achieve great impact towards environmental remediation and require more attention. 
Though current MOFs-based mercury detection and removal studies do not completely satisfy above points, but they are still considered great materials which can be operated in aqueous environment and show higher efficiencies than that of other existing tactics. As an important research topic for environmental remediation and healthcare applications, many researchers are currently devoted to the development of MOFs towards mercury recognition and separation, which will be able to solve all the difficulties and to commercialize the MOFs as $\mathrm{Hg}$ absorbers in the near future.

Author Contributions: M.S. and K.-W.S. wrote and proofread the manuscript. Both authors have read and agreed to the published version of the manuscript.

Funding: This research was funded by the Ministry of Science and Technology of Taiwan under the contract. MOST 109-2811-M-009-520-MY3 and MOST 109-2112-M-009-013.

Institutional Review Board Statement: Not applicable.

Informed Consent Statement: Not applicable.

Data Availability Statement: No new data were created or analyzed in this study. Data sharing is not applicable to this article.

Conflicts of Interest: The authors declare no conflict of interest.

\section{References}

1. Huang, J.-H.; Shetaya, W.H.; Osterwalder, S. Determination of (Bio)-available mercury in soils: A review. Environ. Pollut. 2020, 263, 114323. [CrossRef]

2. Botasini, S.; Heijo, G.; Méndez, E. Toward decentralized analysis of mercury (II) in real samples. A critical review on nanotechnology-based methodologies. Anal. Chim. Acta 2013, 800, 1-11. [CrossRef]

3. Xie, Z.-J.; Bao, X.-Y.; Peng, C.-F. Highly Sensitive and Selective Colorimetric Detection of Methylmercury Based on DNA Functionalized Gold Nanoparticles. Sensors 2018, 18, 2679. [CrossRef]

4. Shellaiah, M.; Simon, T.; Venkatesan, P.; Sun, K.W.; Ko, F.-H.; Wu, S.-P. Cysteamine-modified diamond nanoparticles applied in cellular imaging and $\mathrm{Hg}^{2+}$ ions detection. Appl. Surf. Sci. 2019, 465, 340-350. [CrossRef]

5. Aderinto, S.O. Fluorescent, colourimetric, and ratiometric probes based on diverse fluorophore motifs for mercuric(II) ion (Hg ${ }^{2+}$ ) sensing: Highlights from 2011 to 2019. Chem. Pap. 2020, 74, 3195-3232. [CrossRef] [PubMed]

6. Kobielska, P.A.; Howarth, A.J.; Farha, O.K.; Nayak, S. Metal-organic frameworks for heavy metal removal from water. Coord. Chem. Rev. 2018, 358, 92-107. [CrossRef]

7. Selid, P.D.; Xu, H.; Collins, E.M.; Face-Collins, M.S.; Zhao, J.X. Sensing Mercury for Biomedical and Environmental Monitoring. Sensors 2009, 9, 5446-5459. [CrossRef]

8. Bernhoft, R.A. Mercury Toxicity and Treatment: A Review of the Literature. J. Environ. Public Health 2011, 2012, 1-10. [CrossRef] [PubMed]

9. Langford, N.J.; Ferner, R.E. Toxicity of mercury. J. Hum. Hypertens. 1999, 13, 651-656. [CrossRef]

10. Rana, M.; Balcioglu, M.; Robertson, N.M.; Hizir, M.S.; Yumak, S.; Yigit, M.V. Low picomolar, instrument-free visual detection of mercury and silver ions using low-cost programmable nanoprobes. Chem. Sci. 2017, 8, 1200-1208. [CrossRef]

11. Gauthama, B.; Narayana, B.; Sarojini, B.; Suresh, N.; Sangappa, Y.; Kudva, A.K.; Satyanarayana, G.; Raghu, S.V. Colorimetric "off-on" fluorescent probe for selective detection of toxic $\mathrm{Hg}^{2+}$ based on rhodamine and its application for in-vivo bioimaging. Microchem. J. 2021, 166, 106233. [CrossRef]

12. Busairi, N.; Syahir, A. Recent Advances in Mercury Detection: Towards Enabling a Sensitive and Rapid Point-of-Check Measurement. J. Toxicol. Risk Assess 2018, 4, 010.

13. Nolan, E.M.; Lippard, S.J. Tools and Tactics for the Optical Detection of Mercuric Ion. Chem. Rev. 2008, 108, 3443-3480. [CrossRef]

14. Shellaiah, M.; Sun, K.W. Luminescent Metal Nanoclusters for Potential Chemosensor Applications. Chemosensors 2017, 5, 36. [CrossRef]

15. Shuai, H.; Xiang, C.; Qian, L.; Bin, F.; Xiaohui, L.; Jipeng, D.; Chang, Z.; Jiahui, L.; Wenbin, Z. Fluorescent sensors for detection of mercury: From small molecules to nanoprobes. Dyes Pigment. 2021, 187, 109125. [CrossRef]

16. Dai, D.; Li, Z.; Yang, J.; Wang, C.; Wu, J.-R.; Wang, Y.; Zhang, D.; Yang, Y.-W. Supramolecular Assembly-Induced Emission Enhancement for Efficient Mercury(II) Detection and Removal. J. Am. Chem. Soc. 2019, 141, 4756-4763. [CrossRef] [PubMed]

17. Zhao, L.; Zhang, Z.; Liu, Y.; Wei, J.; Liu, Q.; Ran, P.; Li, X. Fibrous strips decorated with cleavable aggregation-induced emission probes for visual detection of $\mathrm{Hg}^{2+}$. J. Hazard. Mater. 2020, 385, 121556. [CrossRef] [PubMed]

18. Kumar, P.; Deep, A.; Kim, K.-H. Metal organic frameworks for sensing applications. TrAC Trends Anal. Chem. 2015, 73, 39-53. [CrossRef]

19. Li, Y.; Hu, T.; Chen, R.; Xiang, R.; Wang, Q.; Zeng, Y.; He, C. Novel thiol-functionalized covalent organic framework as adsorbent for simultaneous removal of BTEX and mercury (II) from water. Chem. Eng. J. 2020, 398, 125566. [CrossRef] 
20. Chen, L.; Liu, D.; Peng, J.; Du, Q.; He, H. Ratiometric fluorescence sensing of metal-organic frameworks: Tactics and perspectives. Coord. Chem. Rev. 2020, 404, 213113. [CrossRef]

21. Razavi, S.A.A.; Morsali, A. Metal ion detection using luminescent-MOFs: Principles, strategies and roadmap. Coord. Chem. Rev. 2020, 415, 213299. [CrossRef]

22. Devaraj, M.; Sasikumar, Y.; Rajendran, S.; Ponce, L.C. Review-Metal Organic Framework Based Nanomaterials for Electrochemical Sensing of Toxic Heavy Metal Ions: Progress and Their Prospects. J. Electrochem. Soc. 2021, 168, 037513. [CrossRef]

23. Vardali, S.C.; Manousi, N.; Barczak, M.; Giannakoudakis, D.A. Novel Approaches Utilizing Metal-Organic Framework Composites for the Extraction of Organic Compounds and Metal Traces from Fish and Seafood. Molecules 2020, 25, 513. [CrossRef] [PubMed]

24. Li, X.; Ma, W.; Li, H.; Zhang, Q.; Liu, H. Sulfur-functionalized metal-organic frameworks: Synthesis and applications as advanced adsorbents. Coord. Chem. Rev. 2020, 408, 213191. [CrossRef]

25. Chen, L.; Luque, R.; Li, Y. Controllable design of tunable nanostructures inside metal-organic frameworks. Chem. Soc. Rev. 2017, 46, 4614-4630. [CrossRef] [PubMed]

26. Xia, W.; Mahmood, A.; Zou, R.; Xu, Q. Metal-organic frameworks and their derived nanostructures for electrochemical energy storage and conversion. Energy Environ. Sci. 2015, 8, 1837-1866. [CrossRef]

27. Lee, K.J.; Lee, J.H.; Jeoung, S.; Moon, H.R. Transformation of Metal-Organic Frameworks/Coordination Polymers into Functional Nanostructured Materials: Experimental Approaches Based on Mechanistic Insights. Acc. Chem. Res. 2017, 50, $2684-2692$. [CrossRef]

28. Xie, Z.; Xu, W.; Cui, X.; Wang, Y. Recent Progress in Metal-Organic Frameworks and Their Derived Nanostructures for Energy and Environmental Applications. ChemSusChem 2017, 10, 1645-1663. [CrossRef] [PubMed]

29. Song, Y.; Li, X.; Sun, L.; Wang, L. Metal/metal oxide nanostructures derived from metal-organic frameworks. RSC Adv. 2014, 5, 7267-7279. [CrossRef]

30. Heo, D.Y.; Do, H.H.; Ahn, S.H.; Kim, S.Y. Metal-Organic Framework Materials for Perovskite Solar Cells. Polymers 2020, $12,2061$. [CrossRef]

31. Kaur, H.; Sundriyal, S.; Pachauri, V.; Ingebrandt, S.; Kim, K.-H.; Sharma, A.L.; Deep, A. Luminescent metal-organic frameworks and their composites: Potential future materials for organic light emitting displays. Coord. Chem. Rev. 2019, $401,213077$. [CrossRef]

32. Wu, G.; Huang, J.; Zang, Y.; He, J.; Xu, G. Porous Field-Effect Transistors Based on a Semiconductive Metal-Organic Framework. J. Am. Chem. Soc. 2017, 139, 1360-1363. [CrossRef] [PubMed]

33. He, J.; Xu, J.; Yin, J.; Li, N.; Bu, X.-H. Recent advances in luminescent metal-organic frameworks for chemical sensors. Sci. China Mater. 2019, 62, 1655-1678. [CrossRef]

34. Wu, S.; Min, H.; Shi, W.; Cheng, P. Multicenter Metal-Organic Framework-Based Ratiometric Fluorescent Sensors. Adv. Mater. 2020, 32, 1805871. [CrossRef] [PubMed]

35. Samanta, P.; Let, S.; Mandal, W.; Dutta, S.; Ghosh, S.K. Luminescent metal-organic frameworks (LMOFs) as potential probes for the recognition of cationic water pollutants. Inorg. Chem. Front. 2020, 7, 1801-1821. [CrossRef]

36. Huang, S.-Z.; Liu, S.-S.; Zhang, H.-j.; Han, Z.; Zhao, G.; Dong, X.-Y.; Zang, S.-Q. Dual-Functional Proton-Conducting and pH-Sensing Polymer Membrane Benefiting from a Eu-MOF. ACS Appl. Mater. Interfaces 2020, 12, 28720-28726. [CrossRef] [PubMed]

37. Wang, Y.; Hu, Y.; He, Q.; Yan, J.; Xiong, H.; Wen, N.; Cai, S.; Peng, D.; Liu, Y.; Liu, Z. Metal-organic frameworks for virus detection. Biosens. Bioelectron. 2020, 169, 112604. [CrossRef]

38. Gai, S.; Zhang, J.; Fan, R.; Xing, K.; Chen, W.; Zhu, K.; Zheng, X.; Wang, P.; Fang, X.; Yang, Y. Highly Stable Zinc-Based Metal-Organic Frameworks and Corresponding Flexible Composites for Removal and Detection of Antibiotics in Water. ACS Appl. Mater. Interfaces 2020, 12, 8650-8662. [CrossRef] [PubMed]

39. Tang, J.; Feng, D.; Yang, J.; Ma, X.; Wang, X.-Q. A turn-on luminescent probe for $\mathrm{Fe}^{3+}$ and ascorbic acid with logic gate operation based on a zinc(ii)-based metal-organic framework. New J. Chem. 2020, 44, 8728-8735. [CrossRef]

40. Wu, R.-Z.; Yang, X.; Zhang, L.-W.; Zhou, P.-P. Luminescent lanthanide metal-organic frameworks for chemical sensing and toxic anion detection. Dalton Trans. 2017, 46, 9859-9867. [CrossRef]

41. Hu, Z.; Deibert, B.J.; Li, J. Luminescent metal-organic frameworks for chemical sensing and explosive detection. Chem. Soc. Rev. 2014, 43, 5815-5840. [CrossRef]

42. Dalapati, R.; Nandi, S.; Biswas, S. Post-synthetic modification of a metal-organic framework with a chemodosimeter for the rapid detection of lethal cyanide via dual emission. Dalton Trans. 2020, 49, 8684-8692. [CrossRef]

43. Koo, W.-T.; Jang, J.-S.; Kim, I.-D. Metal-Organic Frameworks for Chemiresistive Sensors. Chem 2019, 5, 1938-1963. [CrossRef]

44. Lustig, W.P.; Mukherjee, S.; Rudd, N.D.; Desai, A.V.; Li, J.; Ghosh, S.K. Metal-organic frameworks: Functional luminescent and photonic materials for sensing applications. Chem. Soc. Rev. 2017, 46, 3242-3285. [CrossRef] [PubMed]

45. Goswami, R.; Mandal, S.C.; Pathak, B.; Neogi, S. Guest-Induced Ultrasensitive Detection of Multiple Toxic Organics and Fe3+ Ions in a Strategically Designed and Regenerative Smart Fluorescent Metal-Organic Framework. ACS Appl. Mater. Interfaces 2019, 11, 9042-9053. [CrossRef]

46. Tchalala, M.R.; Bhatt, P.M.; Chappanda, K.N.; Tavares, S.R.; Adil, K.; Belmabkhout, Y.; Shkurenko, A.; Cadiau, A.; Heymans, N.; De Weireld, G.; et al. Fluorinated MOF platform for selective removal and sensing of $\mathrm{SO}_{2}$ from flue gas and air. Nat. Commun. 2019, 10, 1-10. [CrossRef] 
47. Chen, G.; Guo, Z.; Zeng, G.; Tang, L. Fluorescent and colorimetric sensors for environmental mercury detection. Analyst 2015, 140, 5400-5443. [CrossRef]

48. Rouhani, F.; Morsali, A. Goal-Directed Design of Metal-Organic Frameworks for HgII and PbII Adsorption from Aqueous Solutions. Chem. Eur. J. 2018, 24, 17170-17179. [CrossRef] [PubMed]

49. Tan, H.; Liu, B.; Chen, Y. Lanthanide Coordination Polymer Nanoparticles for Sensing of Mercury(II) by Photoinduced Electron Transfer. ACS Nano 2012, 6, 10505-10511. [CrossRef] [PubMed]

50. Sohrabi, M.R. Preconcentration of mercury(II) using a thiol-functionalized metal-organic framework nanocomposite as a sorbent. Microchim. Acta 2014, 181, 435-444. [CrossRef]

51. Zhang, X.; Shen, B.; Zhu, S.; Xu, H.; Tian, L. UiO-66 and its Br-modified derivates for elemental mercury removal. J. Hazard. Mater. 2016, 320, 556-563. [CrossRef] [PubMed]

52. Li, X.; Wang, B.; Cao, Y.; Zhao, S.; Wang, H.; Feng, X.; Zhou, J.; Ma, X. Water Contaminant Elimination Based on Metal-Organic Frameworks and Perspective on Their Industrial Applications. ACS Sustain. Chem. Eng. 2019, 7, 4548-4563. [CrossRef]

53. Fang, X.; Zong, B.; Mao, S. Metal-Organic Framework-Based Sensors for Environmental Contaminant Sensing. Nano-Micro Lett. 2018, 10, 1-19. [CrossRef]

54. Yao, C.-X.; Zhao, N.; Liu, J.-C.; Chen, L.-J.; Liu, J.-M.; Fang, G.-Z.; Wang, S. Recent Progress on Luminescent Metal-Organic Framework-Involved Hybrid Materials for Rapid Determination of Contaminants in Environment and Food. Polymers 2020, 12, 691. [CrossRef]

55. Yee, K.-K.; Reimer, N.; Liu, J.; Cheng, S.-Y.; Yiu, S.-M.; Weber, J.; Stock, N.; Xu, Z. Effective Mercury Sorption by Thiol-Laced Metal-Organic Frameworks: In Strong Acid and the Vapor Phase. J. Am. Chem. Soc. 2013, 135, 7795-7798. [CrossRef]

56. Wang, Q.; Astruc, D. State of the Art and Prospects in Metal-Organic Framework (MOF)-Based and MOF-Derived Nanoca-talysis. Chem. Rev. 2020, 120, 1438-1511. [CrossRef]

57. Cui, J.; Ren, S.; Sun, B.; Jia, S. Optimization protocols and improved strategies for metal-organic frameworks for immobilizing enzymes: Current development and future challenges. Coord. Chem. Rev. 2018, 370, 22-41. [CrossRef]

58. Hu, M.-L.; Razavi, S.A.A.; Piroozzadeh, M.; Morsali, A. Sensing organic analytes by metal-organic frameworks: A new way of considering the topic. Inorg. Chem. Front. 2020, 7, 1598-1632. [CrossRef]

59. Dalapati, R.; Biswas, S. Post-synthetic modification of a metal-organic framework with fluorescent-tag for dual naked-eye sensing in aqueous medium. Sens. Actuators B Chem. 2017, 239, 759-767. [CrossRef]

60. Safaei, M.; Foroughi, M.M.; Ebrahimpoor, N.; Jahani, S.; Omidi, A.; Khatami, M. A review on metal-organic frameworks: Synthesis and applications. TrAC Trends Anal. Chem. 2019, 118, 401-425. [CrossRef]

61. Al-Ghoul, M.; Issa, R.; Hmadeh, M. Synthesis, size and structural evolution of metal-organic framework-199 via a reactiondiffusion process at room temperature. CrystEngComm 2016, 19, 608-612. [CrossRef]

62. Al Amery, N.; Abid, H.; Al-Saadi, S.; Wang, S.; Liu, S. Facile directions for synthesis, modification and activation of MOFs. Mater. Today Chem. 2020, 17, 100343. [CrossRef]

63. Klinowski, J.; Almeida Paz, F.A.; Silva, P.; Rocha, J. Microwave-Assisted Synthesis of Metal-Organic Frameworks. Dalton Trans. 2011, 40, 321-330. [CrossRef]

64. Thomas-Hillman, I.; Laybourn, A.; Dodds, C.; Kingman, S.W. Realising the environmental benefits of metal-organic frameworks: Recent advances in microwave synthesis. J. Mater. Chem. A 2018, 6, 11564-11581. [CrossRef]

65. Le, V.N.; Kwon, H.T.; Vo, T.K.; Kim, J.-H.; Kim, W.-S.; Kim, J. Microwave-assisted continuous flow synthesis of mesoporous metal-organic framework MIL-100 (Fe) and its application to $\mathrm{Cu}(\mathrm{I})$-loaded adsorbent for $\mathrm{CO} / \mathrm{CO}_{2}$ separation. Mater. Chem. Phys. 2020, 253, 123278. [CrossRef]

66. Li, W.-J.; Tu, M.; Cao, R.; Fischer, R.A. Metal-organic framework thin films: Electrochemical fabrication techniques and corresponding applications \& perspectives. J. Mater. Chem. A 2016, 4, 12356-12369. [CrossRef]

67. Wang, Z.; Li, Z.; Ng, M.; Milner, P.J. Rapid mechanochemical synthesis of metal-organic frameworks using exogenous organic base. Dalton Trans. 2020, 49, 16238-16244. [CrossRef]

68. Vaitsis, C.; Sourkouni, G.; Argirusis, C. Chapter 11-Sonochemical synthesis of MOFs. In Metal-Organic Frameworks for Bio-medical Applications; Mozafari, M., Ed.; Woodhead Publishing: Cambridge, UK, 2020; pp. 223-244.

69. Kalaj, M.; Cohen, S.M. Postsynthetic Modification: An Enabling Technology for the Advancement of Metal-Organic Frameworks. ACS Cent. Sci. 2020, 6, 1046-1057. [CrossRef]

70. Shellaiah, M.; Sun, K.W. Review on Sensing Applications of Perovskite Nanomaterials. Chemosensors 2020, 8, 55. [CrossRef]

71. Yang, J.; Wang, Z.; Li, Y.; Zhuang, Q.; Zhao, W.; Gu, J. Porphyrinic MOFs for reversible fluorescent and colorimetric sensing of mercury(II) ions in aqueous phase. RSC Adv. 2016, 6, 69807-69814. [CrossRef]

72. Zhang, X.; Xia, T.; Jiang, K.; Cui, Y.; Yang, Y.; Qian, G. Highly sensitive and selective detection of mercury (II) based on a zirconium metal-organic framework in aqueous media. J. Solid State Chem. 2017, 253, 277-281. [CrossRef]

73. Samanta, P.; Desai, A.V.; Sharma, S.; Chandra, P.; Ghosh, S.K. Selective Recognition of $\mathrm{Hg}^{2+}$ ion in Water by a Functionalized Metal-Organic Framework (MOF) Based Chemodosimeter. Inorg. Chem. 2018, 57, 2360-2364. [CrossRef] [PubMed]

74. Xiaoxiong, Z.; Wenjun, Z.; Cuiliu, L.; Xiaohong, Q.; Chengyu, Z. Eu ${ }^{3+}$-Postdoped UIO-66-Type Metal-Organic Framework as a Luminescent Sensor for $\mathrm{Hg}^{2+}$ Detection in Aqueous Media. Inorg. Chem. 2019, 58, 3910-3915. [CrossRef] [PubMed]

75. Wang, Z.; Yang, J.; Li, Y.; Zhuang, Q.; Gu, J. Zr-Based MOFs integrated with a chromophoric ruthenium complex for specific and reversible $\mathrm{Hg}^{2+}$ sensing. Dalton Trans. 2018, 47, 5570-5574. [CrossRef] 
76. Li, W.-Y.; Yang, S.; Li, Y.-A.; Li, Q.-Y.; Guan, Q.; Dong, Y.-B. Synthesis of an MOF-based $\mathrm{Hg}^{2+}$-fluorescent probe via stepwise post-synthetic modification in a single-crystal-to-single-crystal fashion and its application in bioimaging. Dalton Trans. 2019, 48, 16502-16508. [CrossRef]

77. Kim, J.; Oh, J.S.; Park, K.C.; Gupta, G.; Lee, C.Y. Colorimetric detection of heavy metal ions in water via metal-organic framework. Inorg. Chim. Acta 2019, 486, 69-73. [CrossRef]

78. Wang, H.; Wang, X.; Liang, M.; Chen, G.; Kong, R.-M.; Xia, L.; Qu, F. A Boric Acid-Functionalized Lanthanide Metal-Organic Framework as a Fluorescence "Turn-on" Probe for Selective Monitoring of $\mathrm{Hg}^{2+}$ and $\mathrm{CH}_{3} \mathrm{Hg}^{+}$. Anal. Chem. 2020, 92, 3366-3372. [CrossRef]

79. Xia, T.; Song, T.; Zhang, G.; Cui, Y.; Yang, Y.; Wang, Z.; Qian, G. A Terbium Metal-Organic Framework for Highly Selective and Sensitive Luminescence Sensing of $\mathrm{Hg}^{2+}$ Ions in Aqueous Solution. Chem. A Eur. J. 2016, 22, 18429-18434. [CrossRef]

80. Liu, X.; Lin, H.; Xiao, Z.; Fan, W.; Huang, A.; Wang, R.; Zhang, L.; Sun, D. Multifunctional lanthanide-organic frameworks for fluorescent sensing, gas separation and catalysis. Dalton Trans. 2016, 45, 3743-3749. [CrossRef]

81. Razavi, S.A.A.; Masoomi, M.Y.; Morsali, A. Double Solvent Sensing Method for Improving Sensitivity and Accuracy of Hg(II) Detection Based on Different Signal Transduction of a Tetrazine-Functionalized Pillared Metal-Organic Framework. Inorg. Chem. 2017, 56, 9646-9652. [CrossRef]

82. Wan, Y.; Zou, D.; Cui, Y.; Yang, Y.; Qian, G. A Zn based anionic metal-organic framework for trace $\mathrm{Hg}^{2+}$ ion detection. J. Solid State Chem. 2018, 266, 70-73. [CrossRef]

83. Pankajakshan, A.; Kuznetsov, D.; Mandal, S. Ultrasensitive Detection of $\mathrm{Hg}$ (II) Ions in Aqueous Medium Using Zinc-Based Metal-Organic Framework. Inorg. Chem. 2019, 58, 1377-1381. [CrossRef]

84. Khatun, A.; Panda, D.K.; Sayresmith, N.; Walter, M.G.; Saha, S. Thiazolothiazole-Based Luminescent Metal-Organic Frameworks with Ligand-to-Ligand Energy Transfer and $\mathrm{Hg}^{2+}$-Sensing Capabilities. Inorg. Chem. 2019, 58, 12707-12715. [CrossRef]

85. Jiang, J.; Lu, Y.; Liu, J.; Zhou, Y.; Zhao, D.; Li, C. An acid-base resistant Zn-based metal-organic framework as a luminescent sensor for mercury(II). J. Solid State Chem. 2020, 283, 121153. [CrossRef]

86. Wu, P.; Liu, Y.; Liu, Y.; Wang, J.; Li, Y.; Liu, W.; Wang, J. Cadmium-Based Metal-Organic Framework as a Highly Selective and Sensitive Ratiometric Luminescent Sensor for Mercury(II). Inorg. Chem. 2015, 54, 11046-11048. [CrossRef] [PubMed]

87. Liu, B.-H.; Liu, D.-X.; Yang, K.-Q.; Dong, S.-J.; Li, W.; Wang, Y.-J. A new cluster-based metal-organic framework with triazine backbones for selective luminescent detection of mercury(II) ion. Inorg. Chem. Commun. 2018, 90, 61-64. [CrossRef]

88. El Taher, B.J.; Sabouni, R.; Ghommem, M. Luminescent metal organic framework for selective detection of mercury in aqueous media: Microwave-based synthesis and evaluation. Colloids Surf. A Physicochem. Eng. Asp. 2020,607, 125477. [CrossRef]

89. Basaleh, A.S.; Sheta, S.M. Novel advanced nanomaterial based on ferrous metal-organic framework and its application as chemosensors for mercury in environmental and biological samples. Anal. Bioanal. Chem. 2020, 412, 3153-3165. [CrossRef]

90. Li, Y.; Ma, D.; Chen, C.; Chen, M.; Li, Z.; Wu, Y.; Zhu, S.; Peng, G. A hydrostable and bromine-functionalized manganeseorganic framework with luminescence sensing of $\mathrm{Hg}^{2+}$ and antiferromagnetic properties. J. Solid State Chem. 2019, 269, 257-263. [CrossRef]

91. Song, Y.; Fan, R.; Fan, J.; Xing, K.; Du, X.; Wang, P.; Yang, Y. Highly sensitive and selective fluorescent probes for Hg ${ }^{2+}$ in $\mathrm{Ag}(\mathrm{i}) / \mathrm{Cu}(\mathrm{ii}) 3 \mathrm{D}$ supramolecular architectures based on noncovalent interactions. Dalton Trans. 2016, 45, 16422-16432. [CrossRef] [PubMed]

92. Jana, A.K.; Natarajan, S. Fluorescent Metal-Organic Frameworks for Selective Sensing of Toxic Cations $\left(\mathrm{Tl}^{3+}, \mathrm{Hg}^{2+}\right)$ and $\mathrm{Highly}^{2}$ Oxidizing Anions $\left(\left(\mathrm{CrO}_{4}\right)^{2-},\left(\mathrm{Cr}_{2} \mathrm{O}_{7}\right)^{2-},\left(\mathrm{MnO}_{4}\right)^{-}\right)$. ChemPlusChem 2017, 82, 1153-1163. [CrossRef]

93. Xiao, J.; Liu, J.; Gao, X.; Ji, G.; Wang, D.; Liu, Z. A multi-chemosensor based on Zn-MOF: Ratio-dependent color transition detection of $\mathrm{Hg}$ (II) and highly sensitive sensor of Cr (VI). Sens. Actuators B Chem. 2018, 269, 164-172. [CrossRef]

94. Fu, H.-R.; Zhao, Y.; Xie, T.; Han, M.-L.; Ma, L.-F.; Zang, S.-Q. Stable dye-encapsulated indium-organic framework as dual-emitting sensor for the detection of $\mathrm{Hg}^{2+} / \mathrm{Cr}_{2} \mathrm{O}_{7}{ }^{2-}$ and a wide range of nitro-compounds. J. Mater. Chem. C 2018, 6, 6440-6448. [CrossRef]

95. Li, F.; Hong, Y.-S.; Zuo, K.-X.; Sun, Q.; Gao, E.-Q. Highly selective fluorescent probe for $\mathrm{Hg}^{2+}$ and $\mathrm{MnO}_{4}{ }^{-}$by the two-fold interpenetrating metal-organic framework with nitro functionalized linkers. J. Solid State Chem. 2019, 270, 509-515. [CrossRef]

96. Yang, Y.-J.; Liu, D.; Li, Y.-H.; Dong, G.-Y. Two new luminescent ternary Cd(II)-MOFs by regulation of aromatic dicarboxylate ligands used as efficient dual-responsive sensors for toxic metal ions in water. Polyhedron 2019, 159, 32-42. [CrossRef]

97. Mahmoud, M.E.; Moussa, Z.; Prakasam, T.; Li, L.; Abiad, M.G.; Patra, D.; Hmadeh, M. Lanthanides based metal organic frameworks for luminescence sensing of toxic metal ions. J. Solid State Chem. 2020, 281, 121031. [CrossRef]

98. Ren, M.; Wang, H.; Liu, Y.; Ma, Q.; Jia, W.; Liu, M.; Wang, H.; Lu, Y. Fluorescent Determination of Mercury (II) and Glutathione Using Amino-MIL-53(Al) Nanosheets. Anal. Lett. 2020, 53, 2700-2714. [CrossRef]

99. Yang, L.; Li, X.; Qin, C.; Shao, K.-Z.; Su, Z.-M. A fluorescent sensor for highly selective sensing of nitro explosives and Hg(ii) ions based on a 3D porous layer metal-organic framework. CrystEngComm 2016, 18, 4765-4771. [CrossRef]

100. Gong, W.-J.; Ren, Z.-G.; Li, H.-X.; Zhang, J.-G.; Lang, J.-P. Cadmium(II) Coordination Polymers of 4-Pyr-poly-2-ene and Carboxylates: Construction, Structure, and Photochemical Double [2 + 2] Cycloaddition and Luminescent Sensing of Nitroaromatics and Mercury(II) Ions. Cryst. Growth Des. 2017, 17, 870-881. [CrossRef]

101. Su, Y.-Q.; Qu, Y.-H.; Fu, L.; Cui, G.-H. An unprecedented binodal (4,6)-connected Co(II) MOF as dual-responsive luminescent sensor for detection of acetylacetone and $\mathrm{Hg}^{2+}$ ions. Inorg. Chem. Commun. 2020, 118, 108013. [CrossRef] 
102. Sun, X.; Yang, P.; Hou, G.; Wei, J.; Wang, X.; Yang, D.; Zhang, X.; Dong, H.; Zhang, F. Luminescent Functionalised Supramolecular Coordination Polymers Based on an Aromatic Carboxylic Acid Ligand for Sensing $\mathrm{Hg}^{2+}$ Ions Aust. J. Chem. $2017,70,786-791$.

103. Li, Q.; Wang, C.; Tan, H.; Tang, G.; Gao, J.; Chen, C.-H. A turn on fluorescent sensor based on lanthanide coordination polymer nanoparticles for the detection of mercury(ii) in biological fluids. RSC Adv. 2016, 6, 17811-17817. [CrossRef]

104. Li, W.-X.; Li, H.-X.; Li, H.-Y.; Chen, M.-M.; Shi, Y.-X.; Lang, J.-P. 1,4-Bis(2-(pyridin-4-yl)vinyl)naphthalene and Its Zinc(II) Coordination Polymers: Synthesis, Structural Characterization, and Selective Luminescent Sensing of Mercury(II) Ion. Cryst. Growth Des. 2017, 17, 3948-3959. [CrossRef]

105. Zhang, S.-R.; Wang, W.; Xu, G.-J.; Yao, C.; Xu, Y.-H.; Su, Z.-M. A fluorescent sensor for selective, sensitive, and recyclable detection of mercury(II) in aqueous solution based on a zinc(II) coordination polymer. Inorg. Chem. Commun. 2018, 89, 73-77. [CrossRef]

106. Gong, W.-J.; Yao, R.; Li, H.-X.; Ren, Z.-G.; Zhang, J.-G.; Lang, J.-P. Luminescent cadmium(ii) coordination polymers of 1,2,4,5tetrakis(4-pyridylvinyl)benzene used as efficient multi-responsive sensors for toxic metal ions in water. Dalton Trans. 2017, 46, 16861-16871. [CrossRef]

107. Wang, X.; Han, Y.; Han, X.X.; Hou, X.; Wang, J.-J.; Fu, F. Highly selective and sensitive detection of $\mathrm{Hg}^{2+}, \mathrm{Cr}_{2} \mathrm{O}_{7}^{2-}$, and nitrobenzene/2,4-dinitrophenol in water via two fluorescent Cd-CPs. New J. Chem. 2018, 42, 19844-19852. [CrossRef]

108. Fang, Y.-M.; Ye, X.; Xia, L.; Dong, W.-W.; Zhao, J.; Li, D.-S. Four different dimensional Zn(II) coordination polymers as fluorescent sensor for detecting $\mathrm{Hg}^{2+}, \mathrm{Cr}_{2} \mathrm{O}_{7}{ }^{2-}$ in aqueous solution. J. Solid State Chem. 2018, 266, 181-188. [CrossRef]

109. Lin, J.; Cheng, Q.; Zhou, J.; Lin, X.; Reddy, R.C.K.; Yang, T.; Zhang, G. Five 3D lanthanide-based coordination polymers with 3,3,6T13 topology: Structures and luminescent sensor for $\mathrm{Hg}^{2+}$ and $\mathrm{Pb}^{2+}$ ions. J. Solid State Chem. 2019, 270, 339-345. [CrossRef]

110. Rachuri, Y.; Parmar, B.; Bisht, K.K.; Suresh, E. Multiresponsive Adenine-Based Luminescent Zn(II) Coordination Polymer for Detection of $\mathrm{Hg}^{2+}$ and Trinitrophenol in Aqueous Media. Cryst. Growth Des. 2017, 17, 1363-1372. [CrossRef]

111. Zhu, H.; Han, C.; Li, Y.-H.; Cui, G.-H. Two new coordination polymers containing long flexible bis(benzimidazole) ligand as luminescent chemosensors for acetylacetone and $\mathrm{Hg}$ (II) ions detection. J. Solid State Chem. 2020, 282, 121132. [CrossRef]

112. Ravikumar, A.; Panneerselvam, P.; Morad, N. Metal-Polydopamine Framework as an Effective Fluorescent Quencher for Highly Sensitive Detection of $\mathrm{Hg}(\mathrm{II})$ and $\mathrm{Ag}(\mathrm{I})$ Ions through Exonuclease III Activity. ACS Appl. Mater. Interfaces 2018, 10, 20550-20558. [CrossRef]

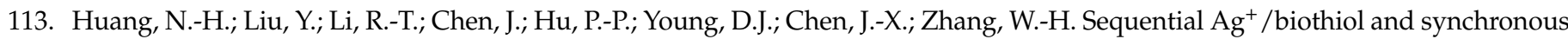
$\mathrm{Ag}^{+} / \mathrm{Hg}^{2+}$ biosensing with zwitterionic $\mathrm{Cu}^{2+}$-based metal-organic frameworks. Analyst 2020, 145, 2779-2788. [CrossRef]

114. Huang, N.-H.; Li, R.-T.; Fan, C.; Wu, K.-Y.; Zhang, Z.; Chen, J.-X. Rapid sequential detection of $\mathrm{Hg}^{2+}$ and biothiols by a probe DNA-MOF hybrid sensory system. J. Inorg. Biochem. 2019, 197, 110690. [CrossRef]

115. Wu, L.-L.; Wang, Z.; Zhao, S.-N.; Meng, X.; Song, X.-Z.; Feng, J.; Song, S.-Y.; Zhang, H.-J. A Metal-Organic Framework/DNA Hybrid System as a Novel Fluorescent Biosensor for Mercury(II) Ion Detection. Chem. A Eur. J. 2015, 22, 477-480. [CrossRef] [PubMed]

116. Wang, C.; Tang, G.; Tan, H. Colorimetric determination of mercury(II) via the inhibition by ssDNA of the oxidase-like activity of a mixed valence state cerium-based metal-organic framework. Microchim. Acta 2018, 185, 475. [CrossRef]

117. Wu, F.; Ye, J.; Cao, Y.; Wang, Z.; Miao, T.; Shi, Q. Recent advances in fluorescence sensors based on DNA-MOF hybrids. Luminescence 2020, 35, 440-446. [CrossRef]

118. Chen, H.-L.; Li, R.-T.; Wu, K.-Y.; Hu, P.-P.; Zhang, Z.; Huang, N.-H.; Zhang, W.-H.; Chen, J.-X. Experimental and theoretical validations of a one-pot sequential sensing of $\mathrm{Hg}^{2+}$ and biothiols by a 3D Cu-based zwitterionic metal-organic framework. Talanta 2020, 210, 120596. [CrossRef] [PubMed]

119. Wu, X.-J.; Kong, F.; Zhao, C.-Q.; Ding, S.-N. Ratiometric fluorescent nanosensors for ultra-sensitive detection of mercury ions based on AuNCs/MOFs. Analyst 2019, 144, 2523-2530. [CrossRef]

120. Govindaraju, S.; Puthiaraj, P.; Lee, M.-H.; Yun, K. Photoluminescent AuNCs@UiO-66 for Ultrasensitive Detection of Mercury in Water Samples. ACS Omega 2018, 3, 12052-12059. [CrossRef] [PubMed]

121. Marieeswaran, M.; Panneerselvam, P. A magnetic nanoscale metal-organic framework (MNMOF) as a viable fluorescence quencher material for ssDNA and for the detection of mercury ions via a novel quenching-quenching mechanism. RSC Adv. 2020, 10, 3705-3714. [CrossRef]

122. Hu, P.-P.; Liu, N.; Wu, K.-Y.; Zhai, L.-Y.; Xie, B.-P.; Sun, B.; Duan, W.-J.; Zhang, W.-H.; Chen, J.-X. Successive and Specific Detection of $\mathrm{Hg}^{2+}$ and $\mathrm{I}^{-}$by a DNA@MOF Biosensor: Experimental and Simulation Studies. Inorg. Chem. 2018, 57, 8382-8389. [CrossRef] [PubMed]

123. Wang, X.; Wang, H.; Guo, L.; Chen, G.; Kong, R.; Qu, F.; Xia, L. Colorimetric detection of Hg(ii) based on the gold amalgamtriggered reductase mimetic activity in aqueous solution by employing AuNP@MOF nanoparticles. Analyst 2020, 145, 1362-1367. [CrossRef]

124. Zhang, Y.; Song, J.; Pan, Q.; Zhang, X.; Shao, W.; Quan, C.; Li, J. An Au@NH2-MIL-125(Ti)-based multifunctional platform for colorimetric detections of biomolecules and $\mathrm{Hg}^{2+}$. J. Mater. Chem. B 2020, 8, 114-124. [CrossRef]

125. Guo, M.; Chi, J.; Li, Y.; Waterhouse, G.I.N.; Ai, S.; Hou, J.; Li, X. Fluorometric determination of mercury(II) based on dual-emission metal-organic frameworks incorporating carbon dots and gold nanoclusters. Microchim. Acta 2020, 187, 534. [CrossRef] [PubMed]

126. Yang, Y.; Liu, W.; Cao, J.; Wu, Y. On-site, rapid and visual determination of $\mathrm{Hg}^{2+}$ and $\mathrm{Cu}^{2+}$ in red wine by ratiometric fluorescence sensor of metal-organic frameworks and CdTe QDs. Food Chem. 2020, 328, 127119. [CrossRef] [PubMed] 
127. Shellaiah, M.; Sun, K.W. Inorganic-Diverse Nanostructured Materials for Volatile Organic Compound Sensing. Sensors 2021, 21, 633. [CrossRef]

128. Zhang, X.; Jiang, Y.; Zhu, M.; Xu, Y.; Guo, Z.; Shi, J.; Han, E.; Zou, X.; Wang, D. Electrochemical DNA sensor for inorganic mercury(II) ion at attomolar level in dairy product using $\mathrm{Cu}(\mathrm{II})$-anchored metal-organic framework as mimetic catalyst. Chem. Eng. J. 2020, 383, 123182. [CrossRef]

129. Salandari-Jolge, N.; Ensafi, A.A.; Rezaei, B. Ultra-sensitive electrochemical aptasensor based on zeolitic imidazolate framework-8 derived Ag/Au core-shell nanoparticles for mercury detection in water samples. Sensors Actuators B Chem. 2021, $331,129426$. [CrossRef]

130. Zhang, X.; Zhu, M.; Jiang, Y.; Wang, X.; Guo, Z.; Shi, J.; Zou, X.; Han, E. Simple electrochemical sensing for mercury ions in dairy product using optimal $\mathrm{Cu}^{2+}$-based metal-organic frameworks as signal reporting. J. Hazard. Mater. 2020, 400, 123222. [CrossRef] [PubMed]

131. Fu, L.; Xie, K.; Wang, A.; Lyu, F.; Ge, J.; Zhang, L.; Zhang, H.; Su, W.; Hou, Y.-L.; Zhou, C.; et al. High selective detection of mercury (II) ions by thioether side groups on metal-organic frameworks. Anal. Chim. Acta 2019, 1081, 51-58. [CrossRef]

132. Qing, M.; Chen, S.; Xie, S.; Tang, Y.; Zhang, J.; Yuan, R. Encapsulation and Release of Recognition Probes Based on a Rigid Three-Dimensional DNA “Nanosafe-box" for Construction of a Electrochemical Biosensor. Anal. Chem. 2020, 92, 1811-1817. [CrossRef]

133. Singh, S.; Numan, A.; Zhan, Y.; Singh, V.; Van Hung, T.; Nam, N.D. A novel highly efficient and ultrasensitive electro-chemical detection of toxic mercury (II) ions in canned tuna fish and tap water based on a copper metal-organic framework. J. Hazard. Mater. 2020, 399, 123042. [CrossRef]

134. Kokkinos, C.; Economou, A.; Pournara, A.; Manos, M.; Spanopoulos, I.; Kanatzidis, M.; Tziotzi, T.; Petkov, V.; Margariti, A.; Oikonomopoulos, P.; et al. 3D-printed lab-in-a-syringe voltammetric cell based on a working electrode modified with a highly efficient Ca-MOF sorbent for the determination of $\mathrm{Hg}(\mathrm{II})$. Sens. Actuators B Chem. 2020, 321, 128508. [CrossRef]

135. Zhang, L.; Feng, L.; Li, P.; Chen, X.; Jiang, J.; Zhang, S.; Zhang, C.; Zhang, A.; Chen, G.; Wang, H. Direct Z-scheme photocatalyst of hollow CoSx@CdS polyhedron constructed by ZIF-67-templated one-pot solvothermal route: A signal-on photoelectrochemical sensor for mercury (II). Chem. Eng. J. 2020, 395, 125072. [CrossRef]

136. Chen, Y.; Bai, X.; Ye, Z. Recent Progress in Heavy Metal Ion Decontamination Based on Metal-Organic Frameworks. Nanomaterials 2020, 10, 1481. [CrossRef] [PubMed]

137. Rezaei Kahkha, M.R.; Daliran, S.; Oveisi, A.R.; Kaykhaii, M.; Sepehri, Z. The Mesoporous Porphyrinic Zirconium Metal-Organic Framework for Pipette-Tip Solid-Phase Extraction of Mercury from Fish Samples Followed by Cold Vapor Atomic Absorption Spectrometric Determination. Food Anal. Methods 2017, 10, 2175-2184. [CrossRef]

138. Hasankola, Z.S.; Rahimi, R.; Shayegan, H.; Moradi, E.; Safarifard, V. Removal of $\mathrm{Hg}^{2+}$ heavy metal ion using a highly stable mesoporous porphyrinic zirconium metal-organic framework. Inorg. Chim. Acta 2020, 501, 119264. [CrossRef]

139. Li, J.; Li, X.; Alsaedi, A.; Hayat, T.; Chen, C. Synthesis of highly porous inorganic adsorbents derived from metal-organic frameworks and their application in efficient elimination of mercury(II). J. Colloid Interface Sci. 2018, 517, 61-71. [CrossRef]

140. Leus, K.; Perez, J.P.H.; Folens, K.; Meledina, M.; Van Tendeloo, G.; Du Laing, G.; Van Der Voort, P. UiO-66-(SH) 2 as stable, selective and regenerable adsorbent for the removal of mercury from water under environmentally-relevant conditions. Faraday Discuss. 2017, 201, 145-161. [CrossRef] [PubMed]

141. Li, J.; Liu, Y.; Ai, Y.; Alsaedi, A.; Hayat, T.; Wang, X. Combined experimental and theoretical investigation on selective removal of mercury ions by metal organic frameworks modified with thiol groups. Chem. Eng. J. 2018, 354, 790-801. [CrossRef]

142. Fu, L.; Wang, S.; Lin, G.; Zhang, L.; Liu, Q.; Fang, J.; Wei, C.; Liu, G. Post-functionalization of UiO-66-NH 2 by 2,5-Dimercapto1,3,4-thiadiazole for the high efficient removal of $\mathrm{Hg}$ (II) in water. J. Hazard. Mater. 2019, 368, 42-51. [CrossRef]

143. Ding, L.; Luo, X.; Shao, P.; Yang, J.; Sun, D. Thiol-Functionalized Zr-Based Metal-Organic Framework for Capture of Hg(II) through a Proton Exchange Reaction. ACS Sustain. Chem. Eng. 2018, 6, 8494-8502. [CrossRef]

144. Li, M.-Q.; Wong, Y.-L.; Lum, T.-S.; Leung, K.S.-Y.; Lam, P.K.S.; Xu, Z. Dense thiol arrays for metal-organic frameworks: Boiling water stability, $\mathrm{Hg}$ removal beyond $2 \mathrm{ppb}$ and facile crosslinking. J. Mater. Chem. A 2018, 6, 14566-14570. [CrossRef]

145. Yang, P.; Shu, Y.; Zhuang, Q.; Li, Y.; Gu, J. A robust MOF-based trap with high-density active alkyl thiol for the super-efficient capture of mercury. Chem. Commun. 2019, 55, 12972-12975. [CrossRef]

146. Lin, D.; Liu, X.; Huang, R.; Qi, W.; Su, R.; He, Z. One-pot synthesis of mercapto functionalized Zr-MOFs for the enhanced removal of $\mathrm{Hg}^{2+}$ ions from water. Chem. Commun. 2019, 55, 6775-6778. [CrossRef] [PubMed]

147. Zhao, M.; Huang, Z.; Wang, S.; Zhang, L.; Zhou, Y. Design of 1-Cysteine Functionalized UiO-66 MOFs for Selective Adsorption of $\mathrm{Hg}(\mathrm{II})$ in Aqueous Medium. ACS Appl. Mater. Interfaces 2019, 11, 46973-46983. [CrossRef] [PubMed]

148. Liu, F.; Xiong, W.; Feng, X.; Cheng, G.; Shi, L.; Chen, D.; Zhang, Y. Highly recyclable cysteamine-modified acid-resistant MOFs for enhancing $\mathrm{Hg}$ (II) removal from water. Environ. Technol. 2019, 41, 1-11. [CrossRef]

149. He, Y.; Hou, Y.-L.; Wong, Y.-L.; Xiao, R.; Li, M.-Q.; Hao, Z.; Huang, J.; Wang, L.; Zeller, M.; He, J.; et al. Improving stability against desolvation and mercury removal performance of $\mathrm{Zr}(\mathrm{iv})$-carboxylate frameworks by using bulky sulfur functions. J. Mater. Chem. A 2017, 6, 1648-1654. [CrossRef]

150. Chen, S.; Feng, F.; Li, S.; Li, X.-X.; Shu, L. Metal-organic framework DUT-67 (Zr) for adsorptive removal of trace Hg ${ }^{2+}$ and $\mathrm{CH}_{3} \mathrm{Hg}^{+}$in water. Chem. Speciat. Bioavailab. 2018, 30, 99-106. [CrossRef] 
151. Liu, Q.; Zhang, Q.; Liu, B.; Ma, J. A new synthesis and adsorption mechanism of $\mathrm{ZrO}_{2}$ based metal-organic frames for efficient removal of mercury ions from aqueous solution. Ceram. Int. 2019, 45, 15720-15724. [CrossRef]

152. Xiong, Y.Y.; Li, J.Q.; Le Gong, L.; Feng, X.F.; Na Meng, L.; Zhang, L.; Meng, P.P.; Luo, M.B.; Luo, F. Using MOF-74 for Hg ${ }^{2+}$ removal from ultra-low concentration aqueous solution. J. Solid State Chem. 2017, 246, 16-22. [CrossRef]

153. Wang, C.-M.; Lin, Y.-J.; Pan, M.-F.; Su, C.-K.; Lin, T.-Y. A Highly Stable Framework of Crystalline Zinc Phosphite with Selective Removal, Recovery, and Turn-On Sensing Abilities for Mercury Cations in Aqueous Solutions. Chem. Eur. J. 2018, 24, 9729-9734. [CrossRef] [PubMed]

154. Esrafili, L.; Gharib, M.; Morsali, A. The targeted design of dual-functional metal-organic frameworks (DF-MOFs) as highly efficient adsorbents for $\mathrm{Hg}^{2+}$ ions: Synthesis for purpose. Dalton Trans. 2019, 48, 17831-17839. [CrossRef] [PubMed]

155. Wu, Y.; Xu, G.; Wei, F.; Song, Q.; Tang, T.; Wang, X.; Hu, Q. Determination of Hg (II) in tea and mushroom samples based on metal-organic frameworks as solid phase extraction sorbents. Microporous Mesoporous Mater. 2016, 235, 204-210. [CrossRef]

156. Mon, M.; Qu, X.; Ferrando-Soria, J.; Pellicer-Carreño, I.; Sepúlveda-Escribano, A.; Ramos-Fernandez, E.V.; Jansen, J.C.; Armentano, D.; Pardo, E. Fine-tuning of the confined space in microporous metal-organic frameworks for efficient mercury removal. J. Mater. Chem. A 2017, 5, 20120-20125. [CrossRef]

157. Yazdi, M.N.; Yamini, Y.; Asiabi, H.; Alizadeh, A. A metal organic framework prepared from benzene-1,3,5-tricarboxylic acid and copper(II), and functionalized with various polysulfides as a sorbent for selective sorption of trace amounts of heavy metal ions. Microchim. Acta 2018, 185, 525. [CrossRef]

158. Xu, W.-Q.; Lin, C.-C.; Qiu, Y.-X.; He, S.; Jiang, T.; Liu, X.-J.; Xie, L.-J.; Fuhr, O.; Fenske, D.; Jiang, J.-J. A Recoverable Complex with Nitrogen-Rich Double Rings for Hg(II) Sorption. ChemistrySelect 2018, 3, 7592-7595. [CrossRef]

159. Xu, W.-Q.; He, S.; Liu, S.-J.; Liu, X.-H.; Qiu, Y.-X.; Liu, W.-T.; Jiang, L.-C.; Jiang, J.-J. Post-synthetic modification of a metal-organic framework based on 5-aminoisophthalic acid for mercury sorption. Inorg. Chem. Commun. 2019, 108, 107515. [CrossRef]

160. Liang, L.; Chen, Q.; Jiang, F.; Yuan, D.; Qian, J.; Lv, G.; Xue, H.; Liu, L.; Jiang, H.-L.; Hong, M. In situ large-scale construction of sulfur-functionalized metal-organic framework and its efficient removal of $\mathrm{Hg}$ (ii) from water. J. Mater. Chem. A 2016, 4, 15370-15374. [CrossRef]

161. Jiang, S.-Y.; He, W.-W.; Li, S.-L.; Su, Z.-M.; Lan, Y.-Q. Introduction of Molecular Building Blocks to Improve the Stability of Metal-Organic Frameworks for Efficient Mercury Removal. Inorg. Chem. 2018, 57, 6118-6123. [CrossRef]

162. Wang, C.; He, C.; Luo, Y.-H.; Su, S.; Wang, J.-Y.; Hong, D.-L.; He, X.-T.; Chen, C.; Sun, B.-W. Efficient mercury chloride capture by ultrathin 2D metal-organic framework nanosheets. Chem. Eng. J. 2020, 379, 122337. [CrossRef]

163. Tian, J.; Shi, C.; Xiao, C.; Jiang, F.; Yuan, D.; Chen, Q.; Hong, M. Introduction of Flexibility into a Metal-Organic Framework to Promote $\mathrm{Hg}$ (II) Capture through Adaptive Deformation. Inorg. Chem. 2020, 59, 18264-18275. [CrossRef] [PubMed]

164. Halder, S.; Mondal, J.; Ortega-Castro, J.; Frontera, A.; Roy, P. A Ni-based MOF for selective detection and removal of $\mathrm{Hg}^{2+}$ in aqueous medium: A facile strategy. Dalton Trans. 2017, 46, 1943-1950. [CrossRef] [PubMed]

165. Li, G.-P.; Zhang, K.; Zhang, P.-F.; Liu, W.-N.; Tong, W.-Q.; Hou, L.; Wang, Y.-Y. Thiol-Functionalized Pores via Post-Synthesis Modification in a Metal-Organic Framework with Selective Removal of Hg(II) in Water. Inorg. Chem. 2019, 58, $3409-3415$. [CrossRef]

166. Li, K.; Li, J.-J.; Zhao, N.; Xie, T.-T.; Di, B.; Xu, L.-L. Thioether-based recyclable metal-organic frameworks for selective and efficient removal of $\mathrm{Hg}^{2+}$ from water. Dalton Trans. 2019, 48, 17800-17809. [CrossRef]

167. Han, Y.; Zheng, H.; Liu, K.; Wang, H.; Huang, H.; Xie, L.-H.; Wang, L.; Li, J.-R. In-Situ Ligand Formation-Driven Preparation of a Heterometallic Metal-Organic Framework for Highly Selective Separation of Light Hydrocarbons and Efficient Mercury Adsorption. ACS Appl. Mater. Interfaces 2016, 8, 23331-23337. [CrossRef] [PubMed]

168. Mon, M.; Lloret, F.; Ferrando-Soria, J.; Martí-Gastaldo, C.; Armentano, D.; Pardo, E. Selective and Efficient Removal of Mercury from Aqueous Media with the Highly Flexible Arms of a BioMOF. Angew. Chem. Int. Ed. 2016, 55, 11167-11172. [CrossRef]

169. Saleem, H.; Rafique, U.; Davies, R.P. Investigations on post-synthetically modified UiO-66- $\mathrm{NH}_{2}$ for the adsorptive removal of heavy metal ions from aqueous solution. Microporous Mesoporous Mater. 2016, 221, 238-244. [CrossRef]

170. Wu, J.; Zhou, J.; Zhang, S.; Alsaedi, A.; Hayat, T.; Li, J.; Song, Y. Efficient removal of metal contaminants by EDTA modified MOF from aqueous solutions. J. Colloid Interface Sci. 2019, 555, 403-412. [CrossRef] [PubMed]

171. Rouhani, F.; Morsali, A. Fast and Selective Heavy Metal Removal by a Novel Metal-Organic Framework Designed with In-Situ Ligand Building Block Fabrication Bearing Free Nitrogen. Chem. A Eur. J. 2018, 24, 5529-5537. [CrossRef] [PubMed]

172. Hakimifar, A.; Morsali, A. Urea-Based Metal-Organic Frameworks as High and Fast Adsorbent for $\mathrm{Hg}^{2+}$ and $\mathrm{Pb}^{2+} \mathrm{Removal} \mathrm{from}^{2}$ Water. Inorg. Chem. 2019, 58, 180-187. [CrossRef] [PubMed]

173. Mon, M.; Bruno, R.; Tiburcio, E.; Viciano-Chumillas, M.; Kalinke, L.H.G.; Ferrando-Soria, J.; Armentano, D.; Pardo, E. Multivariate Metal-Organic Frameworks for the Simultaneous Capture of Organic and Inorganic Contaminants from Water. J. Am. Chem. Soc. 2019, 141, 13601-13609. [CrossRef] [PubMed]

174. Ru, J.; Wang, X.; Wang, F.; Cui, X.; Du, X.; Lu, X. UiO series of metal-organic frameworks composites as advanced sorbents for the removal of heavy metal ions: Synthesis, applications and adsorption mechanism. Ecotoxicol. Environ. Saf. 2021, $208,111577$. [CrossRef]

175. Li, H.; Liu, H.; Zhang, J.; Cheng, Y.; Zhang, C.; Fei, X.; Xian, Y. Platinum Nanoparticle Encapsulated Metal-Organic Frameworks for Colorimetric Measurement and Facile Removal of Mercury(II). ACS Appl. Mater. Interfaces 2017, 9, 40716-40725. [CrossRef] [PubMed] 
176. Shi, M.; Lin, D.; Huang, R.; Qi, W.; Su, R.; He, Z. Construction of a Mercapto-Functionalized Zr-MOF/Melamine Sponge Composite for the Efficient Removal of Oils and Heavy Metal Ions from Water. Ind. Eng. Chem. Res. 2020, 59, 13220-13227. [CrossRef]

177. Liu, F.; Xiong, W.; Feng, X.; Shi, L.; Chen, D.; Zhang, Y. A novel monolith ZnS-ZIF-8 adsorption material for ultraeffective Hg (II) capture from wastewater. J. Hazard. Mater. 2019, 367, 381-389. [CrossRef]

178. Nosike, E.I.; Jiang, Z.; Miao, L.; Akakuru, O.U.; Yuan, B.; Wu, S.; Zhang, Y.; Zhang, Y.; Wu, A. A novel hybrid nanoadsorbent for effective $\mathrm{Hg}^{2+}$ adsorption based on zeolitic imidazolate framework (ZIF-90) assembled onto poly acrylic acid capped $\mathrm{Fe}_{3} \mathrm{O}_{4}$ nanoparticles and cysteine. J. Hazard. Mater. 2020, 392, 122288. [CrossRef]

179. Huang, L.; He, M.; Chen, B.; Hu, B. A designable magnetic MOF composite and facile coordination-based post-synthetic strategy for the enhanced removal of $\mathrm{Hg}^{2+}$ from water. J. Mater. Chem. A 2015, 3, 11587-11595. [CrossRef]

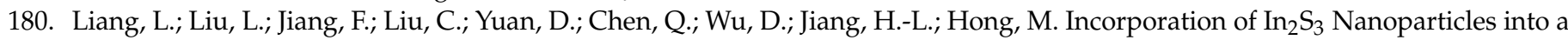
Metal-Organic Framework for Ultrafast Removal of Hg from Water. Inorg. Chem. 2018, 57, 4891-4897. [CrossRef] [PubMed]

181. Ke, F.; Jiang, J.; Li, Y.; Wan, X.; Ko, S. Highly selective removal of $\mathrm{Hg}^{2+}$ and $\mathrm{Pb}^{2+}$ by thiol-functionalized $\mathrm{Fe}_{3} \mathrm{O}_{4} @ \mathrm{metal}$-organic framework core-shell magnetic microspheres. Appl. Surf. Sci. 2017, 413, 266-274. [CrossRef]

182. Sun, D.T.; Peng, L.; Reeder, W.S.; Moosavi, S.M.; Tiana, D.; Britt, D.K.; Oveisi, E.; Queen, W.L. Rapid, Selective Heavy Metal Removal from Water by a Metal-Organic Framework/Polydopamine Composite. ACS Cent. Sci. 2018, 4, 349-356. [CrossRef]

183. Abdollahi, N.; Akbar Razavi, S.A.; Morsali, A.; Hu, M.-L. High capacity Hg(II) and Pb(II) removal using MOF-based nanocomposite: Cooperative effects of pore functionalization and surface-charge modulation. J. Hazard. Mater. 2020, $387,121667$. [CrossRef]

184. Liu, Y.; Li, H.; Liu, J. Theoretical prediction the removal of mercury from flue gas by MOFs. Fuel 2016, 184, 474-480. [CrossRef]

185. Tang, H.; Fang, H.; Duan, Y.; Sholl, D.S. Predictions of $\mathrm{Hg}^{0}$ and $\mathrm{HgCl}_{2}$ Adsorption Properties in UiO-66 from Flue Gas Using Molecular Simulations. J. Phys. Chem. C 2019, 123, 5972-5979. [CrossRef]

186. Zhao, S.; Mei, J.; Xu, H.; Liu, W.; Qu, Z.; Cui, Y.; Yan, N. Research of mercury removal from sintering flue gas of iron and steel by the open metal site of Mil-101(Cr). J. Hazard. Mater. 2018, 351, 301-307. [CrossRef]

187. Dong, L.; Huang, Y.; Liu, L.; Liu, C.; Xu, L.; Zha, J.; Chen, H.; Liu, H. Investigation of Elemental Mercury Removal from Coal-Fired Boiler Flue Gas over MIL101-Cr. Energy Fuels 2019, 33, 8864-8875. [CrossRef]

188. Chen, D.; Zhao, S.; Qu, Z.; Yan, N. Cu-BTC as a novel material for elemental mercury removal from sintering gas. Fuel 2018, 217, 297-305. [CrossRef]

189. Zhou, J.; Cao, L.; Wang, Q.; Tariq, M.; Xue, Y.; Zhou, Z.; Sun, W.; Yang, J. Enhanced $\mathrm{Hg}^{0}$ removal via $\alpha-\mathrm{MnO}_{2}$ anchored to MIL-96(Al). Appl. Surf. Sci. 2019, 483, 252-259. [CrossRef]

190. Zhang, X.; Shi, Q.; Shen, B.; Hu, Z. MIL-100(Fe) supported Mn-based catalyst and its behavior in $\mathrm{Hg}^{0}$ removal from flue gas. J. Hazard. Mater. 2020, 381, 121003. [CrossRef]

191. Yang, Z.; Li, H.; Yang, J.; Feng, S.; Liu, X.; Zhao, J.; Qu, W.; Li, P.; Feng, Y.; Lee, P.-H.; et al. Nanosized Copper Selenide Functionalized Zeolitic Imidazolate Framework-8 (CuSe/ZIF-8) for Efficient Immobilization of Gas-Phase Elemental Mercury. Adv. Funct. Mater. 2019, 29, 1807191. [CrossRef]

192. Yang, J.; Zhu, W.; Qu, W.; Yang, Z.; Wang, J.; Zhang, M.; Li, H. Selenium Functionalized Metal-Organic Framework MIL-101 for Efficient and Permanent Sequestration of Mercury. Environ. Sci. Technol. 2019, 53, 2260-2268. [CrossRef] [PubMed]

193. Zhao, S.; Chen, D.; Xu, H.; Mei, J.; Qu, Z.; Liu, P.; Cui, Y.; Yan, N. Combined effects of Ag and UiO-66 for removal of elemental mercury from flue gas. Chemosphere 2018, 197, 65-72. [CrossRef] [PubMed]

194. Zhang, X.; Shen, B.; Shen, F.; Si, M.; Yuan, P. The behavior of the manganese-cerium loaded metal-organic framework in elemental mercury and NO removal from flue gas. Chem. Eng. J. 2017, 326, 551-560. [CrossRef]

195. Rudd, N.D.; Wang, H.; Fuentes-Fernandez, E.M.A.; Teat, S.J.; Chen, F.; Hall, G.; Chabal, Y.J.; Li, J. Highly Efficient Luminescent Metal-Organic Framework for the Simultaneous Detection and Removal of Heavy Metals from Water. ACS Appl. Mater. Interfaces 2016, 8, 30294-30303. [CrossRef]

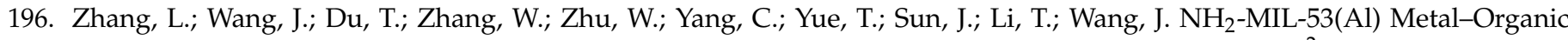
Framework as the Smart Platform for Simultaneous High-Performance Detection and Removal of $\mathrm{Hg}^{2+}$. Inorg. Chem. 2019, 58, 12573-12581. [CrossRef] [PubMed]

197. Radwan, A.; El-Sewify, I.M.; Shahat, A.; Azzazy, H.M.E.; Khalil, M.M.H.; El-Shahat, M.F. Multiuse Al-MOF Chemosensors for Visual Detection and Removal of Mercury Ions in Water and Skin-Whitening Cosmetics. ACS Sustain. Chem. Eng. 2020 8, 15097-15107. [CrossRef]

198. Shahat, A.; Elsalam, S.A.; Herrero-Martínez, J.M.; Simó-Alfonso, E.F.; Ramis-Ramos, G. Optical recognition and removal of Hg(II) using a new self-chemosensor based on a modified amino-functionalized Al-MOF. Sens. Actuators B Chem. 2017, 253, 164-172. [CrossRef]

199. Esrafili, L.; Gharib, M.; Morsali, A. Selective detection and removal of mercury ions by dual-functionalized metal-organic frameworks: Design-for-purpose. New J. Chem. 2019, 43, 18079-18091. [CrossRef]

200. Xiong, Y.; Su, L.; Yang, H.; Ye, F.; Zhang, P. Fabrication of copper sulfide using a Cu-based metal organic framework for the colorimetric determination and the efficient removal of $\mathrm{Hg}^{2+}$ in aqueous solutions. New J. Chem. 2015, 39, 9221-9227. [CrossRef] 
201. Moradi, E.; Rahimi, R.; Safarifard, V. Porphyrinic zirconium-based MOF with exposed pyrrole Lewis base site as an efficient fluorescence sensing for $\mathrm{Hg}^{2+}$ ions, DMF small molecule, and adsorption of $\mathrm{Hg}^{2+}$ ions from water solution. J. Solid State Chem. 2020, 286, 121277. [CrossRef]

202. Yang, H.; Peng, C.; Han, J.; Song, Y.; Wang, L. Three-dimensional macroporous Carbon/Zr-2,5-dimercaptoterephthalic acid metal-organic frameworks nanocomposites for removal and detection of $\mathrm{Hg}(\mathrm{II})$. Sens. Actuators B Chem. 2020, $320,128447$. [CrossRef]

203. Shellaiah, M.; Thirumalaivasan, N.; Sun, K.W.; Wu, S.-P. A pH cooperative strategy for enhanced colorimetric sensing of Cr(III) ions using biocompatible L-glutamic acid stabilized gold nanoparticles. Microchem. J. 2021, 160, 105754. [CrossRef]

204. Shellaiah, M.; Simon, T.; Thirumalaivasan, N.; Sun, K.W.; Ko, F.-H.; Wu, S.-P. Cysteamine-capped gold-copper nanoclusters for fluorometric determination and imaging of chromium(VI) and dopamine. Microchim. Acta 2019, 186, 788. [CrossRef] [PubMed]

205. Shellaiah, M.; Chen, Y.-C.; Simon, T.; Li, L.-C.; Sun, K.W.; Ko, F.-H. Effect of Metal Ions on Hybrid Graphite-Diamond Nanowire Growth: Conductivity Measurements from a Single Nanowire Device. Nanomaterials 2019, 9, 415. [CrossRef] [PubMed]

206. Shellaiah, M.; Sun, K.W. Review on Nanomaterial-Based Melamine Detection. Chemosensors 2019, 7, 9. [CrossRef]

207. He, J.; Wu, X.; Long, Z.; Hou, X. Fast and sensitive fluorescent and visual sensing of cysteine using Hg-metalated PCN-222. Microchem. J. 2019, 145, 68-73. [CrossRef] 